Illinois State University

ISU ReD: Research and eData

Theses and Dissertations

2-25-2021

\title{
A Teacher Shortage And Lack Of Representation In The Classroom: A Neoliberal And Critical Race Study Of The Broken Teacher Pipeline And The Impact On Education Majors
}

Sara Piotrowski

Illinois State University, scpiotrowski@gmail.com

Follow this and additional works at: https://ir.library.illinoisstate.edu/etd

Part of the Education Policy Commons, Higher Education Administration Commons, and the Teacher Education and Professional Development Commons

\section{Recommended Citation}

Piotrowski, Sara, "A Teacher Shortage And Lack Of Representation In The Classroom: A Neoliberal And Critical Race Study Of The Broken Teacher Pipeline And The Impact On Education Majors" (2021). Theses and Dissertations. 1402.

https://ir.library.illinoisstate.edu/etd/1402

This Dissertation is brought to you for free and open access by ISU ReD: Research and eData. It has been accepted for inclusion in Theses and Dissertations by an authorized administrator of ISU ReD: Research and eData. For more information, please contact ISUReD@ilstu.edu. 


\section{A TEACHER SHORTAGE AND LACK OF REPRESENTATION IN THE CLASSROOM: A NEOLIBERAL AND CRITICAL RACE STUDY OF THE BROKEN TEACHER PIPELINE AND THE IMPACT ON EDUCATION MAJORS}

\section{SARA CHRISTINE PIOTROWSKI}

\section{Pages}

Teacher education attrition is a largely understudied topic, especially from the perspective of the college student. What factors prevented education majors from graduating with a teaching degree? There are countless studies about teacher attrition within the first five years in the classroom (DeAngelis et al., 2013; Kopkowski, 2008; Office of Postsecondary Education [OPE], 2015), but the research is sparse when it comes to the retention rate of education majors. Why do students get accepted and enter college as education majors and then not graduate with a degree to become a teacher? The purpose of this study was to consider factors influencing teacher candidates who drop their education major before becoming a K-12 or high school teacher. By studying why college students who major in teacher education programs are not able to successfully complete their program, this research provides reasons why this happens, when it happens, and how to better support these college students. This study highlights how the leaky teacher pipeline, the teacher shortage, the impact on K-12 and secondary teachers, the impact on colleges of education, and the lack of diversity in education could all be improved by addressing the experiences of teacher education majors. This study found itself situated between two competing and contrasting conceptual frames. Neoliberalism and the critical frameworks guided the fundamental questions surrounding teacher education 
attrition. Are fewer people becoming teachers because it simply costs too much to go to college, and teaching positions are not glamorous and do not pay well? That would be the neoliberal way of approaching the question. Conversely, the critical framework would ask the question in terms of the diminished "pool" of perspective teachers, particularly those of color. Since desegregation, the field of education has been increasingly dominated by white educators and now fewer people overall want to be teachers. The National Center for Education Statistics ([NCES], 2016b) stated that for the 2015-2016 school year, public school teachers were 76.6\% female and $80.1 \%$ white. These two frameworks helped to not only craft the research questions, but also juxtaposed this complex issue. This study will explore why some individuals who want to teach when arriving at a college campus do not become licensed teachers.

KEYWORDS: teacher preparation, teacher pipeline, teacher shortage, diversity, lack of representation, critical race theory, neoliberalism 


\title{
A TEACHER SHORTAGE AND LACK OF REPRESENTATION IN THE CLASSROOM: A NEOLIBERAL AND CRITICAL RACE STUDY OF THE BROKEN TEACHER PIPELINE AND THE IMPACT ON EDUCATION MAJORS
}

SARA CHRISTINE PIOTROWSKI

\author{
A Dissertation Submitted in Partial \\ Fulfillment of the Requirements \\ for the Degree of \\ DOCTOR OF PHILOSOPHY \\ Department of Educational Administration and Foundations \\ ILLINOIS STATE UNIVERSITY
}

2021 
(C) 2021 Sara Christine Piotrowski 


\section{A TEACHER SHORTAGE AND LACK OF REPRESENTATION IN THE CLASSROOM: A NEOLIBERAL AND CRITICAL RACE STUDY OF THE BROKEN TEACHER PIPELINE AND THE IMPACT ON EDUCATION MAJORS}

SARA CHRISTINE PIOTROWSKI

COMMITTEE MEMBERS:

Dianne Renn, Chair

Beth Hatt

Neil Sappington

Monica Noraian 


\section{ACKNOWLEDGMENTS}

I am forever indebted to my committee of educational rock stars. Dr. Neil Sappington, you were my first professor in this program and I'm grateful you came out of your muchdeserved retirement to help me finish my degree. Dr. Monica Noraian, you are a mentor, role model, colleague, and a true friend. I am honored to have one of my first teacher education professors serving on my dissertation committee. You have played an enormous role in shaping me as an educator, leader, and a working-mother. The stars aligned so Dr. Beth Hatt could be my qualitative methods instructor during my last course, which helped shape this study. As my methodologist, you pushed me to ask tough questions, look critically at the data, and were extremely patient with me during this long journey. Lastly, Dr. Dianne Renn, thank you for chairing my committee and always having my best interests in mind. During course work, serving as your GA, working on grants, and the superintendency rewrite, I appreciate how you exposed me to a variety of experiences which helped me grow as an educator and a leader. As a whole, I am thankful to the entire EAF Department for offering encouragement and authentic experiences along the way.

I also wanted to extend many thanks to the other departments at "Midwestern University" who made this study possible. Thank you to my colleagues in the Teaching and Learning Department for inviting me to be part of the instructional team and helping me to connect with students for this study. Placing student teachers is no small task, so I am indebted to the teacher education center on campus, and Gary Higham in particular, who assisted with this study and offered additional insight. All of this would not have been possible if it wasn't for the Department of History, my "home” department. Thank you to Ross, Ron, Dan, Andrew, Richard, Kyle, Katrin, Christine, Linda, and the whole crew in Schroeder. 
The saying "it takes a village" is a complete under statement when it comes to the support and generosity I've received over the years. I am beyond blessed to have such dedicated friends. Huge thanks to my HQMFers, we're more than a book club! Rano, Julie, Buzzy, Erin, Angie, Devin, and Pener, you have literally been my angels since I wandered onto BU's campus. Relocating to a new town just before a pandemic is not ideal, but when you have pals like Kate, Megan, Laura, Crystal, and Kelly cheering you on, life is a bit easier.

Thank you to my extraordinary family. Aunt Sharon and Aunt Nancy, you have been constant fixtures in my life; thank you both for what you've done for me and the kids. I hit the sibling jackpot when it comes to you, Jeff, and it's an exceptionally sweet bonus to have Brittani, Grant, and Madison in my life. Tom and Joan Riley, there are not enough words to express how much I love and adore you. I would not be here if it wasn't for the sacrifices you made or the work ethic you instilled in me. Also, I'm still very sorry for my teenage years. This degree deserves four additional names: Matt, Jake, Brooke, and Ike. You have been my biggest cheerleaders during this journey. I'm sorry for all the times my dissertation took me away from our family or my anxiety caused additional stress. Jake and Brooke, please view my sacrifices as an example of how you can do anything if you put your mind to it and work hard. Your creativity, curiosity, and humor inspire me. To the world's best cuddle buddy who is on my lap as I type this, thank you, Ike, for being the world's best dog. To Matt, you are the glue that holds our family together. After two Masters' Degrees and a PhD, I promise I am done being a student (but always a lifelong leaner). Thank you for always supporting my dreams and crazy ideas. I could not have done this without you. Lastly, I would like to express my appreciation to all the participants in this study. I am incredibly grateful that you shared your stories with me and made this study possible. 


\section{CONTENTS}

Page

ACKNOWLEDGMENTS

TABLES viii

CHAPTER I: WHERE HAVE ALL THE TEACHERS GONE? 1

$\begin{array}{ll}\text { Purpose of the Study } & 1\end{array}$

$\begin{array}{ll}\text { Overview of Study } & 4\end{array}$

Leaking Teacher Pipeline $\quad 5$

$\begin{array}{ll}\text { Teacher Shortage } & 6\end{array}$

Impact on K-12 and High School (Secondary) Teachers $\quad 6$

$\begin{array}{ll}\text { Impact on Colleges of Education } & 8\end{array}$

The Need for Representation in the Classroom Also Known as "Lack of Diversity” 9

$\begin{array}{ll}\text { Research Questions } & 11\end{array}$

$\begin{array}{ll}\text { Conceptual Framework } & 11\end{array}$

$\begin{array}{ll}\text { Neoliberalism } & 13\end{array}$

$\begin{array}{ll}\text { Privatization } & 15\end{array}$

Market Forces and Impact of Free Markets 16

$\begin{array}{ll}\text { Accountability Movement in Education } & 17\end{array}$

$\begin{array}{ll}\text { Critical Lenses } & 19\end{array}$

Challenge Inequitable Practices in Teacher Recruitment \& Training 22

$\begin{array}{ll}\text { Effects of Institutional Whiteness } & 23\end{array}$

Representation of all Students, Families, \& Communities $\quad 24$

$\begin{array}{ll}\text { Researcher Positionality } & 25\end{array}$ 
$\begin{array}{ll}\text { Chapter Summary } & 26\end{array}$

CHAPTER II: WE SHOULD HAVE SEEN THIS COMING 27

$\begin{array}{ll}\text { Historical Trends } & 27\end{array}$

The Consequences of Brown v. Board 28

Elementary and Secondary Education Act (ESEA) 31

No Child Left Behind (NCLB) 32

Every Student Succeeds Act (ESSA) 33

$\begin{array}{ll}\text { Neoliberalism Consequences } & 37\end{array}$

The Profession That Lacks an Identity and Sought to Be Highly-Qualified 40

$\begin{array}{ll}\text { Current Issues } & 43\end{array}$

Teacher Shortage 43

Teaching Lacks Representation $\quad 45$

CHAPTER III: RESEARCH METHODOLOGY 50

$\begin{array}{lr}\text { Research Problem and Research Questions } & 50\end{array}$

Why Is This Study Important? $\quad 50$

$\begin{array}{lr}\text { Research Paradigm } & 50\end{array}$

$\begin{array}{ll}\text { Researcher Positionality } & 51\end{array}$

Data Collection and Sampling $\quad 53$

$\begin{array}{ll}\text { Methods } & 55\end{array}$

$\begin{array}{ll}\text { Analysis } & 57\end{array}$

$\begin{array}{lr}\text { Trustworthiness } & 59\end{array}$

$\begin{array}{ll}\text { Ethical Issues } & 61\end{array}$

$\begin{array}{ll}\text { Contributions to the Field } & 61\end{array}$ 
CHAPTER IV: THE CRITICAL EVENT

$\begin{array}{ll}\text { Meet the Participants } & 63\end{array}$

“The Transfers" $\quad 64$

$\begin{array}{ll}\text { Trevon } & 64\end{array}$

$\begin{array}{ll}\text { Andre } & 66\end{array}$

$\begin{array}{ll}\text { Cora } & 67\end{array}$

$\begin{array}{ll}\text { Enzo } & 68\end{array}$

$\begin{array}{ll}\text { “The Transfers” Summary } & 69\end{array}$

$\begin{array}{ll}\text { "The Gateways" } & 70\end{array}$

$\begin{array}{ll}\text { Joshua } & 70\end{array}$

$\begin{array}{ll}\text { Lauren } & 71\end{array}$

$\begin{array}{ll}\text { Daniel } & 72\end{array}$

“The Gateways” Summary $\quad 72$

“Teaching Is NOT What I Expected”

$\begin{array}{ll}\text { Olivia } & 74\end{array}$

$\begin{array}{ll}\text { Kayla } & 74\end{array}$

$\begin{array}{ll}\text { Imani } & 75\end{array}$

$\begin{array}{ll}\text { Xavier } & 75\end{array}$

$\begin{array}{ll}\text { Jessica } & 76\end{array}$

“Teaching Is Not What I Expected” Summary 77

$\begin{array}{ll}\text { Chapter Summary } & 77\end{array}$

CHAPTER V: DEMOGRAPHIC DATA AND INTERVIEW ANALYSIS 80

Part 1: Program Demographic Data Adds Context $\quad 80$ 
The Tables Don't Lie $\quad 81$

$\begin{array}{ll}\text { Table Summary } & 90\end{array}$

$\begin{array}{ll}\text { Trends Highlighted in the Tables } & 90\end{array}$

Part 2: Analysis of Qualitative Interviews 93

Review of the Participants $\quad 94$

$\begin{array}{ll}\text { Time-Ordered Matrix } & 94\end{array}$

Variable-by-Variable Matrix $\quad 99$

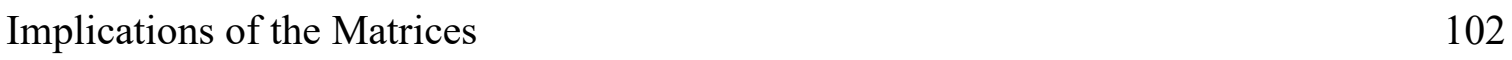

$\begin{array}{ll}\text { Theoretical Frameworks and Analysis } & 103\end{array}$

$\begin{array}{ll}\text { Neoliberal Analysis } & 103\end{array}$

$\begin{array}{ll}\text { Critical Lenses Analysis } & 107\end{array}$

$\begin{array}{ll}\text { Chapter Summary and Conclusion } & 110\end{array}$

CHAPTER VI: FINDINGS, IMPLICATIONS, CALL TO ACTION 111

Introduction and Purpose of the Study 112

$\begin{array}{ll}\text { Research Questions } & 112\end{array}$

$\begin{array}{ll}\text { Question } 1 & 113\end{array}$

$\begin{array}{ll}\text { Question } 2 & 115\end{array}$

$\begin{array}{ll}\text { Question } 3 & 116\end{array}$

$\begin{array}{ll}\text { Leaky Teacher Pipeline } & 117\end{array}$

$\begin{array}{ll}\text { Teacher Shortage } & 121\end{array}$

Impact on K-12 and High School (Secondary) Teachers 122

$\begin{array}{ll}\text { Impact on Colleges of Education } & 126\end{array}$ 
The Need for Representation in the Classroom Also Known as

"Lack of Diversity"

My Epiphany

What Surprised Me

What I Did Not Expect to Find

Future Research

Call to Action

APPENDIX A: ONLINE SURVEY

APPENDIX B: CONSENT FORM FOR THE INTERVIEWS

APPENDIX C: INTERVIEW QUESTIONS

APPENDIX D: FULL TEACHER EDUCATION DROP OUT TIME ORDERED MATRIX 158 


\section{TABLES}

Table

Page

1. Number of Teachers vs. Secondary Teachers (in thousands) 7

2. Unfilled Secondary Education Positions in Illinois High Schools 8

3. Race/Ethnicity Comparison of Students Versus Teachers by Percentage 10

4. Contrasting Conceptual Frameworks 12

5. Race/Ethnicity Comparison of Students Versus Teachers by Percentage 46

6. Comparison of Race and Gender in Programs of Study, Full University Population, 81 and Teachers in State in Percentages

7. Overall Student Population in Programs Included in the Study: Male vs. Female and Students of Color vs. White by Percentage

8. Student Population in Specific Programs Included in the Study: Race and Gender by Percentage

9. Student Population Enrolled in Summer School by Specific Programs Included in the Study: Male vs. Female and Students of Color vs. White by Percentage

10. Mode GPA Over a Five-Year Trend by Program Included in the Study

11. Mode GPA of Students Enrolled in Summer School by Program Determined Over a Five-Year Period

12. Total Student Enrollment in Programs Included in the Study by Race from Fall 2015 through Fall 2018

13. Teacher Education Drop Out Time Ordered Matrix

14. Teacher Education Major Variable-by-Variable Matrix 


\section{CHAPTER I: WHERE HAVE ALL THE TEACHERS GONE?}

My study became all too real when a student of color cried in my office because she was dropping the education sequence and was getting her degree in "just" History. I felt helpless. My job is to prepare future History-Social Sciences teachers and on that specific day, my hands were tied. She had come to the institution where I work specifically to become a teacher, and because of a few mediocre grades, she would have to stay two more semesters. Paying for college by herself, she did not see that as a viable option. Additionally, she had already failed the content exam twice. Each attempt costs over a hundred dollars and passing it is required to student teach. This solidified why I have to pursue my study. Becoming a teacher requires completing a series of tasks in the two years leading up to graduation. In my role, I prepare wide-eyed co-eds for their careers in the field of education. In my experiences working with prospective teachers, they feel overwhelmed by the volume of tasks they must complete while also concluding their coursework. At last count, forty-two boxes need to be checked in order to graduate and obtain licensure. I am not suggesting that we make it easier for people to become teachers. However, I wish to explore if colleges of education are properly supporting future teachers. Furthermore, I also question if all forty-two "boxes" are necessary to become an effective professional educator.

\section{Purpose of the Study}

The focus of this study was to consider factors influencing the teacher pipeline that may have caused teacher candidates to drop their education majors before becoming K-12 or high school teachers. Of particular interest are leaks in the education sequencing pipeline within colleges of education (COE) that seem to be discouraging teachers candidates from completing their teaching credentials. Our country needs good public-school teachers. Teachers are a 
valuable human resource and "well-prepared, capable teachers have the largest impact on student learning" (Darling-Hammond, 2003, p. 7). It goes without saying that students deserve, and parents expect, an effective teacher in the classroom. While preparing to write this, I assumed that defining what it means to be an effective teacher would be simple and easy to find. It turns out that identifying what makes a good teacher is not simple because they are responsible to such a wide variety of stakeholders: students, parents, administrators, legislators, and the federal government, to name just a few. Each constituency would have different expectations for the role of teacher. I turned to Powell's (2012) Your Introduction to Education: Explorations in Teaching to find a basic definition of an effective teacher and to my surprise, I found the following: "The search for a neatly packaged description of an effective teacher dates back for centuries, even millennia. The best we can come up with are lists of characteristics based on observation and available data, along with anecdotal descriptions" (p. 20). Even a widely-used introduction in an education textbook found it hard to define what it means to be an effective teacher. This study will explore why some individuals who want to teach when arriving at a college campus do not become licensed teachers.

The teacher pipeline that would place these teacher candidates in high school classrooms is leaking at several vital points. First, there is a swelling teaching shortage plaguing our country's public schools. This is occurring as evidenced by teacher shortages that are being reported across the country (DeAngelis et al., 2013; Kopkowski, 2008; OPE, 2015). According to a report from the U.S. Department of Education, the current high-need fields in schools that serve low-income students are as follows: Bilingual Education and English Language Acquisition, Foreign Language, Mathematics, Reading Specialist, Science, and Special Education (Cross, 2017, p. 7). News of the teacher shortage can be found just about everywhere, 
and low-income areas have been hit harder. When looking at Illinois, for example, in 2019, a total of 1,858 teaching positions were unfilled (Illinois State Board of Education [ISBE], 2019a). When scrolling through the list by county, over and over again I saw all of same subjects listed above. Additionally, the U.S. Department of Education commissioned a beginning teacher longitudinal study that confirmed these alarming numbers: "Among all beginning teachers in $2007-08,10$ percent did not teach in 2008-09, 12 percent did not teach in 2009-10, 15 percent did not teach in 2010-11, and 17 percent did not teach in 2011-12" (Gray et al., 2015, p. 3). In short, within a five-year period, the number of beginning teachers who left the field increased significantly. To lose almost half of the field's new teachers throughout their first five years is a daunting statistic. Not only is the field of education failing to replenish its workforce, but educators also cannot get recruits to stay. While this looks at the profession as a whole, this study will focus on K-12 and secondary education majors. This shortage also impacts COEs. Despite needing qualified educators, teacher preparation programs have seen a decrease in the number of candidates applying to their programs (OPE, 2015).

The U.S. Department of Education also reports a sharp drop in the number of students enrolled in teacher preparation programs. For the 2008-2009 academic year, there were 719,081 college students enrolled in education programs compared to 465,536 in 2013-2014 (OPE, 2015). That is a loss of over 250,000 future teachers! Let that number sink while contemplating the ramifications of fewer college students majoring in teacher education. The teacher shortage not only hurts our public schools, but COEs. In addition to a shortage of teachers, there is a noticeable lack of racial and ethnic diversity and educational inclusion to meet the needs of $21^{\text {st }}$ century learners and demographics. The lack of racial and ethnic diversity in the teaching force impacts students at all levels. The NCES (2016b) reported that for the 2015-2016 school year, 
$76.6 \%$ of public-school teachers were female and $80.1 \%$ were white. The connection between the teacher pipeline and the lack of diversity in education is obvious. White students can see that they are represented in the teaching force and can quite literally and figuratively see themselves growing up to be teachers. White students only account for $48.6 \%$ of the population and that number is predicted to drop to $45.2 \%$ by 2026 (NCES, 2016a, Table 203.50). Students of color benefit from having teachers of color. While researching ethnic matching, Donald Easton-Brooks (2019) found evidence that "Black teachers account for 5 to 8 percent growth in mathematics scores and 16 to 17 percent of the change or growth in reading achievement scores. In comparison, white teachers only account for 2 to 3 percent of the growth in academic achievement of these students" (p. 33). Think about how that would be compounded each year of a child's time in school. Additionally, it is not just about a "diverse" teaching force, but there are real consequences to the achievement of students of color and LGBTQ+ students by having teachers that can affirm their identities. All of these previously outlined factors led me to this study in the hopes of determining why teacher candidates do not become licensed educators.

\section{Overview of Study}

This study will focus on exploring the leaks in the COEs, coupled with the problems matching teacher candidates to represent the students they will be teaching. A possible cause of this problem lies in the origins of teacher education attrition. What factors are causing education majors not to become teachers in general or for K-12 and secondary teachers in particular? An interview-based study investigating the factors that lead to education majors dropping their sequence was conducted using qualitative methods, along with demographic data, to bring a greater understanding of the phenomenon and lead to solutions that ensure success for all teacher candidates. This study will investigate what demographics and outside factors are affecting 
teacher candidates' ability to finish their education programs. Teacher education attrition is a largely understudied topic. There is a considerable amount of research that explores teacher attrition and how it correlates to teacher preparation. A review of scholarly journals regarding topics in higher education revealed a focus on persistence (students returning the next term) and retention (the institution's ability campus-wide to retain students each year). What was lacking from all of this research was the attrition rates of specific areas of study. In the case, very little was found regarding teacher education majors' attrition rates, which further demonstrates the importance of this study.

\section{Leaking Teacher Pipeline}

The American College Testing (ACT) organization collects data when high school students take their exam, and they reported that $15 \%$ of high school students expressed interest in the field of education in 2010 and that percentage dropped to 12\% in 2014 (ACT, 2015). While that may not seem like a large decrease, it is a loss of over 5,000 potential teachers. And that is just from the high school students who took the ACT and accurately reported their career aspirations. Not only are fewer people entering the field of education, but even fewer are sticking around. A nationwide statistic shows that "one-third of all new teachers leave their initial placements after only three years of teaching, and $46 \%$ do so within the first five years" (Kopkowski, 2008). The teacher pipeline is leaking, which not only impacts current publicschool students, but also causes a domino effect on the entire field. The teacher shortage is in full swing, and the impact is already wreaking havoc on our nation's public schools. To be clear, the pipeline is not leaking at the same rate in all areas. "Hard-to-staff schools" disproportionally serve low-income students and students of color (Philip et al., 2019, p. 254). In these schools, ineffective learning climate and low achievement often result in teachers leaving in droves. Lack 
of teacher attrition in turn results in an instability in the school community and adds significant monetary costs to the district to recruit and hire new teachers.

\section{Teacher Shortage}

The state of Illinois issued a report in September of 2018 entitled "Teach Illinois Strong Teachers, Strong Classrooms: Policy Solutions to Alleviate Teachers Shortage in Illinois.” For a year, ISBE (2018b) commissioned a "year of study" by holding 40 focus group sessions and meeting with over 400 educators (p. 2). While the teacher shortage impacts all the school districts across the state in differing ways, overwhelmingly, the study found that this shortage disproportionately impacts special education and bilingual education (English as a Second Language), as those positions account for forty-eight percent of the total vacancies (ISBE, 2018b, p. 4). This same report stated that in Illinois "between 2010 and 2016, the number of [teacher] candidates enrolling in and completing teacher preparation programs decreased by 53 percentages points" (p. 3). Nationally, between 2008 and 2016, there was a "23 percent decline in the number of people completing teacher preparation programs" (ISBE, 2018b, p. 3). This steady decline in teacher preparation programs, both across the country and in Illinois, highlights just how wide-reaching the problem has become and how quickly it accelerated. This study will focus specifically on those teacher candidates who wish to teach high school-aged students and those grade levels that are also greatly affected by the teacher shortage.

\section{Impact on K-12 and High School (Secondary) Teachers}

The national trend of teacher attrition has risen from $5.1 \%$ in 1992 to $8.4 \%$ in 2005 , and that rate has remained steady (Carver-Thomas \& Darling-Hammond, 2017, p. 3). This is alarming and illustrates how this study will focus on teacher education attrition. This newest version of the teacher shortage is making bigger headlines because the number of positions 
unfilled is increasing, and the number of students enrolling in COEs is decreasing. Exploring the attrition rate of K-12 secondary teachers and focusing on why those students who choose to major in K-12 secondary education do not become teachers will help to better support those particular education majors. Table 1 (NCES, 2016b, Table 209.10) compares the total number of teachers in public schools across the United States during selected years between 1987 and 2016 to the total number of secondary teachers. There has been an increase in 889,000 secondary teachers during those years. While this study explored K-12 and secondary teachers, the data in the table that follows looks solely at secondary teachers.

\section{Table 1}

Number of Teachers vs. Secondary Teachers (in thousands)

\begin{tabular}{|c|c|c|c|c|c|c|c|}
\hline & $1987-88$ & 1990-91 & $\begin{array}{l}1999- \\
2000\end{array}$ & 2003-04 & $2007-08$ & 2011-12 & $2015-16$ \\
\hline $\begin{array}{l}\text { Total \# of } \\
\text { teachers }\end{array}$ & 2,323 & 2,559 & 3,002 & 3,251 & 3,405 & 3,385 & 3,827 \\
\hline $\begin{array}{l}\text { Total \# of } \\
\text { Secondary } \\
\text { Teachers }\end{array}$ & 1,031 & 1,118 & 1,401 & 1,534 & 1,680 & 1,659 & 1,920 \\
\hline
\end{tabular}

This data highlights a steady increase in the number of secondary teachers. On the surface, this appears to be promising. However, the teacher shortage has resulted in an increased number of unfilled teaching positions. According to the ISBE report Educator Supply and Demand in Illinois (2018a), secondary education positions have been left unfilled across the state. The number of unfilled vacancies has been steadily increasing since 2008 (ISBE, 2018b, p. 4). Table 2 breaks down this information according to content area. 


\section{Table 2}

Unfilled Secondary Education Positions in Illinois High Schools

\begin{tabular}{l|ll} 
Unfilled Positions & $2016-2017$ & $2015-2016$ \\
\hline Foreign Language (Spanish, Other) & 47.3 & 53.7 \\
Science (General, Other, Biology, Chemistry, \& Physics) & 67.3 & 47.5 \\
Mathematics (General, Other, Algebra, Geometry & 48.4 & 47 \\
English/Language Arts & 32.9 & 41.5 \\
History-Social Sciences & 8.5 & 19.8
\end{tabular}

This data set is particularly discouraging since so many students were left without qualified educators to teach those subjects. To see this staggering number of unfilled positions in foreign language, science, mathematics, English/Language Arts, and history-social sciences reinforces why I must conduct this study. There are college students who wanted to teach those very subjects who did not become teachers. This also speaks to the wider issues of the attack on public education. But it begs the question, if the profession could "make day-to-day teaching an attractive, challenging job that intelligent, creative, and ambitious people will gravitate toward" (Goldstein, 2014, p.11), would recruitment and retention become less of an issue? These unfilled positions create another layer of concerns. If positions are filled, they are usually taught by substitute teachers or teachers with certifications outside the content area. This obviously has a negative impact on students. The ISBE (2018b) report also highlighted how the highest number of unfilled vacancies were in Chicago Public Schools and rural school districts (p.6). Armed with these statistics, this research study targeted when and why teacher education majors discontinue their career path and offers support and solutions for these preservice educators.

\section{Impact on Colleges of Education}

Exploring the reasons hopeful teacher education majors are not able and/or willing to complete their educator preparations programs is multi-layered and involves analyzing multiple 
perspectives. It is clear who enrolls in teacher preparation programs. As mentioned previously, according to the NCES (2016b), over three-quarters of public-school teachers were female, and four-fifths were white during the 2015-2016 school year. The national trend of teacher attrition has risen from $5.1 \%$ in 1992 to $8.4 \%$ in 2005, and that rate has remained steady (Carver-Thomas \& Darling-Hammond, 2017, p. 3). The statistics listed above are cause for concern, and this impacts the COEs. According to ISBE (2018b) there is work that educator preparation programs (EPPs) can employ to approach teacher training. The study cites that other states have "eliminated credit hour and course requirements and, instead, require students to show mastery in specific areas and subject" (2018b, p. 16). That same study also suggests that EPPs and local education agencies collaborate to "design, develop and implement preparation routes that support the workforce needs of their communities and regions" (p. 16). This has further implications if not all stakeholders are involved in this process. While tackling the teacher shortage problem, it would behoove the state of Illinois, and the field of education as a whole, to also add "diversifying the teacher workforce" to the top of their priority list.

\section{The Need for Representation in the Classroom Also Known as "Lack of Diversity"}

The teacher shortage is just one part of a more significant, systemic problem. Simply put, the teaching force lacks representation, which for many years has been described as "lack of diversity." There is a huge discrepancy between those developing into teachers versus the overall student population. The NCES (2016b) reported that for the 2015-2016 school year, public school teachers were overwhelmingly white females. There are historical reasons why so many more once pursued teaching and why they are now leaving the field (Berliner \& Biddle, 1995). What was once the "most prestigious profession open to young women...[they] have access to many other professions, and education has lost its ability to attract the most talented 
women with but modest salaries" (Berliner \& Biddle, 1995, p.104). Women now have more career options, but many are not pursuing teaching due to the changes in salary compared to other jobs requiring a college degree. Additionally, students need to, at various times during their education career, be taught by someone who looks like them and can relate to their shared cultural experiences (Redding, 2019). Table 3 (NCES, 2016a, Table 203.50) illustrates how that is not happening in public school classrooms across the county.

Table 3

Race/Ethnicity Comparison of Students Versus Teachers by Percentage

\begin{tabular}{|c|c|c|c|c|c|c|}
\hline & White & Black & Hispanic & $\begin{array}{l}\text { Asian/Pacific } \\
\text { Islander }\end{array}$ & $\begin{array}{l}\text { American } \\
\text { Indian/Alaskan } \\
\text { Native }\end{array}$ & $\begin{array}{l}\text { Two or } \\
\text { more } \\
\text { races }\end{array}$ \\
\hline Students & 48.6 & 15.6 & 26.4 & 5.4 & 1.0 & 2.9 \\
\hline Teachers & 80.1 & 6.7 & 8.8 & 2.3 & .03 & 1.4 \\
\hline
\end{tabular}

The information in Table 3 reveals that these numbers do not add up. White students only account for $48.6 \%$ of the population, and that number is predicted to drop to $45.2 \%$ by 2026 (NCES, 2016a, Table 203.50). This data illustrates why any exploration of preparation attrition must address the needs of the field. Black, Hispanic, Asian/Pacific Islander, American Indian/Alaskan Native, and students of two or more races accounted for $51.3 \%$ of the student body, but when combined, only account for $19.23 \%$ of the teaching force. One small way to promote representation in the teaching field would be to study the teacher education attrition rate.

The leaky teacher pipeline can be repaired, but it will take reflection and change at every level. One way to fix the leak is to expand the teaching force by starting locally. Teachers need to be home-grown, "especially that of the teachers of color who successfully navigated school 
and chose to return to their communities- supports the notion underlying ethnic capital theory" (Irizarry \& Antrop-Gonzalez, 2013, p. 256). Another way to solve the problem is to introduce future teachers to all students: "Before one can become a multicultural educator, one must become a multicultural person" (Irizarry \& Antrop-Gonzalez, 2013, p. 256). When a teacher returns to the neighborhood school to teach, it should be done with enormous pride. It should not be viewed as a last resort or a second choice. This comes with helping future teachers understand they are making a lifestyle choice. All of the aforementioned factors have led me to this study. Given the number of reasons why the teacher pipeline is leaking (and in some instances gushing), this study will explore one way to fix the problem. How can COEs stop teacher education attrition?

\section{Research Questions}

1.) What is the nature of student attrition in secondary and K-12 teacher education programs?

a. What patterns in student demographics exist?

b. What factors do teacher candidates attribute to their attrition?

2.) What are key turning points for teacher candidates in deciding not to continue with teacher education?

3.) Based on the study, what are the implications for teacher education and policy?

\section{Conceptual Framework}

Why do students get accepted and enter college as education majors but then not graduate and become teachers, in this case, specifically K-12 and secondary education teachers? This is an understudied phenomenon and there are a wide variety of contributing factors. Exploring the reasons hopeful teacher education majors are not able to graduate with teaching degrees is multi- 
layered and involves studying different angles. Two contrasting frameworks and two competing visions pertain to this study, but both can help establish the parameters of the conceptual framework for this research. Table 4 illustrates the contrasting visions of neoliberalism and critical lenses.

\section{Table 4}

\section{Contrasting Conceptual Frameworks}

\begin{tabular}{ll} 
Neoliberalism & Critical Lenses \\
\hline Privatization & $\begin{array}{l}\text { Challenge Inequitable Practices in Teacher } \\
\text { Recruitment \& Training }\end{array}$ \\
$\begin{array}{l}\text { Market Forces \& Impact of Free Markets } \\
\text { Accountability Movement in Education }\end{array}$ & $\begin{array}{l}\text { Effects of Institutional Whiteness } \\
\text { Representation of all Students, Families, \& } \\
\text { Communities }\end{array}$
\end{tabular}

On the one hand, neoliberalism seems like the most appropriate conceptual framework. Education was once an institution afforded to everyone (Darling-Hammond, 2010; Ravitch, 2014). However, the ongoing, successful polarization of education explains how this is no longer the case. According to neoliberalism, education has largely been successfully reframed "as a commodity; schools as business; the purpose of education completely removed from its role in a democracy: these are extreme views and make it quite clear that the Right wishes to privatize as much as possible of what we consider public or belong to the public good" (Casey, 2016, p. 132). Higher education, specifically colleges of education, now has to compete with for-profit institutions that attract teacher candidates on the basis that they will give them personalized, corporate attention (Giroux, 2014). Public schools and public colleges and universities are suffering too, as state funding is decreasing (Ravitch, 2014). Instead of fostering a culture providing the very best for the next generation (through a college education in this instance), neoliberalism now views them as a burden and is charging them for this inconvenience. How 
does increasing the "standards" and the tests for becoming a teacher relate to the politics of education? This study makes the connection between conservative, free-market ideals that impact students entering college and the domino effect on teachers in our public schools.

On the other hand, the critical lenses, specifically Critical Race Theory (CRT) and Critical Whiteness Theory (CWT), helped to expose how and why the neoliberal takeover has slowly eroded public education. Critical Race Theory (CRT) is a "framework that can be used to theorize, examine, and challenge the ways race and racism implicitly and explicitly impact on social structures, practices, and discourses" (Yosso, 2005, p. 70). Application of CRT should explain how issues perpetrated by neoliberalism have impacted the leaky teacher pipeline. The fact teachers are predominately white is a nation-wide problem which is not self-solving. Enter CWT. CWT puts the "hegemony of whiteness that has so naturalized itself within the field of U.S. education goes undetected, despite the major implications it imposes on the educational equity of the students of color" (Matias \& Mackey, 2016, p. 34). Therefore, CWT must be a part of this study because it "provides a framework to deconstruct how whites accumulate racial privilege beyond the naïve acknowledgment that Band-Aids only come in light-beige" (McIntosh, 2001). CRT is only one piece of the puzzle, and alone, it was not helping this researcher to capture what was preventing candidates from becoming teachers. It pointed this study in the right direction but did not explain the role of whiteness in the equation of why this impacts a person's decision to major in teacher education. After digging deeper, critical whiteness studies "provided a ying to the yang studies of race" (Matias \& Mackey, 2016, p. 35).

\section{Neoliberalism}

Any high school student who aspires to go to college and study to become a teacher should be given a chance to do so. Ideally, our public schools would prepare the next generation 
of teachers (and all other professions as well). To do so, "public schools need the support of the public that funds them, they should have the widest possible community support. Community support means democratic governance" (Ravitch, 2014, p. 289). This approach is being compromised under the conceptual framework of neoliberalism; thus, big government is viewed as incompetent, inefficient, and looking to take away personal freedoms. Education now has to compete with for-profit institutions that attract students on the basis that they will give them personalized, corporate attention. Public schools are suffering too, as state funding is decreasing. Giroux (2005) writes, "schools more closely resemble either malls or jails, and teachers, forced to get revenue for their school by adopting market values, increasingly function as circus barkers hawking everything from hamburgers to pizza parties--- that is, when they are not reduced to prepping students for standardized tests" (p. 2). Potential educators are tasked with challenging this "corporate capitalist fairytale" (Giroux, 2005, p.3) known as neoliberalism. College students experience firsthand the massive tuition increases as an example of how neoliberalism is hurting their generation. Is this preventing education majors from becoming teachers? Giroux (2005) reports tuition has increased by $47 \%$ over the past decade at four-year institutions. Instead of fostering a culture providing the absolute best for the next generation (through a college education in this instance), neoliberalism now views them as a burden and is charging them for this inconvenience. This also makes teaching seem less appealing, "given teachers' loss of professional autonomy, a general lack of respect for the profession, and an obsession with highstakes testing, the sociopolitical context for public education has become bleak" (Nieto, 2015, p. 54). It is tough to tell college students to financially invest in their education to enter a field currently experiencing the same neoliberal pressures. 


\section{Privatization}

The biggest problem is that colleges of education are not addressing the disparity of educational opportunities for the pluralistic student body, but instead seek to comply with mandates from multiple levels of government. Even more disconcerting is how this wave of neoliberal education reformers view "literacy, public service, human rights, and morality in this neoliberal notion of education [as] damaged concepts, stripped of any sense of reason, responsibility, or obligation to a just society" (Giroux, 2014, p. 13). It is deflating as an educator to see our profession stripped of autonomy and reduced (in the eyes of many) to a job that does not require specialized training (Sleeter, 2008; Ravitch, 2014; Darling-Hammond \& Bransford, 2005). Neoliberalism has become a "tool for restoration of elite power in which education serves as a resource for global competition and private wealth accumulation" (Sleeter, 2008, p. 1948). By removing education from the critical discourse, neoliberals have attacked and demonized social institutions like public education.

Evaluation of teachers should target improvement, and "good systems are designed so that teachers are not penalized for teaching students who have the greatest educational needs. They explicitly seek to provide incentives that recognize and reward teachers who work with challenging students" (Darling-Hammond, 2010, p. 320). Furthermore, it is unfair to students and novice teachers to place them in high-need classrooms until they have demonstrated competence in the classroom (Darling-Hammond, 2010, p. 195). Plus, reducing teacher effectiveness to an exam is ineffective and misguided. Casey (2016) explains how testing can be taken out of context as "instrumental reason can tell us exactly how well a particular student did on an exam, and it can even tell us how accurate the exam was in testing the information the exam was designed for, but it can never tell us why we should be teaching something or why 
some things should be on the test rather than others" (Casey, 2016, p. 127). This is a positivist view of education, which reduces the students to pieces of data. Positivism suggests that there is only one objective solution to any given problem. When thinking of public-school students and teachers, this view simply does not fit. All stakeholders must be involved in the why, and that has not been permissible in the neoliberal era.

\section{Market Forces and Impact of Free Markets}

A criticism of free-market ideals applied to education is how the emphasis has shifted toward conformity and profit at the expense of our public schools and universities (Sleeter 2008; Giroux, 2014; Casey, 2016). Entrepreneurs and private companies have swarmed the education market. Ravitch (2014) expounds on this concerning reality:
Almost overnight, consultants and vendors offered their services to advise districts and states on how to design teacher evaluation systems, how to train teachers, how to train principals, how to turn around failing schools, how to use new technologies, how to engage in data-driven decision making, and on and on. (p. 15)

This is not to suggest that public education be averse to new technologies, but the privatization agenda has created an even greater divide between the haves and have-nots, putting equity further out of reach, all the while applying the rhetoric of inclusion and expanding opportunity for all. The inequities in education have only fueled the conservative argument that our schools need rescuing and market solutions are the only viable options. This mentality has penetrated into our colleges of education. While responding to the demands of the public schools, teacher preparation programs have inadvertently eroded their profession and have made the teaching major appear to be more tedious. 


\section{Accountability Movement in Education}

According to the No Child Left Behind Act (2001), a teacher deemed "highly qualified" must have "a bachelor's degree, full state certification or licensure, and prove that they know each subject they teach" (p. 1461). Broadly stated, it is assumed these qualities can be fairly measured and then guaranteed for all students. NCLB (2001) ushered in a wave of accountability measures and "advocated for a narrow, more teacher-proof curriculum that comes with the descriptor of 'standardized' and is seen as evidence of 'raising standards" and neoliberal 'accountability"' (Casey, 2016, p. 10). In A Nation at Risk, The National Commission on Excellence in Education (1983) brought forth the standards movement which sent public schools and states into a tailspin when they could not agree on national history standards (Ravitch, 2010). With no comprehensive strategy left to carry out the reforms $A$ Nation at Risk outlined, "to fill the lack, along came the test-based accountability movement, embodied by the No Child Left Behind law" (Ravitch, 2010, p. 30). NCLB (2001) became the poster child for neoliberal policies in the form of graduation rates and tests scores as a measurement for a school's success. The devaluing of teachers has been one of the lasting impacts from NCLB, as its implied data could tell the story of a classroom, which could not be further from the truth (Mehta, 2013).

A key piece of the education narrative adding to the drain on public education is the idea of accountability. There is nothing wrong with wanting to hold someone accountable for their actions and those subsequent outcomes. While it may seem like teachers are under fire, the concept of accountability is not new to education. Another writer who explored the neoliberal ideal of accountability is Gene V. Glass. In his book Fertilizers, Pills, and Magnetic Strips: The Fate of Public Education in America (2008), Glass illustrated the problem surrounding the bureaucratic language of accountability with examples of how it "pervades contemporary public 
institutions of all types [in the form of]: goal setting, standards, zero-based budgeting, formative and summative evaluation" (p. 14). These practices have put the public sector (specifically public education) under scrutiny in terms of their finances in conjunction with their effectiveness or lack thereof. Accountability has taken on direct forms through various policies and laws over the years. The first accusation stemming from accountability has been to fire bad teachers immediately. The coveted "highly effective" title placed teachers as the sole reason for the rise and fall of test scores. The key statistic that has been used over and over again in some variation is the idea that "an effective teacher can bring about three times as much learning in a year as a hapless, ineffective teacher" (Ravitch, 2014, p. 100). This can be viewed within a single year or over a three-year period. This faulty explanation takes the human element out of education and is based on the work of the statistician William Sanders. He claimed his statistic modeling could "determine how much 'value' a teacher added to her students' testing performance... he could isolate the "value added' by the teacher of that child" (Ravitch, 2014, p. 100). Unfortunately, the Sanders formula did not take into account racial, socioeconomic, and parental characteristics, which is why the critical lenses must also be entertained in this study.

This neoliberal approach to measuring teacher effectiveness is reckless and has penetrated the national narrative. Teacher quality control has become more important than continual teacher development. Eric Hanushek is a Senior Fellow at the Hoover Institution at Stanford and offers three suggestions to improve teacher quality: "recruit higher-caliber teachers, improve the skills of current teachers, and the 'deselection' of the bottom teachers based on their performance, defined as the test scores of their students" (as cited in Ravitch, 2014, p. 104). Hanushek's theory of "deselection" is alarming because it is hard to measure effectiveness year after year. What happens if a teacher is deemed ineffective every other year? Alternatively, what 
if a teacher is highly effective at one school and not in the next? This seems like an unstable approach that does not account for the human element of teaching or the experiences of the students. Teachers are interacting with students, not nameless figures; they are children with names, faces, and aspirations. It seems that this is punishing "teachers who choose to teach the students with the greatest needs or for being assigned to a class with such students" (Ravitch, 2014, p. 112). Multiple measures of practice and student outcomes should be used when evaluating teachers. The constant threat of accountability has drained the profession and made it less appealing, which ultimately has impacted the teacher pipeline. Neoliberal pressures offer one side of the frame for this study, but the critical lenses have the potential to respond to other layers of the teacher education attrition.

\section{Critical Lenses}

This study explored both Critical Race Theory (CRT) and Critical Whiteness Theory (CWT) to situate the research. CRT is a "framework that can be used to theorize, examine, and challenge the ways race and racism implicitly and explicitly impact on social structures, practices, and discourses" (Yosso, 2005, p. 70). To tackle diversity issues, public education must recognize and apply CRT to fully understand the issues perpetrated by neoliberalism. The fact teachers are predominately white is a nation-wide problem which will not resolve itself. However, exploring educational policy through this lens allows us to surmise why the profession is not accessible to everyone. Deficit thinking "takes the position that minority students and families are at fault for poor academic performance because the (a) students enter school without the normative cultural knowledge and skills, and (b) parents neither value nor support their child's education" (Yosso, 2005, p. 75). Gloria Ladson-Billings (1999) explains why CRT is vital: 
The meaning and value imputed to whiteness that CRT becomes a valuable intellectual and social tool for deconstruction, reconstruction, and construction: the deconstruction of oppressive structure and discourses, reconstruction of human agency, and construction of equitable and socially just relations of power. (p.19)

Before CRT was a theoretical frame found in education, it gained a following in the legal world, and the principles are transferable. Racism, discrimination, and bias have long been a normalized, accepted narrative and public education was indeed not the exception. As a permanent fixture in schools, policies must actively unmask, combat, and expose racism.

From obvious discrimination like school segregation and linguistic labels like "at-risk," CRT tasks educators to analyze the circumstances, policies, and procedures which are the foundation of public education. Race, economic, and social status should not inhibit access to education (Darling-Hammond, 1996, 2005). Education has repeatedly been labeled as the Civil Rights issue of our time, but from the perspective of the oppressed, this has been a long, arduous, uphill battle. Landmark cases like Plessy v. Ferguson (1896) and Brown v. Board of Education (1954) are just two examples of the countless, flawed, upward fight. CRT argues that sweeping, systemic changes are essential to achieving education free of racism and discrimination, which would also help explain the teacher education attrition rate.

Critical Whiteness Theory (CWT) argues that the "hegemony of whiteness that has so naturalized itself within the field of U.S. education goes undetected, despite the major implications it imposes on the educational equity of the students of color" (Matias \& Mackey, 2016, p. 34). Applying this theory, alongside CRT, will help to combat the neoliberal bias which has permeated teacher education. Matias and Mackey (2016) conducted a study of their white, middle-class, female students who were taking a teacher education diversity class. Students 
enrolled in this particular course intended to teach in an urban setting. As their professors, Matias and Mackey (2016) surmised that critical race pedagogies are essential to help fight off racism in the classroom, but "the inclusion of pedagogies specific to critical whiteness studies have yet to be articulated" (p. 33). They used targeted, heavy self- reflection to help white students understand their place of privilege. Teacher preparation has the responsibility of highlighting the problems with the "white savior" mentality many white teachers assume. As CWT continues to develop, it can be argued that since such a large portion of teachers are white, prospective teachers must examine and understand their place of privilege. Easton-Brooks (2019) called attention to the evidence that has demonstrated how "teachers of color can assist in engaging these students [of color], and the attribute they bring to the table could be used to assist White teachers in better engaging students of color" (p. 35). This notion highlights how teachers of color could help both students and their white colleagues, which further emphasizes their importance to schools. This researcher has long assumed that the research paradigm would fall under the critical theory umbrella. The goal of this study is to bring about social transformation and explore power relations. How did this fit into the never-ending cycle of the homogeny in the field of education? This study will add to the body of work supporting teacher education. When exploring the phenomenon of a cycle, it is hard to identify the starting point. Where will the research "break in" to explore why there is a particular type of teacher? Who majors in teacher education, but more importantly, who does not? Why do candidates who break the norm and major in teacher education not cross the finish line? Understanding neoliberal pressures, in conjunction with the critical lenses, will offer a multidimensional approach to improving teacher education. 


\section{Challenge Inequitable Practices in Teacher Recruitment \& Training}

Diversity in education, particularly the teaching force, is still a major issue today. In her book The Teacher Wars, Dana Goldstein (2014) states that only 17\% of public-school teachers are teachers of color (p. 270). Recruiting more teachers of color to match the diversity of American's children must become a priority for the field of teacher preparation as a whole. Representation in the classroom is critical to our schools and the need has often been referred to as "diversifying the profession." Ultimately, it is important that students can affirm their identity and historically students of color have not had that opportunity. This also means moving past the typical application of the word "diversity" to recognize that teacher recruitment and training is simply inequitable. Teacher recruitment and training of diverse education majors must become priority number one for colleges of education. Stafford Hood and Laurence J. Parker's (1989) study of the initial teacher certification tests in Illinois and Pennsylvania compares how the two states utilized bias review boards. While Illinois incorporated the input of the bias review board during the entire process, compared to one day in Pennsylvania, their study sheds light on a deeper issue. Hood and Parker (1989) concluded that "tests for initial teacher certification have been viewed as serving a 'gatekeeping' function to screen out academically incompetent candidates" (p.518). Exploring biased teacher certification will be a focal point of this study. Did teacher education majors give up after not being able to pass specific tests? At the beginning of this chapter, I referred to the student of color who was in my office crying because she had not passed the content exam twice. She was feeling inadequate, so she dropped the education sequence. How often does this happen, and is it necessary? How can COEs ensure that their course sequences are recognizing the needs of all students that will be in the classrooms of the teacher candidates they are preparing? 


\section{Effects of Institutional Whiteness}

In his book, A Pedagogy of Anticapitalistic Antiracism: Whiteness, Neoliberalism, and Resistance in Education, Zachary A. Casey (2016) cites critical Black feminist scholar Patricia Hill Collins (2000) when defining oppression as “"any unjust situation where, systemically and over a long period of time, one group denies another group access to the resources of society"” (p. 8). Using this definition, Casey characterizes anticapitalist antiracism pedagogy as the "two greatest systems of inequity preventing the realization of a more fully human society in the United States and in the world more broadly" (p. 9). His claim is powerful, but then he outlines how the public education system illustrates the oppressive combination. Oppression does not happen in isolation and neoliberalism has not only reinforced but has profited from the disparities found in our public schools and universities. Such discourse of anti-capitalist antiracism "locates capitalist exploitation at the center of white supremacy and sees the two systems of exploitation operating under the same perverse logics of greed, nationalism, and exceptionalism" (Casey, 2016, p. 10). The concept of "white supremacy" holds a negative connotation, so I initially hesitated to quote Casey because I do not believe the vast majority of educators are perpetuating white supremacy. However, when I dove deeper into this work, I found this idea of "whiteness" in all its forms — good, bad, and otherwise — is attached to a privilege nearly half of the public-school kids are not afforded. Teacher education has fallen victim to the neoliberal divide and Casey (2016) explains how "both antiracist struggle on the part of white people, as well as teacher education for social justice, to show how capitalist logics such as neoliberalism have pervaded both spaced and closed off opportunities for social transformation" (p. 10). Additionally, those lost "opportunities" can be found in both our public schools and our colleges of education, which together, have created a gaping hole in the teacher 
education pipeline (Ladson-Billings, 2006). As stated previously, the compounded problem of racial inequity in our public schools as prevented (either by choice or by an institutional barrier) students of color from entering the field of education. The response to neoliberalism in our public school and universities should be to utilize critical race theory and critical whiteness theory into the body of work which influences education at every single level.

\section{Representation of all Students, Families, \& Communities}

Another way to solve the problem is to introduce our future teachers to all students since "before one can become a multicultural educator, one must become a multicultural person" (Irizarry \& Antrop-Gonzalez, 2013, p. 256). During their teacher training, students need to have intentional, authentic experiences. This comes with helping future teachers understand they are making a lifestyle choice. Public schools are supposed to protect our students and create an environment that fosters learning, inquiry, and creativity. They should be the breeding ground for the next generation of democratic citizens. Unfortunately, "public schools in low-income neighborhoods serving predominately Black and Latino young people have become training grounds for the juvenile detention centers, jails, and prisons that await many students, and they serve as fertile soil for army recruiters" (Oparah, 2014, p. 109). This new, racially-charged, neoliberal narrative in our public schools has created a cycle of disdain toward public schools, resulting in our leaky teacher pipeline.

While people of color cannot see themselves as teachers due to an oppressive work environment, it is also important to note how teachers of color have been historically pushed out if they do, in fact, enter the education sector. Prior to Brown v. Board of Education (1954), there were a large number of Black educators and administrators who lost their jobs because white people did not deem them fit to teach their children. This landmark case will be addressed in 
greater detail in Chapter II as it was the first in a long string of policies that pushed out teachers of color. The Civil Rights Act of 1964 did not extend protection to Black teachers who were not retained and reclassifications of Elementary and Secondary Education Act (ESEA) created a loophole that allowed for lopsided hiring and hiring practices (Carter Andrews, et al, 2019, p. 7). Table 3 highlighted the discrepancies between the race of students compared to their overwhelmingly white teachers. In addition to the aforementioned federal policies that pushed out teachers of color, state and local measures can explain why there is total underrepresentation from all minoritized groups. These polices impact all communities of color as "Native American teachers are a declining share of the teacher workforce, and the Latinx teacher-Latinx student gap is larger than any other racial or ethnic group" (Carter Andrews, et al, 2019, p. 7). A lot of works needs to be done to reverse this damage and "pull" teachers of color back into the classroom.

\section{Researcher Positionality}

I am fully aware of my privilege. While I am a first-generation college student, I am also a white, middle-class female who is completing an advanced degree. Additionally, I was taught by many people that looked and acted like me and had similar cultural experiences. These were my role models, and I desperately wanted to follow in their footsteps. When studying the phenomenon of who becomes teachers and why, I was aware of both "insider-outsider" and “outsider-within" concepts (Banks, 1998), as well as the other variations of cross-cultural

researchers. I will address these concepts in greater detail in Chapter 3, but to the students I was interviewing, I was an outsider to them. I understood my privilege and how those factors allowed me to navigate the world of teacher-preparation with relative ease. I tackled all the red tape and made it to the other side. I interviewed students who did not, and I was sensitive to 
their circumstances while learning about their experiences. I conducted research that helped me understand why and how to fix the problem.

\section{Chapter Summary}

As a first-generation college student, it was a foregone conclusion I would attend college. My working-class parents wanted nothing short of the absolute best for me and my brother and worked so we did not have student loan debt from our undergraduate degrees (for which I am forever appreciative). I did not initially enroll in a teacher preparation program, but during my sophomore year, I converted. It was not until I assumed my current position coordinating student teaching placements, after five years of teaching in public high schools, that I realized how neoliberalism has manipulated and altered the foundations of teacher education. A significant assault on the teacher pipeline impacts those very students who are about to enroll in education programs, as they do not equate their educational experiences to a rewarding career (Nieto, 2015; Ravitch 2014). Neoliberalism has instilled this philosophy in our youth by continually reminding them that "the most capable organize the world, they produce; the least capable, survive" (Freire, 2005, p. 104). If students are sitting in their K-12 classrooms, they need to feel they would be welcomed back and well-prepared to teach in our public-school system. This study will explore the factors influencing the teacher pipeline that have caused teacher candidates to drop their education majors before becoming high school teachers. The next chapter will critically review the literature and historical trends that have brought us to this place of inequity. 


\section{CHAPTER II: WE SHOULD HAVE SEEN THIS COMING}

Over the past few months when I have given countless people the "elevator speech" about this study, my educator and historian friends nod their head with approval. One colleague sarcastically responded, "It's as if we should have seen this coming." When combing through the literature and policies surrounding the topics of teacher preparation and how they impact aspiring educators, I would have to agree with my colleague that we absolutely should have seen this coming! This literature review is divided into three parts in an effort to best outline what has been published to date that supports the need to study why teacher education majors do not become licensed educators. First, I review the historical trends and outline why the critical lenses must be explored when studying teacher education attrition. Next, I analyze the neoliberal consequences that impact teacher education. Finally, I look at current trends in education and situate them within the parameters of the study.

\section{Historical Trends}

Tackling the historical trends in education can provide a roadmap of the current issues facing public education. For the purposes of arguing "we should have seen this coming," I will highlight how Brown v. Board of Education (1954), the Elementary and Secondary Education Act (ESEA) of 1965, the No Child Left Behind (NCLB) of 2002, and the Every Student Succeeds Act (ESSA) of 2015 each have played a significant role. Not included, but arguably just as important, one could include the GI Bill (1944), the creation of the U.S. Department of Education (1980), A Nation at Risk (1983), or Goals 2000: Educate American Act (1994). These historical events, along with many others, have impacted legislation and still influence teaching today. These broader historical trends must be explored before putting the history of teacher preparation under the microscope. 


\section{The Consequences of Brown v. Board}

Brown v. Board of Education (1954) is often heralded as landmark legislation, and it certainly has solidified its place in history. I will explore the significance of the case, but first, it is essential to include Mendez v. Westminster (1946), out of which, eight years prior to Brown v. Board of Education, Mexican Americans in California won a class action lawsuit to dismantle their segregated school system. This case prohibited segregation in California's public schools and would serve as a precedent for Brown v. Board of Education. The Supreme Court ruled that "separate but equal" was not constitutional for Black and White students in our nation's public schools. This court case is widely viewed as the starting point for the modern Civil Rights movement in the United States. In reversing the 1896 Plessy v. Ferguson decision that legalized racial segregation of public facilities, Brown v. Board sought to hold our public schools accountable for the education of White and Black students. In his book, The Allure of Order: High Hopes, Dashed Expectations, and the Troubled Quest to Remake American Schooling (2013), Jal Mehta highlights how Brown v. Board not only pointed out how schools were failing minority students, but more importantly, that it was the precursor to the lesser known standardsbased reform of the 1960s and 1970s (p. 65). Public institutions of every size and shape were scrutinized, and the economic pressures of the time only further highlighted the shortcomings of public schools.

Cases like Mendez v. Westminster (1946) and Brown v. Board of Education (1954) had unintended consequences for qualified educators of color and their communities. From a distance, dismantling the "separate but equal" doctrine reads like an enormous victory. However, the long-term consequences would have a lasting impact on the entire public school system. I was first exposed to the harm of Brown v. Board of Education (1954) when I listened to 
Malcom Gladwell's podcast Revisionist History. Episode three from season two is entitled "Miss Buchanan's Period of Adjustment." I was shocked to learn about what the podcast refers to as "historical amnesia," the fact that so many qualified, Black teachers lost their jobs because of this "landmark" decision. White parents certainly would not allow Black teachers in the classroom, so these educators simply faded away. This ultimately led to the decline in Black educators over time. Easton-Brooks (2019) discussed the problems surrounding Brown v. Board of Education (1954): "Roughly 90 percent of Black principals in integrated schools in Southern states were replaced, fired, or demoted" (p. 29). Integration at the expense of qualified Black educators did not solve the problem; it simply created a new one. It is important to review both the causes and long-term consequences of mandated changes and the ways that public institutions, in this case public schools, found a loophole to advance the white supremacy agenda.

While Brown v. Board is often hailed as the moment when schools began desegregation, researchers like Karolyn Tyson (2011) write about the unintended consequences of the landmark decisions. In her book, Integration Interrupted: Tracking Black Students, and Acting White After Brown (2011), Tyson writes about how society views academic achievement as "acting white." Tyson (2011) shadowed and interviewed Black students for eighteen months and observed how disproportionately low the number of Black students were in advanced classes. She attributes this problem to tracking: "With Black and white students largely segregated within the schools they attend, racialized tracking has made it possible to have desegregation without integration" (Tyson, 2011, p. 6). Public school officials found a loophole when ordered to integrate the students in their schools by segregating within their own buildings. This agenda also calls into question how students were treated if they were "acting white." Herein lies another example of 
the social justice issues that are tied to the leaky teacher pipeline. The promise of Brown $v$. Board will not come to fruition until racially motivated practices like tracking are removed from our public schools.

While education and history classes alike praise Brown v. Board as the springboard for desegregation of public schools, it is essential that the entire story be included in this literature review. While the U.S. Supreme Court ruled racially segregated public schools to be unconstitutional, the aftermath was devastating for Black communities: "While historians have justifiably focused on the struggle for racial integration, they have neglected to explore the Black school closing or their far-reaching consequences" (Cecelski, 1994, p.8). Local school boards were left to interpret the ruling and were given the power to do what they saw fit to serve their communities. Unfortunately, in the 1960s and 1970s, this meant "white southern school leaders routinely shut down Black institutions, no matter how new or well located, and transferred their students to former white schools" (Cecelski, 1994, p.7). The effect of school desegregation on Black teachers and administrators was profoundly important and directly correlates with the lack of representation in the education field today. The consequences of desegregation (whether intended or not) led to the dismantling of Black educators in the south. North Carolina, which represents the typical southern experience, saw the number of Black elementary school principals go from 620 to 170 between 1963 and 1970, and secondary principals decreased from 209 to less than 10 (Cecelski, 1994, p.8). Once the nucleus of Black communities, these schools were either left empty or repurposed. Black teachers in North Carolina did not fare much better: “By 1972, an estimated 3,051 Blacks in North Carolina had lost teaching jobs" (Cecelski, 1994, p.8). As groundbreaking as the Brown v. Board decision was for the desegregation efforts, the lasting impact on Black teachers is still felt today. Each new educational policy has its place in 
history, but often at a great cost.

\section{Elementary and Secondary Education Act (ESEA)}

As part of President Johnson's War on Poverty, the Elementary and Secondary Education Act (ESEA) was the first all-encompassing education bill to be passed. This bill held our schools accountable to the public by ensuring that all children had equal access to education. President Johnson had briefly been a teacher and felt very strongly about the role education played in a child's future. This legislation was part of a more significant movement toward equality. ESEA provided funding for high poverty schools in the form of Title I which was based on the number of children in a district from low-income families. The law has been reauthorized and rebranded since it was initially passed. It was "retooled away from its longstanding emphasis on pouring dollars into poor schools and towards an emphasis on encouraging whole school reform around standards" (Mehta, 2013, p. 226). The emphasis on education reform, instead of solutions to address poverty and inequality, has emerged as criticisms of the act. (Cochran-Smit et al., 2017, p. 580). ESEA set the precedent for future educational reforms to use public schools as the vehicle to address longstanding systemic issues, rather than tackling them concurrently. By creating accountability systems and designations, the ESEA was initially passed to hold public schools accountable for the quality of education provided to all the students. Lower income students, mostly Black and Hispanic, were falling behind their counterparts, and the ESEA sought to offer a "compensatory education" (Goldstein, 2014. p.114). Accountability would still be deeply rooted in the act, but the means by which schools reported their outputs would evolve as "federal aid would now be offered or withheld depending on whether local policymakers followed national directives such as supplying lowincome schools with up-to-date textbooks, establishing school libraries, and pulling at-risk 
student out of class for supplemental tutoring" (Goldstein, 2014. p.114). At the root of each iteration of the act, schools would be accountable, to varying degrees, to the federal government. The two most famous reauthorizations of the ESEA are detailed below.

\section{No Child Left Behind (NCLB)}

Many educators will not argue with the notion that "leaving a child behind" is unacceptable, which is the centerpiece of George W. Bush's comprehensive education reform act. NCLB (2001) is often synonymous with standardized testing, as it increased the federal government's role in education. Its largely bipartisan support made swift passage possible. The goal was to close the achievement gap for poor and minority students. Additionally, NCLB (2001) promised to shape American public schools competing in the global market again. Under NCLB (2001), states were required to test students in reading and math in grades 3 through 8 and once in high school. They were expected to report results for both the student population as a whole, as well as for particular "subgroups" of students, including English-learners, students in special education, racial minorities, and children from low-income families. School districts were accountable for their scores and measured their success on the "adequate yearly progress" (AYP) measuring stick. Additionally, a "highly qualified teacher" would be assigned to each classroom, which was a major blow to teacher preparation programs as this insinuated colleges were not properly preparing educators. NCLB passed shortly after September 11, 2001, when there was a bipartisan presence in Congress. Mehta (2013) emphasizes how new archetypes shape politics: "The creation of a new educational paradigm raised the agenda status of education and created a centrist problem definition that was amenable to standards-based reforms" (p. 239). NCLB (2001) reignited a national conversation about the caliber of education being offered in America. 
Accountability in education is certainly not a new concept, but NCLB shifted the focus from the school as whole to the classroom teacher. Going back to A Nation at Risk (1983), schools were blamed for the poor performance of their students. This report "linked mediocre US student performance to sluggish global economic performance," (National Commission on Excellence in Education, 1983). A clear message was sent to the public that teacher quality matters not only in the classroom, but more importantly, to the economy. In the time between $A$ Nation at Risk (1983) and NCLB (2001), student achievement continued to be the driving force behind accountability. Still under intense scrutiny, public schools were further blamed for the lack of growth. On the coattails of "the teacher matters" narrative from A Nation at Risk (1983), NCLB directly linked student growth to the classroom teachers in the form of intense teacher evaluations. Glass (2008) gave attention to the neoliberal educational policy that is NCLB. He presented a strong argument how this type of legislation like this "has been installed in an attempt to embarrass educators and discredit public education” (p. 203). Race and privilege have been woven into the politics of legislation that should ultimately help public schools, but instead situates teachers as the villains.

\section{Every Student Succeeds Act (ESSA)}

Since the inception of common schools in America, education has been scrambling to find an identity and purpose. NCLB was recently overhauled in the form of the Every Student Succeeds Act (ESSA, 2015), moving the federal government away from one-size-fits-all education and shifting the responsibility back to state government. As this new legislation unfolds, leaving loopholes for charter schools and alternative pathways for teacher certification to flourish, the cycle of educational reform continues. Passed on December 15, 2015, the act took full effect for the 2017-2018 school year. States now have to complete accountability plans, 
and they can "pick their own goals, both a big long-term goal and smaller, interim goals. These goals must address proficiency on tests, English-language proficiency, and graduation rates" (Klein, 2016). As schools comply with the new regulations, this act will very likely become an essential piece of the accountability puzzle.

While far from perfect, ESSA (2015) addresses much of the deficit thinking, the hallmark of NCLB (2001). Title II of the act clearly intends to recruit and retain high-quality teachers. Without prescribing specifically how to recruit teachers and principals, it clearly outlines how states must develop, improve, and implement procedures to bolster a workforce "effective in improving student academic achievement, including effective teachers from underrepresented minority groups and teachers with disabilities" (ESSA, 2015, p. 121). Actively diversifying the teaching force is a significant step toward combatting deficit thinking (Ladson-Billings, 2006). This statement demonstrates how CRT was applied to ESSA. In the same section, it states how the law must "improve equitable access to effective teachers" (ESSA, 2015, p.119). Again, all students, not just those in affluent areas, should have access to the best teachers. This theme of "high-quality" teachers who have been "rigorously well-trained" is woven through the text. Teachers are to utilize the training of their peers and pursue "career opportunities and advanced initiatives that promote professional growth" (ESSA, 2015, p. 120). These tasks outlined in ESSA illustrate how the teaching force should no longer be complacent.

Teachers and leaders are to possess the "skills, credentials, or certifications needed to educate all students in postsecondary education coursework" (ESSA, 2015, p.121). This statement, like others outlining expanded teacher preparation, combat the deficit thinking model in which teachers do not need to be the best and brightest when they are helping at-risk or deficient learners. In fact, this act takes the opposite perspective, tasking public education with 
preparing and continually training teachers (Goldstein, 2014). Compared to NCLB (2001) in which the label "high qualified" was a commodity withheld for certain teachers, ESSA (2015) wants all educators to be effective. ESSA (2015) calls for transferable teaching licenses and training to help identify students with specific learnings needs, "particularly children with disabilities, English learners, students who are gifted and talented, and students with low literacy levels" (p.123). Based on the circumstances mentioned above, schools are to provide instruction based on the needs of each student. This reduces the notion that "one size fits all" can be applied to our classrooms and fights deficit thinking head on.

Some items warrant further clarification in Title II of ESSA. While the act champions educators who can provide evidence of student achievement, there are concerns about providing "differential pay or other incentives, to recruit and retain teachers in high-need academic subjects and in low-income schools, which may include performance-based pay systems" (ESSA, 2015, p.120). This illustrates that not all traces of neoliberalism have been erased. Of the countless sources opposing merit-based systems, Valencia (2015) warns that not only does this fail to consider students' earlier teachers, class-size, and the like, it invites "possible cultural loading and bias on tests, school segregation, school financing, curriculum differentiation (ability grouping and tracking), language suppression, cultural exclusion from the curriculum, and deficit thinking of teachers" (p. 187). CRT would take serious issue with paying teachers based on the performance of their students, illustrating how inequitable this can be for students. In his article, “The Performance Gap: Stereotype Threat, Assessment, and the Education of African American Children," Eric A. Hurley (2009) contemplates the historical context under which African Americans have been educated. Society has created a "negative stereotype about their group's ability on that skill relative to some other group" (p. 98). While attempting to close the 
achievement gap, ESSA (2015) is certainly not free of deficit thinking, but it has (slowly) learned from its ultra-neoliberal predecessors' mistakes.

Instead of looking at the symptoms of failing schools, it is more important to explore the causes, which are unfortunately not addressed anywhere in ESSA (2015). Systemic racism and discrimination must be tackled first. It is crucial to raise the bar for marginalized students so that they can compete in a global marketplace. Just like the deficit thinking applied to students, teaching is often viewed as menial, subpar work. We have a leaky teacher pipeline that must address these conditions and "educators must take neither a position of revenge nor of submission but the position of one who assumes responsible authority as an educator; nor may educators take a paternalistic or scornful attitude toward the lower-class children" (Freire, 2005, p. 128-9). Freire highlights how educators must take an active role in solving the problems facing our schools. CRT is one lens through which the field can do this, but the overwhelmingly white teaching force must also grapple with their privilege. Freire (2005) insists educators proceed with caution when disseminating an irresponsible narrative: "What is not possible, nevertheless, in this effort to overcome certain cultural inheritances that repeat themselves from generation to generation and at times seem to be petrified, is to cease to take their existence into consideration" (p. 126). This can start by applying critical whiteness theory to teacher education courses.

Matias and Mackey (2016) argue that critical whiteness studies will help teacher candidates learn how "whites have accumulated material wealth, economic power, housing and real estate superiority...how they actively operationalize whiteness via investments and false claims of racial ignorance" (2016, p. 34). Exposing teacher candidates to critical whiteness studies should make them more culturally responsive teachers. This could be one way to break 
the cycle of homogeny. These teachers will better understand their students of color, which should equate to more teachers of color. Another layer of critical whiteness studies accounts for why candidates are unable to complete their plan of study and become teachers. In essence, CWT will expose the pitfalls of neoliberalism. This is echoed in the K-12 classrooms. Thus, it is imperative to teach the culture of power "not only to students of color, but for all students who attend school without all the requisite experiences of academic discourse and white ways of being...it is not enough to merely teach the culture of power and then assume by doing so we have provided marginalized students with a 'way out' of poverty" (Casey, 2016, p. 136-137). Merging all these theories together will shape the conceptual framework to help inform our understanding of preservice teacher attrition.

\section{Neoliberalism Consequences}

A significant piece of the neoliberal platform has been siphoning away public funds from social institutions, and the budgets of public universities have been hit hard. Looking at how our federal government apportions funds, it is disheartening to learn "more than $60 \%$ of the federal budget goes to military spending, while only 6 percent is allocated toward education" (Giroux, 2014, p. 9). While the protections our armed forces provide are important, it is hard to believe that such a large portion of our budget should go toward military spending. The Policy and Program Studies Service released the trends in their 2016 brief and the news is not any better. First, "over the roughly two decades, between 1989-1990 and 2012-2013, state and local appropriations for public colleges and universities remained flat, while funding for corrections increased by nearly 90 percent” (Policy and Program Studies Service, 2016, p.1). Given the onslaught of neoliberal policies, this does not seem abnormal. Moreover, "on average, state and local higher education funding per full-time equivalent student fell by 28 percent, while per 
capita spending on corrections increased by 44 percent" (Policy and Program Studies Service, 2016, p.1). This data is a cause for reflection based on Oparah's (2014) work. Given how our country has placed criminal justice at the center of the neoliberal discourse, it is easy to see how universities jumped on board since their funding was decreasing. Additionally, this all goes back to Freire (2005), who asserted the political aspect of the narrative because "neoliberal discourse sometimes criticizes progressive candidates and parties, accusing them of being obsolete because they are ideological; they say that the people no longer accept such a discourse, that they now accept only technical and competent discourses" (p. 20). There has never been a time when the progressive response to neoliberalism needs to be more explicit. The public school/higher education/prison intersection is only further eroding education in general, but even more so, is decimating the teacher pipeline.

Colleges of education must focus on preparing future educators to understand the purpose of learning. The neoliberal view of the purpose of learning is to perform well on standardized tests. The need to perform well on standardized tests has a direct relationship with the idea of educating all students for college. Casey (2016) argues that preparing every child for college has made teacher education programs accomplices to the neoliberal agenda. He suggests the aims of the capitalist economy go hand-in-hand with the needs of students (p. 137). Rather than being a student-centered agenda, "Every Child College Ready" is more economically driven. At this point, Casey and I begin to disagree. Casey (2016) outlines the three ways teacher education has been complicit in spreading the neoliberal agenda, "through its positioning of P-12 students as commodities, its conception of teachers as technicians, and its fetishization of productivity and student achievement" (p. 143). By unpacking these claims, it becomes clear how Casey veers away from the focus of this research study. When students are viewed solely as pieces of data, 
then yes, that aligns with the neoliberal ideology. I would argue teacher education programs are preparing their students to read and understand data, but it is not the only skill they are being taught. Teacher education programs have responded to the penetration of the neoliberal agenda in our public schools by preparing future teachers who can navigate the world in which they will be employed (Lupinski et al., 2012). With this purpose in mind, educators need to be technicians, but there are other logistical aspects of their job which require quick thinking and flexibility. Casey (2016) argues that training teachers as technicians "who can implement curriculum packages" (p. 139) is a neoliberal concept more concerned with producing measurable results. So yes, if the teacher education program is only preparing candidates to read a script, then that particular program is an extension of the neoliberal machine. The professionalization of teachers cannot "reduce the complexity of teaching to a set of skills or best practices that one can employ simply in order to attain specific (already known) results" (Casey, 2016, p. 139-40). The very best teacher preparation programs must teach the skills needed to be able to navigate the unknown set of circumstances presented to teachers in their classrooms day in and day out. It is narrow-minded of Casey (2016) to lump all teacher preparation programs together. I argue that high-caliber programs are teaching future educators how to navigate the neoliberal pressures while also teaching their students valuable skills and content.

Casey (2016) also claims that teacher education has been appropriating the discourse of neoliberal capitalism by using terms like "effectiveness" and "academic achievement" as a way to measure results (p. 140). He expresses the idea that "the use of academic achievement measures has resulted in a moral and political crisis in teaching as democratic and humanistic purposes of educations are superseded by corporate economic goals and one-size-fits-all standards and high stakes test reverse equity gains of the 1960s and 1970s" (p. 140-141). The 
need to "fetishize productivity" is not necessarily a negative characteristic of a teacher. The definition of productivity can be subjective. If the teacher's productivity is solely linked to standards, the neoliberal trap has prevailed. Over time, I have no issue with teachers coasting through certain parts of their jobs without methodical thought. With experience, the art of teaching becomes second nature. This demonstrates the mastery of tactical, task-oriented skills. Casey (2016) writes "the less time teachers spend reflecting on the minute and complex details of their work in classrooms, the more time they will be able to give their immediate task in a neoliberal education system: to maximize student achievement as measured by standardized tests" (p. 142). Again, I feel Casey is minimizing the work of an educator, but I respect his critique on the impact neoliberalism has on the day-to-day, minute-to-minute interactions taking place in the classroom. However, I do agree that educators as a whole need to critique and question sweeping changes, especially when the proposed changes come from the dominate cultural group.

\section{The Profession That Lacks an Identity and Sought to Be Highly-Qualified}

Another way to advance teacher preparation is to recognize the field as its own unique entity. Casey (2016) urges our field to halt the comparisons to the medical field. He feels that the comparison has done more harm than good. Doctors generally work with patients one-onone, and many treat patients in privately run, for-profit facilities. Teachers, on the other hand, are assigned a classroom full of students, demanding their attention and with varying needs (Casey, 2016, p. 44). Public education cannot turn away students like privately run businesses can, so it's unfair to think there is a comparable field. Teachers at all levels must continue to defend our field proudly: "There are signs of rebellion among workers, young people, students, and teachers, indicating that the US public has been entirely colonized by the bankers, hedge 
fund managers, and other apostles of neoliberalism" (Giroux, 2014, p. 8). This has been demonstrated with recent teacher strikes across the country who are fighting for better learning conditions for their students. High school students are organizing against gun violence in our public schools and are standing up for their right to be safe in school. These are just two recent examples of organized protest against neoliberalism.

Finally, we must ask ourselves, "Can a nation expect to have a good educational system without a stable workforce of experienced educators?” (Ravitch, 2014, p. 132). Teacher training cannot stop when a student walks across the stage and earns a diploma. Public schools and COEs are missing the ideal opportunity to continue their partnership by continuing to support teachers. The training individuals receive in college is only the beginning. Ravitch (2014) wants teacher training to include "a year of study, research, and practice teaching before they are allowed to teach" (p. 141). Presumably, this would come at the end of their four-year liberal arts degree that also focuses on "how to teach, how to manage the classroom, how to deal with disruptive behavior, how to educate students with special needs, and how to engage parents to help their children" (Ravitch, 2014, p. 141). Once employed, the professional development must continue in the form of "on-going practice-based inquiry with classroom-based learning" (Sleeter, 2008, p. 1951). It is cliché, but education requires life-long learning, and this type of career-spanning support is central to the needs of teachers and students but requires funding that neoliberalism has diminished. Examining the cause-and-effect relationship between K-12 public schools, higher education, and the impact of neoliberalism is multi-faceted, complex, and at times, overwhelming. There are indefinite methods to implement change and solve problems. In addition to manipulating public schools, neoliberalism simultaneously infested teacher preparation programs. However, there is a disconnection somewhere because "in contrast to 
previous reports of teachers' negative views of teacher education, since 1990s several surveys of beginning teachers who completed teacher education have found that the vast majority-more than 80 percent—felt they were well prepared for nearly all of the challenges of their work" (Darling-Hammond, 2006, p. 275). While a promising statistic, the numbers very clearly indicate fewer students are entering the field, and those who do, leave the field rather quickly despite changes in teacher preparation that might be expected to provide additional support and induction into the field. Oparah (2014) offers one possible response: "This prisonization and militarization in urban public schools is a sharp contrast to the belief in education as a pipeline to a social and economic mobility that is held by many low-income parents" (p. 103). By creating a hostile environment lending itself to the prison and/or military, neoliberalism has ensured that schools, particularly those of the urban variety, do not offer teacher education as an option. The teacher education pipeline fell into what could be labeled the "student achievement trap." Neoliberal pressure on students and teachers to produce and defend student achievement has left all groups exhausted (Nieto, 2015; Ravitch, 2014). Dating back to the mid-1980s, "neoliberal pressures on education, becoming quite visible, were grounded in the assertion that student achievement was eroding partly because of progressive approaches to teaching and federal interventions to protect minorities" (Sleeter, 2008, p. 1948). While student achievement will be discussed in the following sections, the label students earn in K-12 schools often determines their future endeavors. Not only does this hurt a child during their formative years, but it also often helps determine the future (Darling-Hammond 1996, 2010). Under neoliberalism, this is compounded, because teachers are forced to produce and defend the achievements of their students year-after-year. Giroux (2014) argues that teacher education, in order to grow the profession, must stand up for itself in the form of critical pedagogy because it 
"has a responsibility to mediate the tension between a respect for difference and the exercise of authority that is directive, that is, a mode of authority capable of taking a position while not standing still” (Giroux, 2014, p. 98-99).

The neoliberal pressures, in the form of accountability, market reforms, testing, school choice, charter schools, and alternative certification pathways, have created additional obstacles for students and teachers of color. Crucial to understanding the consequences of neoliberalism, an examination of standardized testing highlights the limitations imposed on teachers. As one example "teachers of color possess valuable qualities for effective teaching that are not easily measured on standardized tests" (White el at., 2020, p.455). Teaching involves making connections with students and many teachers feel restricted by a curriculum built around earning high test scores. However, neoliberal policies rewarding schools that produce the highest scores, result in school closures and the removal of teachers who do not produce results. Those school closures happen more frequently in Black and Brown neighborhoods and teachers of color are pushed out of their jobs. Inroads have been made to combat these practices and there are pockets of intentional teacher education recruitment and preparation, but the long history of systemic disparities requires attacking the problem on all fronts. The strides teacher education programs have made in this area and their current pathway will be discussed in Chapter VI.

\section{Current Issues}

\section{Teacher Shortage}

I started teaching in 2004, as the wave of NCLB reforms were first implemented. This was the only educational environment I knew as a teacher. As I conversed with my veteran colleagues, I was quick to learn how this legislation was shifting the narrative and control in schools (Mehta, 2013). They did not use the term "neoliberalism" to describe how their 
autonomy was being infringed upon, but looking back, this new norm was the direct result of neoliberal policies. As a social studies teacher, I was confused by the notion that only math and reading would be tested. I have come to understand this was part of the neoliberal focus on skills as a measure of success (Ravitch, 2010). Giroux (2018) very recently wrote an article that appeared in the Boston Review entitled "The Slow and Fast Assault on Public Education" in which he proclaims, "neoliberalism has put on the mantle of fascism." Students across the country have stepped up to protest gun control in the wake of the ongoing mass shootings in schools (how this is impacting the teacher pipeline certainly warrants further research). While Giroux (2018) is not happy about the gun violence, he is pleased to see students and teachers are standing up to the neoliberal policies:

Amidst this cataclysm, public schools have been identified as a significant threat to the conservative ruling elite because public education has long been integral to U.S. democracy's dependence on an informed, engaged citizenry. Democracy is predicated on faith in the capacity of all humans for intelligent judgment, deliberation, and action, but this innate capacity must be nurtured.

This pushback in 2018 highlights that even when schools are forced to do more with less, teachers and students are still finding ways to fight for education. Ravitch (2010) illustrates how NCLB "produced mountains of data, not educated citizens. Its advocates then treated that data as evidence of "success"” (p.29). She reasons while A Nation at Risk (1983) set forth recommendations on how to strengthen our schools, it now can be viewed as a "positively idealist, liberal, and prescient" (Ravitch, 2010, p. 29) document compared to the NCLB mandates. 
Furthermore, Freire (2005) outlines a teacher's role: "Our job implies that we teach these subjects with sobriety and competence, but it also requires our involvement in and dedication to overcoming social injustice" (p. 104). I do not appreciate what neoliberal policies have done to education, but I realize it has unearthed injustices. Underfunding of schools is an enormous social justice issue, but it is difficult to digest when school budgets are increasingly spent on "surveillance equipment and policing, including surveillance cameras in corridors and classrooms, metal detectors for entranceways, and security personnel" (Oparah, 2014, p. 109). Public schools are supposed to protect students and create an environment which fosters learning, inquiry, and creativity. They should be the breeding ground for the next generation of democratic citizens. Unfortunately, "public schools in low-income neighborhoods serving predominately Black and Latino young people have become training grounds for the juvenile detention centers, jails, and prisons that await many students, and they serve as fertile soil for army recruiters" (Oparah, 2014, p. 109). Furthermore, a number of recent studies have shown how students of color are disproportionally subject to harsher discipline (Gregory \& Mosely, 2004; Okonofua et al., 2016), but exposure to same-race teachers reduces exclusionary discipline (Lindsay and Hart, 2017; Redding, 2019). This research identifies the problem and highlights how more teachers of color could be part of the solution. This new neoliberal narrative in our public schools has created a cycle of disdain toward public schools, while also highlighting the racial inequities that are contributing to the leaky teacher pipeline.

\section{Teaching Lacks Representation}

The teacher shortage is just one part of a more significant, systemic problem. Simply put, the teaching force lacks representation, which is often referred to as lack of diversity. There is a huge discrepancy between those developing into teachers versus the overall student population. 
As seen in the data from the NCES (2016b), white females make up the majority of publicschool teachers. Students need to, at various times during their education career, be taught by someone who looks like them and can relate to their shared cultural experiences. With data gathered from the NCES (2016a, Table 203.50), Table 5 illustrates how that is not happening in public school classrooms across the county.

\section{Table 5}

Race/Ethnicity Comparison of Students Versus Teachers by Percentage

\begin{tabular}{|c|c|c|c|c|c|c|}
\hline & White & Black & Hispanic & $\begin{array}{l}\text { Asian/Pacific } \\
\text { Islander }\end{array}$ & $\begin{array}{l}\text { American } \\
\text { Indian/Alaskan } \\
\text { Native }\end{array}$ & $\begin{array}{l}\text { Two or } \\
\text { more } \\
\text { races }\end{array}$ \\
\hline Students & 48.6 & 15.6 & 26.4 & 5.4 & 1.0 & 2.9 \\
\hline Teachers & 80.1 & 6.7 & 8.8 & 2.3 & .03 & 1.4 \\
\hline
\end{tabular}

Clearly, these numbers do not add up. White students only account for $48.6 \%$ of the population, and that number is predicted to drop to $45.2 \%$ by 2026 (NCES, 2016a, Table 203.50). This data illustrates why any exploration of preparation attrition must address the needs of the field. Black, Hispanic, Asian/Pacific Islander, American Indian/Alaskan Native, and students of two or more races accounted for $51.3 \%$ of the student body, but when combined, they only account for $19.23 \%$ of the teaching force. One small way to promote representation in the teaching field would be to study the teacher education attrition rate. The teacher workforce should reflect demographics more broadly because cultural responsiveness is needed for successful education for all. Culturally, white teachers have long fallen short of the mark in terms of this proficiency. Access to quality public education remains a prominent civil rights issue. A famous W.E.B. DuBois quote captures the heart of the matter: "'Of all the civil rights for which the world has struggled and fought for 5,000 years, the right to learn is undoubtedly the most 
fundamental...The freedom to learn...has been brought by bitter sacrifice"" (as cited in DarlingHammond, 1996, p. 5). Not only does Darling-Hammond quote DuBois in her own work, but she used part of the quote to title her article "The Right to Learn and the Advancement of Teaching: Research, Policy, and Practice for Democratic Education" (1996). DuBois and countless other leaders in the field understand that a solid, equitable, public education system must "arm people with an intelligence capable of free and independent thought" (DarlingHammond, 1996, p. 5) which makes access to education a social justice issue. When teachers leave the field at such staggering rates, it hurts the school community and has a negative impact on the kids they leave behind. Access to qualified teachers should be a fundamental right of any student who walks through our public-school doors. Teachers' preparation, academic backgrounds, and licensure status impact students' achievement (Darling-Hammond, 1996, 2010). Darling-Hammond (2010) cites studies from both North Carolina and New York City, where students' achievement was "significantly higher if they were taught by a teacher who was certified in his or her field, fully prepared about entry, had higher scores on the teacher licensing test, graduated from a competitive college, had taught for more than 2 years, and was national board certified" (Darling-Hammond, 2010, p. 43). Teachers matter and access to well-qualified and properly trained educators influences student achievement. If students are habitually assigned inadequate teachers, which happens more frequently to low-income minority students (Darling-Hammond, 1996, 2010), they fall behind and run the risk of never catching up. What does this mean for the students? Not only does it mean they fall behind academically, but the problem compounds. Students are tracked, labeled, and/or projected to enroll in less challenging courses (Tyson, 2011). Exposure to college-preparatory, advanced, and honors courses often means a difference in achievement, which in turn results in limited-access to college admissions 
(Darling-Hammond, 1996, 2010). This helps explain why fewer students of color enroll in college and why even fewer choose to enroll in teacher preparation programs. This cycle of inequity in education has become more complex and inequitable over time and significant changes need to be made now before further damage is done. I will present possible solutions in Chapter VI.

The disconnect between the teacher workforce and the student population can be addressed. Gloria Ladson-Billings (2006) tackles the issue head-on in her article entitled "It's Not the Culture of Poverty, It's the Poverty of Culture: The Problem with Teacher Education.” This groundbreaking article confronts the misuse and misdiagnosis of low self-esteem, poverty, and culture. First, she defines the problem with teacher education when students interchange "the poverty of culture" with Michael Harrington's (1997) "the culture of poverty." By confusing these two ideas, teachers "describe what they see as a pathology of poor students and hide behind child poverty as an excuse for why they cannot be successful with some students" (Ladson-Billings, 2006, p. 105). Thus, future teachers are being taught that it is acceptable to be unsuccessful educating children who come from the "culture of poverty." Once instilled in future teachers, the myth is perpetuated and used as a plausible excuse in the classroom. LadsonBillings (2006) analyzed student interviews, journals, and electronic portfolios from her teacher preparation courses. She exposed her (mostly white, middle-class) students to children who differed from them in race, gender, and ethnicity. Her college students were quick to diagnose students with low self-esteem. Ladson-Billings (2006) attributes this to "American culture maintain[ing] a narrative of the individual" (p. 105-106). Public education is quick to blame the failure of individual students, instead of addressing a systemic problem. In my experiences with 
young teachers, they are quick to blame their students rather than looking for a more significant problem.

Another factor contributing to the leaky teacher pipeline is the use of "culture" as a catchall expression, utilized often as a proxy for race (Ladson-Billings, 2006, p. 106). LadsonBillings (2006) states, "Culture is regularly used as a code word for difference and perhaps deviance in the world of teacher education" (p. 106). The overwhelmingly white, middle-class, monolingual teaching force often categorize themselves as having "no culture" or being "regular" (Ladson-Billings, 2006, p. 106). Here is where I see one of the biggest problems. Students in public schools do not connect with their teachers and therefore view education as an unappealing career path to explore. Teacher candidates, mainly white, who seek certification have not been exposed to other races, ethnicities, and cultures, and therefore let their preconceived notions penetrate their pedagogy. Ladson-Billings (2006) offers three solutions. She wants perspective teachers to interact with students in a non-school setting where students are likely to experience success, to experience structured activities in cultural systems, and (when possible), infuse global dimensions into teacher education (Ladson-Billings, 2006, p. 108109).

This literature review only scratched the surface of the vast amount of research already conducted about the historical trends, neoliberal consequences, and current issues facing public education. While thinking about teacher education attrition, these topics (amongst others) are the very epitome of why public teachers are under attack. For those college students entertaining the notion of becoming a teacher, this study will attempt to pinpoint when and why these students drop the major and what the field of education can do to help the epidemic. Chapter Three will present my research methods and explain how I went about studying this very problem. 


\section{CHAPTER III: RESEARCH METHODOLOGY}

\section{Research Problem and Research Questions}

\section{Why Is This Study Important?}

What is the attrition rate of education majors? There are countless studies about teacher attrition within the first five years in the classroom (Kopkowski, 2008; DeAngelis et al., 2013; Office of Postsecondary Education, 2015), but the research is sparse when it comes to the retention rate of education majors. Why do students get accepted and enter college as education majors and then not graduate with a degree to become a teacher? This is an understudied phenomenon that is the missing piece when trying to answer the question, "who wants to be a teacher?" The following research questions were addressed:

1.) What is the nature of student attrition in secondary and K-12 teacher education programs?

a. What patterns in student demographics exist?

b. What factors do teacher candidates attribute to their attrition?

2.) What are key turning points for teacher candidates in deciding not to continue with teacher education?

3.) Based on the study, what are the implications for teacher education and policy?

\section{Research Paradigm}

A paradigm is a way of thinking that refers to "assumptions about the nature of reality and truth, the kinds of questions to explore, and how to go about doing so" (Glesne, 2011, p. 5). Looking at that definition, I explored why potential teachers do not enter American public-school classrooms during a time when there are increasing teacher shortages. This study is situated between two contrasting conceptual frames, neoliberalism and the critical frameworks, which 
will guide the fundamental question of teacher education attrition. Do fewer people pursue teaching careers because of the cost of college, and since teachers' paychecks are less than desirable? Those questions represent the neoliberal approach to the issue. On the other hand, the critical framework would focus the question on the lack of perspective teachers. These two frameworks not only influenced the development of my research questions, but also uncovered invaluable insight into this complex issue.

\section{Researcher Positionality}

I understand that I come from a position of privilege. While I am a first-generation college student, my parents, armed only with their high school diplomas, made it their top priority for my brother and I to earn college degrees. They never intended for both of us to become educators, but that is where we both landed. After spending the better part of 16 years in public education, currently working to prepare future teachers, I have watched our profession be torn to shreds. Where did I learn to take the position to tirelessly defend public school teachers? Where did the anti-teacher narrative originate and why has it gained so much momentum? I found that Banks's (1998) article helped me better understand some of the long-term issues brought on by misguided educational policy that has come to ultimately impact students and limit their opportunities. He writes, "institutional concepts, theories, and paradigms considered neutral often privilege mainstream students and disadvantage low-income students, students of color, and female students...educational neglect of desperate and needy students, to privilege groups who are advantaged, and to legitimize and justify discriminatory educational policies and practices" (Banks, 1998, p.5). Let me break down how this quote reinforces why I want to study who wants to become teachers, and more specifically, why students come to college as education majors and then do not become teachers. While there is an overwhelming number of female 
teachers, there is a disproportionately low number of teachers of color compared to the makeup of our country's public-school students.

From my position as a White, middle-class female, my teachers looked like me, acted like me, and understood me. They became my role models, and I aimed to follow their same path. In fact, when I changed my major from broadcast journalism to secondary education, I reached out to those teachers for advice. They pushed me to become a teacher. Based on what Banks (1998) writes, policies constructed by privileged groups perpetuate the position that lowincome students and students of color are not afforded these same opportunities. That hit me like a ton of bricks. What if I went to a "lower income" school? Would I have received the same education that would have led me to become a teacher? Would a student of color with a similar background have been pushed to not only go to college, but to become a teacher? What if I had parents who did not grasp how crucial a quality public education was for their children?

During my study of who becomes teachers and why, I kept in mind both the "insideroutsider" and "outsider-within" concepts (Banks, 1998), in addition to other cross-cultural research topics. I needed to understand my own background and recognize that it helped me navigate the world of teacher-preparation with few obstacles. I interviewed students who did not have these advantages. These students dropped out of the teacher education sequence. I conducted research that helps me identify the problem and how to fix it.

I must acknowledge how I successfully got to this point in my career because of my position. I cannot fall into the trap Banks (1998) writes of: "Social scientists are human beings who have both minds and hearts. However, their minds and the products of their minds have dominated research discourse in the United States and throughout the Western world" (p. 4). I waded through the policies that led the field of education to a place that limited access to so 
many potential educators. I intend to add to the body of research that will help COEs better prepare future educators while not making those individuals who are causalities of a broken system feel like they are just part of a pointless study.

\section{Data Collection and Sampling}

The data collected for this study came in the form of face-to-face interviews and demographic information gathered from Midwestern University, which long held the reputation as being a leading institution for earning a teaching degree. Nearly one out of every seven teachers in this state earned their degree from the university, and $87 \%$ of school districts in the state report having at least one alum in their employment. (In order to protect the participants of

my study, I cannot provide the source of this statistic). I utilized the robust secondary and K-12 education programs that account for 28 of the 41 accredited teacher education programs at the university. I interviewed students who had previously been enrolled in English, math, historysocial sciences, biology, chemistry, physics, music, and theater teacher education programs. In working for the university, I was able to reach out to former students to see if they wanted to participate in the study. My participation selection is classified as purposeful in the homogenous category based on my access to these students (Hatch, 2002). Hatch (2002) highlighted several types of purposeful sampling strategies that can be utilized with selecting participants.

Purposeful sampling is the opposite of what Hatch (2002) labels "convenience sampling," which he classifies as the most commonly used strategy, the least desirable, and for "students who see their doctoral programs as nothing more than a series of hoops to jump through... [and are looking for a] 'quick and dirty' dissertation” (p. 50). The form of purposeful sampling I chose was homogenous because my participants had the similar characteristic of previously being enrolled in an education program at Midwestern University. 
I began my purposeful, homogenous sampling by reaching out to people on campus who were in similar positions as me or who taught some of the education courses. I asked them to contact students who might be interested in participating. In order to remove any barriers or avoid making students feel uncomfortable, I created a short survey that I was able to send out to perspective interviewees to see if they wanted to participate. I sent that link to other coordinators of student teaching and instructors to give out to their students as well. Because I already had an existing relationship with several of the interviewees, they did not fill out the survey and just responded to my email indicating they wanted to participate. Then my sampling took on another life and morphed into snowball sampling. Initially, I had inquired about participants from other coordinators and instructors, but as time went on, my contacts at the university started forwarding me names and email addresses of students who dropped their program. Students responded to my emails inquiring about their participation almost instantly, which was very reassuring. Some participants offered up names of other students who dropped the education sequence before I even had the chance to ask. My purposeful, homogenous sampling turned into snowball sampling which ultimately created my robust pool of participants. For example, students participating in my study gave me names of their classmates who were faced with similar situations.

The chain reaction helped me to ultimately secure 13 students. I had assumed that it would be difficult to find students, but I only sent three different "rounds" of emails to find interviewees. Once we made contact, students were anxious to tell their stories. These 13 students represented a wide range of secondary and K12 programs, and they offered a variety of experiences. Selection of participants was based on simple criteria: had the student come to Midwestern University to become a teacher and was that student no longer an education major in 
a secondary or K-12 program? During the interviews, I asked students about their views and experiences with teacher education and why they were no longer pursuing a teaching degree.

\section{Methods}

As indicated above when I explained sampling, participants arrived in my office and were ready to discuss why they were no longer an education major. Initially, I had created an online survey (see Appendix A) to help me collect the demographic data of the potential participants. I also designed the survey as a low stakes way of letting the potential participants know what I would be asking. The survey was also shared when other people on campus were helping me recruit. I crafted an email explaining what I was doing, making it easy for people to share. Only one person who filled out the survey opted not to participate in the study. Of the 13 participants, only two filled out the survey. The rest responded directly to me via email and set up an interview time. I emailed the participants the questions before their interview so they knew exactly what I would be asking. The participants granted me consent by signing a form (See Appendix B) when they arrived, and I recorded the interview with each person individually. These interviews took place in my office on campus. The interviews went really well. Students were anxious to tell their stories and were happy to be heard. After conducting the interviews, I transcribed them, and I began organizing the data. I conducted a few interviews and looked for trends and common themes, and then I sent out another round of emails to instructors and program coordinators. That yielded a few more interviews; overall, I completed this cycle three times.

When I reached eleven interviews, I sat down for coffee with my methodologist and discussed the data I had organized. When I proposed this study, I had hoped to interview between ten and fifteen students from a variety of programs. While we were talking, it became 
clear that trends were emerging, and the students' stories had commonalities. My methodologist advised conducting one more interview to confirm that I had reached the point of saturation. I scheduled another interview and then ran into a former student who had since dropped the sequence, and she asked to be in the study. I conducted interviews 12 and 13 and felt very confident that I had reached the level of saturation. Listening to each interview during the transcription and coding process allowed me to get to know the participants even better. While I had guided the interviews with my pre-formulated questions, I let participants add in their own details, inquiries, and ideas. Three clear groups emerged when organizing the data.

The first group to emerge, I deemed "the transfers." These four individuals had deliberately gone to community college before coming to this Midwestern University. The second group I titled "the Gateways," comprised of three students who started their college career at the university. At this particular institution, there are four Gateways for all education programs. Gateway 1 is admission into a particular education program. Gateway 2 requires a series of tasks, generally needing to be completed one year prior to student teaching. Gateway 3 must be completed to student teach, and Gateway 4 requires successfully completing student teaching and passing edTPA, a state-required, performance-based assessment. During my interviews, I was finding that the tasks in Gateway 2 and 3 were causing students to leave the major, hence "the Gateways" grouping title. The final five students became known as the "Teaching is NOT what I expected" group. Our conversations revealed that students had a preconceived notion of what teaching would be like, and their initial education courses revealed that it was considerably more difficult or different than it appeared. Not only did I find trends among the group as a whole but separating them into these three categories helped to streamline 
my recommendations. While analyzing my data, I looked at them as one entity, scrutinized the identified groups above, and pulled out individual anomalies.

\section{Analysis}

After conducting the interviews, I transcribed each interview and listened to them while I was coding. I utilized Miles et al.'s (2014) time-ordered matrix, which is described as having, "columns arranged chronologically by time period to determine when particular phenomena occurred" (p. 202). These columns included their childhood, high school, and each year of college. The students' responses were then put into the appropriate column. I started thinking about the timeline of an education major. I began to view their "life cycle" to see when the "drop out" took place. Sections of the timeline were not explicitly referenced during the interview. I did not want to be rigid and seem to be interrogating the participants. The questions were designed so I would walk through the life cycle of an education major. Because I was wellversed in the course sequence, if a student only got through the first education course in the sequence, I would know that they were roughly in their junior year or a first-semester transfer student. From there, I could ask the appropriate follow-up questions. I wanted to see if there was a correlation between when they decided to become a teacher and when they changed their plan of study. Using the time-ordered matrix, I noted patterns and themes, looked for relationships between variables, and attempted to find a pattern of when students dropped the education sequence and how they reached a turning point to do so. The time-ordered matrix looks at their years as a youth, in high school, in college, and in the future. Miles et al.'s (2014) time-ordered matrix "displays time-linked data referring to phenomena that are bigger than specific 'events,' so as to understand (and perhaps later explain) what was happening" (p. 203). 
After reviewing the data in the time-ordered matrix, I again turned to Miles et al. (2014) to further explain my findings through a different view.

Like the time-ordered matrix, the variable-by-variable matrix helps to "notice that a few major variables are in play, underlying many specific phenomena" (Miles et al., 2014, p. 226). Based on the time-ordered matrix that I created, the variable-by-variable matrix helped me to see if the significant variables of teacher education are connected or interrelated. I looked at a wide variety of issues from family and GPA to outside pressures and second thoughts as different factors that impacted their decision to drop the major. Based on all this information, I was then able to determine why they left the teacher education major. By pinpointing when and where, I can now make recommendations to the university to put supports in place to help students successfully complete their plan of study to become teachers.

In addition to the matrices which were based on the interviews I conducted, I also requested enrollment data from the university. This data included information about gender, race, enrollment numbers, and grade point average. I asked for data involving sexual orientation of education majors. That is not something the university currently collects, but I suggested that is a demographic they should start to track since some potential education majors do not pursue the major because of discrimination in the field. I requested access to the demographics of the students who have dropped the major over the course of the past five years to look at trends in enrollment. While this is a qualitative study, it was important that I utilized demographic data to supplement my findings from the interviews. Given that I interviewed participants from a large cross section of the secondary and K-12 programs, I felt it was important to see the numbers from all of the programs. In Chapter 5, I will introduce my findings and corroborate the interview data with the university-provided demographics. 
After coding the data and using the matrices to make sense of their stories, I found that each participant had what Wolcott (1994) describes as a "critical or key event." Chapter Five will not only explore the matrices but will also explain the university's demographic data. While going through the process, it became clear that a chapter dedicated to the participants' critical events needed to be added between this chapter and the data in Chapter 5. As Wolcott (1994) writes, "just as no research as fieldworker can ever hope to get the whole story down to every last little detail, no researcher as author can ever expect to tell the whole story either" (p. 19). It would be doing their stories and my research an enormous disservice if I did not include each of their turning points. What was the key event or critical moment that turned each of these students away from the teacher education major? I explicitly asked the question and for some students, it was a very quick and easy answer. For others, it involved digging into their background and allowing them to add context. Regardless of each participant's turning point, as Wolcott (1994) advises, "doing less more thoroughly" helped me to not only group them, but to have a better understanding of how this small piece of their story actually echoes a broader theme.

\section{Trustworthiness}

Glesne (2011) argues that as qualitative researchers, "part of demonstrating the trustworthiness of your data is to realize the limitations of your study. Your responsibility is to do the best that you can under certain circumstances" (p. 212). It was very important to me that

all my participants' identities were protected. I decoupled subjects from their department and removed identifiers. I switched their demographics to further protect the participants' confidentiality. As I discussed in the positionality portion of this study, I understand my bias and privilege. I wanted to make sure that did not cloud my methodology or analysis in any way. In 
order to demonstrate an astute level of validity and trustworthiness, I triangulated my data by using "multiple data collection methods, multiple sources, multiple investigators, and/or multiple theoretical perspectives" (Glense, 2011, p. 49). This meant that I compared different sources when reviewing my interviews and cross-referenced it with the demographic data from the university. In speaking to multiple participants from various departments, I was able to gather information from a large cross-section of the secondary and K-12 education majors. I utilized member checking which involves "sharing interview transcripts, analytical thoughts, and/or drafts of the final report with research participants to make sure you (I) are representing them and their ideas accurately" (Glesne, 2011, p. 49). This really goes back to my positionality section again. I successfully completed my teacher education program, so I do not want to add my interpretation as to why the participants did not successfully complete their teaching degree. Students were forthcoming with their stories and spoke with ease about their experiences. All the participants made reference to the circumstances when the onus was on them, but also pointed out what instructional and institutional barriers contributed to their shortcoming. Several of the students told me either "good luck" or "I am really glad someone is looking into this issue" at the end of our interviews. I made sure to establish rapport with the students I did not already know by getting acquainted with them first. We would talk about how they heard about my study or who referred them to me. This put the participant at ease and helped to reassure them that this was a legitimate study. I could tell they genuinely wanted positive change to come from their less-than-ideal experience. I got a few hugs at the end of the interviews and words of praise and encouragement while I worked through the dissertation process. There was a sense of camaraderie that I did not expect, which made me feel responsible to see this through for the sake of future education majors. As a former high school teacher, and in my current role as a 
coordinator of student teaching, I understood the demands placed on classroom teachers and the pressures put on aspiring teachers. Given my background, I successfully gained the trust of my participants, and I took the role of guiding this study very seriously.

\section{Ethical Issues}

Since human subjects were interviewed for this study, I sought and was awarded approval from our Institutional Review Board (IRB) to proceed with my study. While I could not offer my participants money or an instant change in the teacher certification process, I provided reciprocity through the prospect of long-term, meaningful change. My participants volunteered their time, stories, knowledge, and a glimpse into their private lives. All of my participants spoke with me willingly, openly, and on their own time. They were forthcoming with their responses, held themselves accountable, and hoped to improve the system. I listened to my participants carefully and seriously during our interviews. I wanted them to feel like their stories and experiences will help shed light on why others have also left the major, so the field of teacher preparation can better support their students. Their stories shaped this study, and in turn, I was vulnerable to their involvement and what they chose to share. As Glesne (2011) writes, "by providing the opportunity to reflect on and voice answers to your question, you assist them to better understand some aspect of themselves" (p. 178). After conducting the interviews, I could see that students were looking back and also trying to figure out where things went wrong. I believe they viewed me as a person who has the ability to share their experiences to bring about positive, systemic change.

\section{Contributions to the Field}

This study seeks to change the field of teacher preparation by highlighting some of the unnecessary barriers that prevent individuals from becoming teachers. From a lower GPA to the 
inability to pay for additional required tests, this study highlights how students are edged out of programs for reasons beyond their control. By studying why those students who majored in teacher education left the major, I have been able to pinpoint when these shifts most likely occur. Although the data is a generalization of what happened at this particular university, it is transferable to other institutions and in different settings. It is applicable to other situations, populations, and settings. Using the same question set, I hope to continue the study at other institutions to make comparisons. Looking at when, why, and how participants reached the decision to stop pursuing teacher education will help to put supports in place, so students can ultimately succeed, and it will help to retain those students who wish to become teachers. I found ways that the teacher preparation process can be biased, and I hope this will lead to the removal of barriers at this particular institution. I have made the case that there is a teacher shortage, so it is time to review what is stopping people from becoming teachers. I have written about the cyclical life of education reform. Public schools lack diverse faculty, so students do not "see" themselves as teachers. The students who do enroll in teacher education program are disproportionately white females. Upon graduation, they return to our schools to teach, and many leave within the first three-to-five years. The cycle continues. This study intends to help break the cycle and to shrink a serious gap in the literature. Before diving into the data and interview analysis in Chapter V, I found it was important to address the critical event that turned each participant away from their specific teacher education program. In the chapter that follows, I review those critical events and highlight trends that emerged. 


\section{CHAPTER IV: THE CRITICAL EVENT}

\section{Meet the Participants}

In Chapter I, I introduced Mindy whose career-altering meeting with me became the inspiration for this study. After talking with Mindy, counseling her with options, and assuring her that there was in fact life after dropping the education sequence, it dawned on me that she was not alone. I was able to secure interviews with students rather quickly, and they were eager to share their stories. As a qualitative researcher, Wolcott (1994) argues that we need to be storytellers and "to be able to tell a story well is crucial to the enterprise. When we cannot engage others to read our stories — our completed and complete accounts — then our efforts at descriptive research are for naught" (p. 17). It is important that these students' stories are told, shared, and understood. Each of these 13 willing participants entered my office with a different backstory and set of circumstances, but what became clear to me rather quickly was that each student experienced a critical event that caused them to drop the education sequence. Wolcott (1994) stresses the importance of organizing and presenting data in the form of descriptions. For the purposes of this chapter, I will be employing Wolcott's (1994) “critical or key event" approach (p. 19). By focusing on one example, I will be "doing less more thoroughly" (Wolcott, 1994, p. 20). There is no way I could possibly tell each participant's entire story and do them justice; instead, I will "focus on only one or two aspects, creating a story-within-a-story in which the essence (but not the detail) of the whole is revealed or reflected in microcosm" (Wolcott, 1994, p. 19). The critical event that links their stories together comes in the form of their personal turning point. What events or series of events led them to make the decision to drop the teacher education sequence? After listening, transcribing, and coding all the interviews, I have 
placed each of the participants into one of the following groups: the transfers, the gateways, and the teaching is not what I expected group.

\section{"The Transfers"}

When deciding what life has in store after high school, many students choose community college as an affordable option to begin earning college credit without paying the big university price tag. At Midwestern University, 36 percent of education majors are transfer students. The four students I interviewed who transferred into a variety of secondary and K-12 majors did not feel supported upon their arrival and felt overwhelmed by the initial requirements they had to fulfill. Their turning point stories follow below.

\section{Trevon}

Imagine spending two years at community college thinking you were saving money before declaring a major and heading off to a big university. When I spoke with Trevon, I could still hear the frustration in his voice. After graduating high school, he was not exactly sure what he wanted to be and had considered a career in computer science since it seemed like a stable, yet ever-changing industry. Having two grandparents and a mother who were all teachers, Trevon gave into the voices that were in the back of his head and decided to transfer to Midwestern University to be a secondary education major. As his story unfolded about this decision, but not getting into the classes he needed for his first semester on campus, I could hear how defeated he sounded. Trevon said, "The whole purpose of coming (to Midwestern University), going to community college first, was so that I could not stay in college for like more time and spending a ton of money. And now I was looking at three and a half years at a four-year university rather than two and a half. So, it's like, did I save any money at all?" (Interview, 2019). Trevon was dropped from his education major not once, but twice, for not 
meeting a handful of Gateway requirements and not being able to get into the first teacher education course in a three-course sequence, each being a prerequisite in order to continue.

Teacher education majors at Midwestern University have four Gateways they need to complete in order to graduate and earn licensure. They serve as checkpoints throughout their educational career, and often students need to complete the tasks in a Gateway before moving onto the next portion of the teacher education sequence. Gateway 1, for example, includes tasks such as getting a $\mathrm{C}$ or higher in English and speech introduction courses. These are easy to accomplish, but transfer students often have to get their transcripts sent to the appropriate office on campus (in addition to having them sent to the admissions office when they applied). For the transfer student new to campus, this can mean countless extra tasks (and money) in addition to getting acclimated to a new campus and starting classes. After two semesters (one academic year), Trevon was finally allowed to enter the teacher education sequence.

When I met Trevon, he was in his third semester on campus, but first in the teacher education sequence. I was teaching the introduction to secondary education course, which most students are usually excited to take. While a very nice student and a thoughtful contributor to our discussions, I could tell from the beginning that Trevon was put off by the course. It was later in the semester that he told me he planned to drop the education sequence, which was why, a year later, I reached out to him to take part in this study. Little did I know at the time he was in my class, Trevon was experiencing his turning point. The number of hoops he needed to jump through had become too tedious, and the prospect of becoming a teacher seemed to be getting farther away rather than closer. Unlike the other participants in this study, Trevon's turning point actually became a full circle because at the time of the interview he had decided he did, in fact, want to be a teacher. As revealed in his interview, he plans to finish the education sequence 
and student teach next year. I share his story because it is the exception, but one that required tremendous perseverance, patience, and money.

\section{Andre}

After spending two and half years at community college completing his Associate's degree while working full-time, Andre made the decision to transfer to Midwestern University, a full eight months before he would start classes on campus. Knowing he would continue to work full-time while enrolled in the teacher preparation major, he worked and saved during these eight months. Upon learning of his acceptance, he reached out to his advisor to see what he needed to do in order to start in the fall semester, fully prepared to jump into the teacher education sequence. His advisor told him, "You're good, just find a place to live." When Andre arrived on campus he learned, like Trevon, that he had a series of Gateway requirements to complete. At the time of Andre's acceptance into the program, the state's board of education required a 22composite score on the ACT. The university did not require the score, so he was admitted not knowing he would need to improve his score in order to complete his major. The state has since dropped the requirement, but over the years, this deterred many students from proceeding with the education sequence. In fact, when the state dropped the requirement, Midwestern University attempted to contact over 100 students to let them know they could return to complete the program. Unfortunately for Andre, this was not the case. There were eight months between the time he was accepted and arrived on campus, lost time that could have been used to take these necessary steps.

Upon arriving, he found out he had one month to complete the Gateways, which included taking the ACT to raise his score. He took it three times, which cost him over $\$ 500$. Out of frustration with all the additional requirements while also working full-time, he dropped the 
education program. Arriving in class on the first day, he felt blind-sided by the news that he had to re-take the ACT, and each time the score did not make the cut, his morale was further diminished. Learning that this would further push back his graduation by an entire academic year, Andre dropped the education sequence. He felt that expectations were not clearly communicated to transfer students, and he was completely overwhelmed. Leaving his apartment each day at 8 am to attend classes, he would then go to work, most nights arriving home around $10 \mathrm{pm}$. This was when he could begin doing his homework before repeating the cycle the next day. Given that he had to work to pay for school, Andre could not fathom adding additional semesters onto his academic career. He did graduate with a bachelor's in his content area, but it took him two-and-half years on campus to do so. That was the additional semester he was trying to avoid paying for, so in total, including his time at community college, he was in school (and working full-time) for 5 years, including summers.

\section{Cora}

Cora found herself in the same predicament as Trevon and Andre. Arriving as a transfer student from community college she felt overwhelmed by the sheer volume of additional requirements secondary education majors needed to complete within the first month on the new campus. When she could not complete them, she was dropped from her major while still trying to complete the first course in the teacher education sequence. This course required twenty outside clinical hours at diverse high schools located off the university's campus. New to campus, Cora did not know a lot of people nor did she have a car. I was teaching the course and tried to help students in the class arrange rideshares and get to the observations, but most students had jammed packed schedules with little additional room to observe. Finding classmates who had the same time off proved even more difficult than Cora had expected. For 
the course, students had to sign up to observe at the high schools a week in advance, but the schedule was open for the entire semester. Some students signed up for all their hours at the beginning, leaving few choices for the students who did not have the luxury of their own transportation. Cora found navigating this system to be especially difficult without a car and not knowing many people on campus. Feeling discouraged, coupled with the news that she'd been dropped from the teacher education sequence, Cora felt she had little support or guidance as to how to proceed in the major. Her turning point illustrates the extra challenges that transfer students face. Cora was able to graduate in two years with a degree in her content area, and she's currently applying to graduate programs.

\section{Enzo}

Enticed by their high graduation rate, affordable tuition, and stellar reputation for preparing teachers, Enzo also transferred to Midwestern University. Unlike the previous three stories, Enzo progressed farther into the teacher education sequence before dropping the major. Working full-time while navigating the obstacles of transfer students, Enzo admits there was more he could have done to better prepare for the amount of work he had to do, and he felt like he was always trying to catch up. Enzo navigated the difficulties of transferring and cited weird roommate stories, the feeling of inferiority in some of his classes since he was a transfer student and trying to work as a full-time student. He made it to the semester before student teaching and, having taken it five times, Enzo had not passed the content exam, which is required to student teach. I had to deliver the news to him that he could not student teach until he passed it. So, he took a break from school, which, as a turning point, was a rather traumatic one. After having to take a break from school to pay off a tuition debt, he finally sought out help. Living on campus, but not attending the university was a real wake up call. He needed the approval to know that 
dropping the education sequence would not make him appear to be a failure. He pretended to still be a student, going as far as leaving the house at "class time" so his roommates did not know he had dropped out. While Enzo's turning point felt more like hitting rock bottom, he was able to realize that dropping the education sequence would not be failing or letting anyone down. Enzo spent four years on campus, including three summers, and successfully graduated with a degree in his content area and is working full-time for a park district.

\section{"The Transfers" Summary}

As you can see, these four participants highlight the examples of the extra obstacles transfer students face. The rising cost of a college degree often makes community college appealing, especially if you have not settled on a major. Most community college students live at home, so transferring to a big university means living on your own for the first time. This comes with more responsibility and requires additional money. All four of these transfer students had to continue working, two of them at a full-time capacity. The additional hoops that all education majors need to jump through is exacerbated when you are a transfer student. Between getting acclimated to a new campus, living on your own without the transitional experience provided by the dorm experience, and the violent shove into on-campus academic life, the transfer experience at this particular university needs to provide more support. Most universities do extensive summer onboarding programs for incoming freshman. I would suggest a summer bridge program for transfer students as well. A registered student organization (RSO) dedicated specifically to supporting transfer education majors would also benefit these students at the beginning of the semester, as well as serve as support group during their time on campus. While not all transfer students struggle, it is important to recognize that many individuals do. These four stories illustrate why extra support is necessary for student success. Three of these 
four students were first generation college students, which adds an additional layer of anxiety. The transfer experience also brings to light issues surrounding equity and access to the fancy four-year degree. While many traditional students at this university would not start chipping away at the Gateway requirements prior to junior year, the added pressure of completing these tasks adds stress and financial constraints. The next group of students classified for this study are deemed "the Gateways" because they are traditional college students who found their critical event occurred in conjunction with one of the university's gateway requirements.

\section{"The Gateways"}

Like Mindy, the three following students experienced obstacles that caused them to veer off track and ultimately, away from teacher education. Their turning point stories reveal that all three of these individuals came to Midwestern University straight from high school with the sole intention of becoming a teacher. While their experiences varied, the looming Gateway requirements served as the gatekeeping mechanism.

\section{Joshua}

Arriving bright-eyed and bushy-tailed from his high school experience at a small, private high school, Joshua aspired to become like his high school teachers. Plagued with family issues, having navigated the emancipation process, Joshua lacked the guidance young adults so desperately need early in their college career. Admittedly, he did not make attending class a priority, citing one course where he missed 12 times in a semester. His transcript, littered with less-than-average marks, was his ultimate demise. Joshua's turning point was very much selfinflicted. Not able to meet the GPA requirement, his advisor told him the only way to stay in the education major was to retake classes. He could not afford to stay in college longer than four years, so he ultimately dropped the sequence. He remembers his classes fondly, learned a lot, 
and still feels that he would pursue a career connected to education in some way. He has one remaining course but will graduate with his degree in his content area in four years (plus one summer class). His post-graduation plans include working in the automotive industry.

\section{Lauren}

At this point, I have cited several examples of how the Gateway requirements negatively impact students, and Lauren's story is not much different. However, she came to Midwestern University wanting to be a teacher, citing her childhood and high school years as helping to shape that dream. She majored in three different education content areas, but finally settled on one. Having also been a product of a small, private high school, the diverse clinical experiences embedded into the course really opened her eyes to what she might expect in a public school. While she enjoyed the class projects, getting further into the education sequence, Lauren started to feel hesitant about becoming an educator, but did not have the confidence, or a firm reason, to change her major. Ultimately, she failed the content exam three times. This actually gave her the courage and a solid reason to talk to her family and friends about dropping the sequence. Feeling relieved to have addressed the nagging feeling that she did not want to be a teacher, despite having always seen herself as one, Lauren learned that there were career possibilities she did not even know existed. While chatting about what to do next after her decision to drop the program, I knew Lauren was involved in Student Affairs on campus, and I suggested looking into the Master's in College Student Personnel Administration. Having felt pigeonholed in the education sequence, Lauren ultimately found her passion in a related field and will begin her master's degree next semester. 


\section{Daniel}

Of all the interviewees, Daniel got the closest to student teaching. His file was sent out to schools, and he was about to set up a student teaching interview with a school when he dropped the education major. Citing inspiration all the way back to his middle school teachers, Daniel sailed through his courses. Doing what he needed to get by, he learned a lot in his education and content area classes, but he was not getting the best grades. Admittedly, Daniel said he "did not have the foresight to see how that would affect me in the future" (Interview, 2019). "That" being the missed assignments and class absences which had added up over the semesters and years. His turning point was semesters in the making, but it was the realization that he made it to the semester before student teaching and did not meet the GPA requirement. He felt like he ran out of time and no longer saw himself as a teacher. Looking back, he recognized that he had been dealing with some mental health related issues. With the help of counseling, he felt it was best for his journey as an education major to come to an end. When I spoke to him, he was graduating and had a job lined up, in a position where he would be educating people, just not in a traditional classroom. It took him five years to complete his undergraduate degree. He felt satisfied that there would ultimately be an education aspect in his career.

\section{"The Gateways" Summary}

While it is completely understandable to have benchmarks in place to maintain the rigor of the teaching profession, the three-tiered Gateway system can prevent students from progressing in the teacher education sequence based on one less-than-stellar semester or not checking a single box. This initiates a chain reaction for the students. Based on these examples, two of the three students cited a lower GPA as preventing them from moving forward. As opposed to transfer students who start fresh with a new GPA when they arrive, students who start 
at the university as freshman have any poor grades follow them their entire time on campus. Most students in the teacher education sequence end up retaking courses to replace lower grades to raise their GPA. This obviously costs extra time and money, commodities two of these participants did not have. The gateways certainly serve a purpose but can have unintended consequences for those students who genuinely want to continue in the education sequence. It should also be noted that two of the three Gateway students had previously attended private, religious high schools. The curriculum of the teacher preparation programs on campus is certainly geared toward preparing public school teachers, and therefore, being inserted into that environment for the first time, could have certainly played a role in those two students changing their minds about teaching. While the gateways can prevent students from progressing through the sequence, some students from the study reported that their exposure to the profession during their course work caused them to leave the major. These five students make up the "Teaching Is NOT What I Expected" group, and their stories follow.

\section{"Teaching Is NOT What I Expected"}

The teaching profession is unique in that most people have experienced education in the form of a student. Usually, based on positive experiences, people decide to study education, citing dynamic role models. Influential teachers often make the job look effortless and easy. While not intending to mislead their students, who often talk to them about following in their footsteps, the very best teachers sometimes forget to tell future teachers about the workload and expectations of education majors. What follows are the turning point stories of these students who reported that after limited experience within the major, teaching simply was not for them. 


\section{Olivia}

Like many teacher education majors, Olivia cited an impactful high school teacher that inspired her to become a teacher. After completing two courses that included clinical hours, Olivia enrolled in the first secondary education course that requires college students to teach high school students. Once she taught for the first time, she quickly realized this was not something she wanted to do. Her turning point came in the form of actually teaching for the first time. She cited the anxiety it caused to be in front of a room full of students day-in-and-day out when she was teaching during her clinical experience. The lack of personal connection did not sit well with her. Having interviewed Olivia early in her educational journey, she is currently still pursuing her degree in her content area. After four years of course work, she is now a junior.

\section{Kayla}

After being told for so long that she had the temperament of a teacher and having a vested interest in her chosen content area, Kayla arrived at Midwestern University and dove into the coursework. She enjoyed the clinical experiences and getting to be in the high schools to see how it had changed in just the three short years since she graduated. She cited the burdensome red tape teachers have to navigate, plus the thought of the extra money education majors have to spend on things like the content exams, as initially causing her to second-guess the profession. Ultimately, after taking the first course in the secondary education sequence, she talked with family over break since she had been on the fence for a while. She still viewed teaching as an honorable and respectful profession but decided to pursue work in a different field. Kayla will be graduating in four-and-half years with her degree in her content area and hopes to work as a public servant. 


\section{Imani}

While deciding which college to attend, Imani was between two schools, but ultimately chose Midwestern University because of their education program's reputation. During her freshman and sophomore year, she enjoyed her classes, and without realizing it, was falling more in love with her content area. At the start of her junior year, she enrolled in the first education course in the secondary education sequence and about halfway through the semester, she dropped it. She honestly did not know the amount of work it took to become a teacher. After learning about the intense expectations, she talked with her mom about not disappointing her. Once she knew her mom supported her decision, Imani dropped the class and promptly changed her major. She was able to graduate in four years with a degree in her content area, largely because she dropped the education sequence early on in the sequence.

\section{Xavier}

After traveling throughout the state visiting schools with reputable education programs, Xavier decided to attend Midwestern University because he liked the personal attention available to students. As a freshman, his program had upperclassmen work with the new students, and he felt that everyone in the department was very caring and supportive. I had Xavier in class, and a fellow classmate asked me about the student teaching semester and the expectations. I was honest that it was a lot of work and another student asked if anyone ever quit during student teaching. I told the truth and said yes, it happens, and people decide after student teaching that they do not want to pursue the career. This very short exchange with another student caused Xavier to reflect if he truly wanted to be a teacher. He had been inspired by a high school teacher, but it was not until the first secondary education course that he realized how much teachers do, how little they get paid, and how little they are budgeted (for supplies). At the same 
time, he became overwhelmed with clinical hours and wanted to pursue another career. $\mathrm{He}$ finished the class and then dropped the education sequence. Currently, Xavier is a junior in his content area after four years on campus.

\section{Jessica}

Jessica grew up being told she would make a good teacher. She ultimately wanted to have an interesting job she loved that also had some social aspects to it. Between her career criteria and praise for teachers, education seemed like the perfect major. She had envisioned herself attending a small, private school, but she ultimately chose Midwestern University because it was affordable and known for its education program. She liked her small, close knit classes and felt very positive about teaching after finishing the first course in the secondary education sequence. The second course had a required teaching component where university students teach a three-day unit at the university's laboratory high school. After working with the same class period for eleven weeks of the semester, the student taught that class for those three days. She felt totally unprepared to teach and was surprised that she had no idea what she was doing. After she finished her three days of teaching, she did not feel confident about her performance. When the cooperating teacher asked her if she still wanted to be a teacher, she got to thinking that this was not what she wanted to be doing. Her turning point came after having that discussion. She started to feel anxious about student teaching, which would have her teaching all day, every day, not just one period for three days. Instead of finding enjoyment or fulfillment, she felt stress, and dropped the education sequence after that course. Jessica graduated in four years with a degree in her content area while also having to take summer courses. 


\section{"Teaching Is Not What I Expected" Summary}

It is flattering to hear that you would be good at something, especially if that suggestion is coming from someone already in that role. All five of these students reported either being told they would make a good teacher or being influenced by a teacher who made the work look effortless. Clinical experiences are the focal point of most education programs. Getting into schools and either observing teachers or interacting with students puts college students back in the classroom, but from the perspective of the teacher. These clinical experiences seemed to have really resonated with the participants I interviewed because they played a large role in their critical event. It's one thing to check a box when applying to college and choosing education as your major, but finally entering the classroom and learning about all the red tape associated with the profession had these students rethinking their career paths.

\section{Chapter Summary}

While this is certainly not an extensive list of reasons why students decide to drop the education sequence, the patterns discussed in this chapter are certainly cause for concern and reevaluation. There are numerous issues surrounding equity and access to resources and support for education majors. Would "The Transfers" be in the same situation if they did not have to work so much while going to school full-time? These students assumed they would save money by attending community college first. Instead, they were greeted with hidden costs when they arrived on campus, continued to work, and fell further behind. How would "The Gateways" have fared if there were supports in place to ensure easy access to tutoring and mental health supports during their time at school? Targeted, culturally-responsive tutoring must be provided for education majors in conjunction with the teacher education center on a college campus. This would ensure that education majors are getting the specific help they need in their course work 
and general education classes that count toward their GPA. Would the "Teaching Is Not What I Expected" group have been able to make the decision to leave the major sooner if they did not have to wait until first semester junior year to experience the clinical setting? What would life be like for education majors if there were less bureaucratic hoops to jump through, and they could focus on their schooling? The data presented causes great concern for the obstacles potential institutional barriers teachers face before they can even enter a classroom.

The additional financial barriers of education majors became more and more apparent with each interview I conducted. Seeing how a lack of adequate financial resources impacts future teachers highlights the role of social class. A majority of the interview participants referred to finances in some way. Whether it was the financial obstacles of being a college student or the low-starting wages and need for teachers to pay for their own supplies, these participants were certainly thinking about financial security. A pre-service teacher from a middle or upper-class background is less likely to be deterred by the prospect of having to shoulder the financial burden of a classroom compared to a future teacher who arrives at college needing financial assistance. These equity issues must be addressed if the teaching profession ever hopes to increase representation in the education workforce.

While the interviews with each of the participants delve deeper into a variety of questions, utilizing Wolcott's (1994) “critical or key event” allowed for continuity among the participants, but also made sure their individual stories shone through. It is a lot to ask a young adult to pick a career path at age 18 or even 20 and then stick with it. Ultimately, people change their mind or learn about other possibilities. There will certainly be attrition with any major at a university, but I believe that all perspective teachers should have access to the proper training 
and unnecessary barriers should be removed. The following chapter will dive deeper into the data, analyze the rest of the interview findings, and explore key university demographic data. 


\section{CHAPTER V: DEMOGRAPHIC DATA AND INTERVIEW ANALYSIS}

Interviewing former teacher education majors afforded me the opportunity to engage in conversations about the shortcomings of the education programs, the personal setbacks of interviewees, and the underlying issues faced by college students. The data I collected allowed me to frame the results through both the neoliberal and critical lenses. These interviews go beyond anecdotal evidence, and the data below is confirmation of the trends that emerged among these former teacher education majors. Armed with the analysis of the interviews, I utilized university demographic data to further support my findings. National and state trends in teacher education, coupled with my findings, explain why and when students leave their education major. This chapter will present demographic data from Midwestern University's teacher education programs, incorporate analysis of participant interviews, and consider these findings through the neoliberal and critical lenses.

\section{Part 1: Program Demographic Data Adds Context}

According to the board of education for the state location of the Midwestern University, in $2019,82.6 \%$ of the teaching force was white, $5.9 \%$ was Black, $6.7 \%$ was Hispanic, and $1.6 \%$ was Asian. This board of education reports a five-year trend of the teaching force being $83 \%$ white, with the ten-year trend at $85 \%$ (ISBE, 2019b). In 2019, the teaching force in that state was $76.8 \%$ female, which was also true for the reported five-and-ten-year trends. While these numbers reflect the entire teaching force, from early childhood to $12^{\text {th }}$ grade, I thought it was important to add context to this study because in many ways these numbers mirror those of Midwestern University. This study applied both demographic data and the responses from students to explain these numbers. While I studied eight specific secondary and K-12 programs, it is essential to remember that overall, the teaching force is overwhelmingly white and female. 
In the series of tables that follow, I pulled demographic data from Midwestern University to illustrate who was enrolled in the programs I studied. This demographic data both supports and supplements the analysis of the interviews that follows the charts in second part of this chapter. A detailed description accompanies each of the tables.

\section{The Tables Don't Lie}

In each of the following tables, the data presented compares the education programs involved in the study to make a variety of comparisons regarding the race/ethnicity and gender of students in these programs. The university refers to "race/ethnicity" when distributing the data, but for ease of review, I will henceforth use the term "race." I reviewed a variety of demographics in the following seven tables to not only compare the race and gender of the students in this study but also to explore equally important questions like which students enroll in summer school, are there GPA trends, and do these factors shift the percentage of students by race and gender? Table 6 illustrates how the demographics compare when exploring the gender and racial makeup of the programs at Midwestern University that were included in the study, Midwestern University as a whole, and the demographics of the entire state (as discussed below).

\section{Table 6}

Comparison of Race and Gender in Programs of Study, Full University Population, and Teachers in State in Percentages

\begin{tabular}{|c|c|c|c|}
\hline & $\begin{array}{l}\text { COE Program Data } \\
\text { for Current Study }\end{array}$ & $\begin{array}{l}\text { Midwestern } \\
\text { University }\end{array}$ & State \\
\hline Male & $49 \%$ & $44 \%$ & $23.2 \%$ \\
\hline Female & $51 \%$ & $56 \%$ & $76.8 \$$ \\
\hline White & $82 \%$ & $73 \%$ & $82.6 \%$ \\
\hline Black & \multirow{6}{*}{$\begin{array}{l}18 \% * \\
<2 \% \\
* \text { Ethnic group is } \\
\text { suppressed when the } \\
\text { count is less than } 6 .\end{array}$} & $9 \%$ & $59 \%$ \\
\hline Hispanic & & $11 \%$ & $6.7 \%$ \\
\hline Asian & & $2 \%$ & $1.6 \%$ \\
\hline American Indian & & $.08 \%$ & $.2 \%$ \\
\hline Two or More & & $3 \%$ & $.8 \%$ \\
\hline Pacific Islander & & $.1 \%$ & $.1 \%$ \\
\hline
\end{tabular}


The demographics of the programs studied and Midwestern University as a whole, indicate both are preparing more male teachers compared to the $23.2 \%$ of male teachers in the state. It is promising that Midwestern University houses more male teacher candidates as it is important that both genders be represented in the classroom. The demographic breakdown stigmatizes the teaching field as a female-friendly environment, which in turn has kept wages lower. However, studies have shown that male teachers do not motivate their male students any more than their female students (Mills et al., 2004; Marsh et al., 2008). Their studies put to rest the inaccurate gender bias, which has become the accepted narrative perpetuating which gender is best suited to teach. An unsubstantiated perception that male teachers will better be able to handle rowdy boys significantly devalues the hard work of female teachers (Mills et al., 2004). The antiquated view that teaching is about discipline was initially used to support this claim. Misguided notions regarding gender have long plagued the field, making portions of society view the job as women's work, which is also problematic. What I am suggesting would require societal and systemic changes to destigmatize the idea that women make better teachers and that becoming a teacher is not emasculating.

The race of students is an equally important demographic to explore. Unfortunately, when looking at the racial breakdown of educators, the programs studied, Midwestern University, and the state, the numbers indicate that students and teachers are overwhelmingly white. Altogether, Midwestern University is $73 \%$ white, which means that just over a quarter of the student population identifies as another race. Table 6 highlights the disproportionate number of white students enrolled at Midwestern University, in the teacher preparation programs, and in the teaching force as a whole. The following tables dive deeper into the demographic data and explore other factors that could impact students enrolled in teacher education programs. Table 7 
compares, by percentage, male versus female students and students of color versus hite students from the programs included in the study.

\section{Table 7}

Overall Student Population in Programs Included in the Study: Male vs. Female and Students of Color vs. White by Percentage

\begin{tabular}{|l|l|}
\hline & Program Totals by Percentage \\
\hline Male & $49 \%$ \\
\hline Female & $51 \%$ \\
\hline White & $82 \%$ \\
\hline Students of Color & $18 \%$ \\
\hline
\end{tabular}

While the data in Table 7 is included above, I think it is important to spotlight the baseline demographics of the students who were interviewed in this study from nearly one-third of education programs on campus. While similar in terms of gender ( $49 \%$ male to $51 \%$ female), the eight programs that were the focus of this study were $82 \%$ white. Adding context to these numbers, according to the United States Census Bureau, on July 1, 2019, 76.8\% of people in Illinois identified as white alone and $50.9 \%$ were female, which is eerily almost identical to percentages in the same categories at Midwestern University.

(https://www.census.gov/quickfacts/IL). In the following four tables, each program's race and gender demographic data are reviewed. First, Table 8 outlines the race and gender percentages of the programs included in the study. In Table 9, I explore the race and gender of students who enroll in summer school and how that can impact their plans of study as education majors. Table 10 illustrates a five-year GPA trend by program, and Table 11 presents the mode GPA over a five-year period in terms of students taking summer school. Explanations of the data follow each table. 


\section{Table 8}

Student Population in Specific Programs Included in the Study: Race and Gender by Percentage

\begin{tabular}{|l|l|l|l|l|}
\hline Program & Male \% & Female \% & White \% & Students of Color $\%$ \\
\hline $\begin{array}{l}\text { Biology } \\
\text { Education }\end{array}$ & $46 \%$ & $54 \%$ & $84 \%$ & $16 \%$ \\
\hline $\begin{array}{l}\text { Chemistry } \\
\text { Education }\end{array}$ & $52 \%$ & $48 \%$ & $86 \%$ & $14 \%$ \\
\hline $\begin{array}{l}\text { English } \\
\text { Education }\end{array}$ & $29 \%$ & $71 \%$ & $80 \%$ & $20 \%$ \\
\hline $\begin{array}{l}\text { History-Social } \\
\text { Sciences } \\
\text { Education }\end{array}$ & $65 \%$ & $35 \%$ & $84 \%$ & $16 \%$ \\
\hline Math Education & $42 \%$ & $58 \%$ & $88 \%$ & $18 \%$ \\
\hline Music Education & $51 \%$ & $49 \%$ & $80 \%$ & $20 \%$ \\
\hline $\begin{array}{l}\text { Physics } \\
\text { Education }\end{array}$ & Excluded & Excluded & $82 \%$ & $15 \%$ \\
\hline $\begin{array}{l}\text { Theatre } \\
\text { Education }\end{array}$ & $32 \%$ & $68 \%$ & $83 \%$ & $17 \%$ \\
\hline
\end{tabular}

When looking at the demographic data of the eight programs represented in this study, it is important to note that biology education, English education, math education, and theatre education have more female than male students. The data for the gender identity of physics education had to be excluded because one of the groups was less than six. Across all programs, there are drastically more white students than those of the minority groups listed by the university. Music and English education were the only two programs to have $20 \%$ students of color which is still a relatively small percentage. Table 9 takes a closer look at the students who take summer school by percentage. By highlighting male versus female and white versus students of color, I was able to see the portions of the student population in each demographic that took summer classes. 


\section{Table 9}

Student Population Enrolled in Summer School by Specific Programs Included in the Study: Male vs. Female and Students of Color vs. White by Percentage

\begin{tabular}{|l|l|l|l|l|}
\hline Program & Male & Female & White & $\begin{array}{l}\text { Students of } \\
\text { Color }\end{array}$ \\
\hline $\begin{array}{l}\text { Biology } \\
\text { Education }\end{array}$ & Excluded & Excluded & $84 \%$ & $16 \%$ \\
\hline $\begin{array}{l}\text { Chemistry } \\
\text { Education }\end{array}$ & Excluded & Excluded & $86 \%$ & $14 \%$ \\
\hline $\begin{array}{l}\text { English } \\
\text { Education }\end{array}$ & $22 \%$ & $78 \%$ & $80 \%$ & $20 \%$ \\
\hline $\begin{array}{l}\text { History-Social } \\
\text { Sciences } \\
\text { Education }\end{array}$ & $59 \%$ & $41 \%$ & $84 \%$ & $16 \%$ \\
\hline Math Education & $36 \%$ & $64 \%$ & $88 \%$ & $18 \%$ \\
\hline Music Education & $47 \%$ & $53 \%$ & $80 \%$ & $20 \%$ \\
\hline $\begin{array}{l}\text { Physics } \\
\text { Education }\end{array}$ & Excluded & Excluded & $82 \%$ & $15 \%$ \\
\hline $\begin{array}{l}\text { Theatre } \\
\text { Education }\end{array}$ & Excluded & Excluded & $83 \%$ & $17 \%$ \\
\hline
\end{tabular}

Table 9 compared the gender and race of the students who enroll in summer school by percentage. The programs that were excluded from this table had one group that was less than six students. Of the four programs that were able to report the gender of their summer school students, English, math, and music all have more female students who take summer school classes. It is not surprising to see that all of the reported programs had more white students taking summer classes than students of color. Again, English and music education were the only two programs to have $20 \%$ of students of color enrolled in summer school classes. Enrolling in classes during the summer can help students get ahead with earning credits toward their degree, or they can use the time as an opportunity to retake classes to improve their GPA. It was important to incorporate the demographics of the students who take summer school because I did not want to overlook this important factor. Attending summer school "increases student 
persistence and degree completion" (Franke \& Bicknell, 2019, p. 606). Franke and Bicknell's (2019) study highlighted how summer enrollment helps to increase student retention, and they specifically reference financially incentivized summer enrollment which I think would be extremely helpful for education majors. Their research found the most successful programs offered free summer classes if students re-enroll full-time the following fall. This is a concept that I will address in Chapter VI. The next piece of the puzzle requires exploring student success. Table 10 has particular relevance to the study because it evaluates the mode GPA over a five-year tread and is presented by programs in the study.

\section{Table 10}

Mode GPA Over a Five-Year Trend by Program Included in the Study

\begin{tabular}{|l|l|l|}
\hline Program & GPA & $n$ \\
\hline Biology Education & $2.50-2.99$ & 177 \\
\hline Chemistry Education & $2.50-2.99$ & 72 \\
\hline English Education & $3.75-4.00$ & 346 \\
\hline History-Social Sciences Education & $2.50-2.99$ & 549 \\
\hline Math Education & $3.75-4.00$ & 340 \\
\hline Music Education & $3.50-3.74$ & 442 \\
\hline Physics Education & $2.50-2.99$ & 80 \\
\hline Theatre Education & $3.75-4.00$ & 71 \\
\hline
\end{tabular}

Note. GPA is calculated on a 4.0 scale. The variable $n$ designates the total number of students in each program.

In addition to highlighting the demographics of the students in these programs and which students took summer school classes, I also investigated the five-year mode GPA of the programs in this study. The mode GPA is the most frequently reoccurring number in a five-year period. Initially, I had assumed I would use the mean, or average, GPA, but that can be skewed by a small number of low or high GPAs. Utilizing mode as the measure of central tendency accounted for the most commonly occurring GPAs for that program. Interestingly enough, English, math, and theatre education all had a mode GPA of 3.75-4.00 which is the highest GPA 
that students can earn on campus. The remaining four programs, biology, chemistry, historysocial sciences, and physics education all have a mode GPA of 2.50-2.99. It is important to note that the minimum GPA requirement of teacher education majors at Midwestern University is a 2.50. Programs can raise their requirement as they see fit (and many require a 3.00), but it is notable that half of these programs have a mode GPA that includes the minimum to be a teacher education major.

It is crucial to remember how GPA can prevent students from continuing with a program and eventually reaching their goal of student teaching. Recently, there has been a push to rethink the important criteria, or disposition, of a teacher candidate. The case has been made that candidates need to demonstrate the professional behavior, or dispositions, of a teacher (Ripski et al., 2011; Diez, 2007; Borko et al., 2007). Some argue that this even outweighs the knowledge a teacher must possess (Wilkerson, 2006). However, both sides of the disposition debate agree that "checking boxes" to demonstrate the ability to teach is ineffective (Diez, 2007). Another factor to explore is the coded language associated with "professional behavior" and how these concepts originated from white values. Recommendations regarding the dispositions of teacher candidates will be presented in Chapter VI. After looking at the mode GPA over a five-year trend, Table 11 presents the number of students using mode over a five-year period who took summer school broken down by GPA range.

\section{Table 11}

Mode GPA of Students Enrolled in Summer School by Program Determined Over a Five-Year Period

\begin{tabular}{|l|l|l|}
\hline Program & GPA & $\mathrm{n}$ \\
\hline Biology Education & $2.50-2.99$ & 38 \\
\hline Chemistry Education & $3.75-4.00$ & 11 \\
\hline English Education & $3.75-4.00$ & 61 \\
\hline History-Social Sciences Education & $3.00-3.24$ & 88 \\
\hline
\end{tabular}




\begin{tabular}{|l|l|l|}
\hline Math Education & $3.75-4.00$ & 54 \\
\hline Music Education & $3.75-4.00$ & 53 \\
\hline Physics Education & $3.50-4.0$ & 9 \\
\hline Theatre Education & $3.75-4.00$ & 11 \\
\hline
\end{tabular}

Note. GPA is calculated on a 4.0 scale. The variable $n$ designates the total number of students in each program who enrolled in summer school.

Another piece of the demographic data puzzle is looking at the GPA (by mode) of the students who enroll in summer school classes over five years. This data very clearly shows that the majority of students from the programs in the study (excluding biology) who take summer school have a higher GPA. I would infer those high-achieving students are taking those classes to get ahead in their programs. Five of the eight programs have students with a GPA in the 3.754.00 range who are taking summer classes which points to a variety of different conclusions. These students can afford to take summer classes (and presumably are working less during that time), they will have to take fewer classes during the academic year, or they can take additional classes to earn extra teaching endorsements. Table 12, the final table, breaks down the racial demographics of the students from the programs included in the study and highlights the change in percentage from Fall 2015 through Fall 2018.

\section{Table 12}

Total Student Enrollment in Programs Included in the Study by Race from Fall 2015 through Fall 2018

\begin{tabular}{|l|c|c|c|c|c|c|c|c|}
\hline & \multicolumn{2}{|c|}{ Fall 2015} & \multicolumn{2}{c|}{ Fall 2016} & \multicolumn{2}{c|}{ Fall 2017} & \multicolumn{2}{c|}{ Fall 2018 } \\
\hline Race & $n$ & $\%$ & $n$ & $\%$ & $n$ & $\%$ & $n$ & $\%$ \\
\hline $\begin{array}{l}\text { American } \\
\text { Indian/Alaskan } \\
\text { Native }\end{array}$ & $*$ & $*$ & $*$ & $*$ & $*$ & $*$ & $*$ & $*$ \\
\hline Asian & 23 & $2.8 \%$ & 20 & $2.3 \%$ & 23 & $2.7 \%$ & 20 & 2.25 \\
\hline $\begin{array}{l}\text { Black or African } \\
\text { American }\end{array}$ & 27 & $3.3 \%$ & 29 & $3.4 \%$ & 25 & $2.9 \%$ & 22 & $2.4 \%$ \\
\hline $\begin{array}{l}\text { Hawaiian or Pacific } \\
\text { Islander }\end{array}$ & $*$ & $*$ & $*$ & $*$ & $*$ & $*$ & $*$ & $*$ \\
\hline Hispanic & 88 & $10.2 \%$ & 94 & $11.0 \%$ & 81 & $9.4 \%$ & 91 & $10.0 \%$ \\
\hline White & 665 & $81.6 \%$ & 692 & $80.8 \%$ & 707 & $82.0 \%$ & 741 & $81.8 \%$ \\
\hline
\end{tabular}




\begin{tabular}{|l|c|c|c|c|c|c|c|c|}
\hline $\begin{array}{l}\text { Two or More } \\
\text { Selections Excluding } \\
\text { Hispanic }\end{array}$ & 17 & $2.1 \%$ & 21 & $2.5 \%$ & 26 & $3.0 \%$ & 32 & $3.5 \%$ \\
\hline Unspecified & $*$ & $*$ & $*$ & $*$ & $*$ & $*$ & $*$ & $*$ \\
\hline $\begin{array}{l}\text { Total Number of } \\
\text { Students }\end{array}$ & 815 & & 856 & & 862 & & 906 & \\
\hline
\end{tabular}

Note. The variable $n$ designates the total number of students enrolled in the programs included in the study broken down by race. The percentage represents the percent of students of each race out of the total number of students enrolled in these programs.

To conclude the presentation of demographic data in this series of tables, it is necessary to analyze the demographics of students in selected education programs which changed between the fall semester of 2015 and fall of 2018. Unfortunately, the counts had to be suppressed for American Indian/Alaskan Native, Hawaiian or Pacific Islander, and Unspecified because these categories were less than six students and could not be released by the university. The Asian student population consistently landed between 20 and 23 students and ranged between $2.3 \%$ and $2.8 \%$. The percentage and number of Black teacher education majors from programs in this study decreased from 27 down to 22 students over this period of time. This equated to a decrease from $3.35 \%$ to $2.4 \%$. The Hispanic student population from these programs teetered between 88 to 91 students. In fall of 2015 , these students accounted for $10.2 \%$ of the population, hit $11 \%$ in 2016, but fell back to $10 \%$ in 2018. The number of white students increased from 665 to 741 , holding steady around $81 \%$. Students who identified with two or more selections, excluding Hispanic, increased significantly from 17 students to 32 students which is an increase of $2.1 \%$ to $3.5 \%$. Between fall 2015 and fall 2018 , the total number of students in the selected programs rose from 815 to 906 . The increased number of students in the programs included in study is very promising and does insinuate that students are slowly returning to teacher preparation programs. Unfortunately, over the course of that four-year period, the majority of students entering teacher education programs were still white. 


\section{Table Summary}

The previous seven tables presented a plethora of information regarding the demographics of education majors at Midwestern University. To make it digestible, a summarization of themes that emerged follows. The percentage of students enrolled in the programs included in this study from Fall of 2015 through Fall 2018 (Table 11) were overwhelmingly white (81\%). This reaffirmed the demographics from Table 6, which outlined the demographics of Midwestern University, programs in the study, and the state teacher population as a whole. Four of the programs in this study have more female students, but Midwestern University produces more male teachers than the state average. Only two programs in this study report having $20 \%$ students of color. The other six programs include considerably fewer. More white students, female students, and students with higher GPAs take summer school. The data presented uncovers the lack of representation across programs and supplemented the factors and backstories I uncovered from the interviews conducted. These numbers, while not surprising, reinforced why this study is relevant. They also corroborate trends in the field of education, which will be reviewed next. Educational settings at all levels must be culturally, linguistically, and ethnically diverse to represent everyone in the classroom. Recognizing this can increase student success and would slowly begin to shift the imbalance highlighted in these tables.

\section{Trends Highlighted in the Tables}

There are important trends to emphasize and the first is obvious. The teacher education programs at Midwestern University are significantly white. The state where this study takes place is relatively large and many of the metropolitan areas are diverse; yet, as highlighted through this study, the population of teachers is not currently serving the population needs of the 
students. With fewer students of color, there is a domino effect, resulting in fewer teachers of color (and this aligns with the state trend). While Midwestern University is preparing more male teachers overall compared to the state, that is not true of all programs. English education's program was $71 \%$ female, and theatre education was $68 \%$ female. It is important to have more equal representation of both genders in any field (Mills et al., 2004). History-social sciences education is $65 \%$ male which signifies that their programs needs to attract more female students. These numbers make a convincing case that Midwestern University needs to intentionally recruit males and females for certain programs to improve gender representation. The same is true for adding more future teachers of color. Midwestern University must be intentional about diversity.

The results of the demographic inquiry with Midwestern University are consistent with state and national trends. The teaching force is overwhelmingly white. Not only is it apparent by the numbers, but it is also evident when looking at American public-school classrooms. Representation matters, and currently students of color cannot see themselves as teachers because they are not being taught by people who look like them. Research emphasizing the positive experiences of students of color when working with teachers of the same race or ethnicity is becoming more widespread. (Redding, 2019; Easton-Brooks, 2019; Ladson-Billings 1999, 2006, 2009). Furthermore, their white teachers are often not trained or equipped with the skills needed to work with students of color. Gloria Ladson-Billings $(1999,2006,2006,2009)$ is the seminal author on this subject. In her examinations of culturally relevant pedagogy, which is pedagogy grounded in the teachers' cultural competence, Ladson-Billings (2006) found teachers were asking the wrong questions when it came to teaching their students of color. Rather than asking "what to do" she suggests "the problem is rooted in how we think- about the social contexts, about the students, about the curriculum, and about instruction" (Ladson-Billings, 
2006, p. 30). While these issues were outlined in Chapters I and II, it is imperative to reiterate how the lack of representation impacts this study. The Call to Action section in Chapter VI will outline how to put Ladson-Billings $(1999,2006,2009)$ research into action.

These trends matter because the lack of diversity and representation in public school classrooms send the message to future teachers from underrepresented groups that their experiences completing their teaching degree could be different. Easton-Brooks (2019) centered his writing around the concept of "ethnic matching," or the pairing of people receiving services to coordinate with the same race and/or ethnicity the two shares. He found "one of the most critical findings in the research on ethnic matching is the amount of change or increase observed in the achievement scores of students of color when they are paired with a teacher of the student's same race" (p. 33). Easton-Brooks (2019) acknowledged in his work how LadsonBillings' (2009) scholarship about culturally responsive pedagogy and teaching paved the way for his study. Her groundbreaking study, which resulted in the book The Dreamkeepers: Successful Teachers of African American Children (2009), studied eight teachers over the course of three years and then ten years later when Ladson-Billings returned to the community. A major takeaway is how teachers helped students know they were knowledgeable and capable beings and could learn and figure things out (Ladson-Billings, 2009, p. 129). Not to oversimplify her work, but these teachers prepared students for the inequality and racism they would face, while also including their culture in the classroom. Ladson-Billings (2009) findings will be further explored in Chapter IV. Connecting this scholarship to the study, all eight of the programs in this study have $20 \%$ or fewer students of color. According to Midwestern University's website (which cannot be cited in order to protect the identities of the participants) in $2019,74 \%$ of tenure tracked faculty members reported their race to be white. Based upon my knowledge of 
the programs in this study, I am confident they would report the majority of their tenure-tracked faculty members are also white. This data further demonstrates the consequences of the lack of representation in education at all levels.

There are several ways to fix the leaky teacher pipeline and studying university demographic data is just one place to start. Easton-Brooks (2019) discussed the problems with the oppressive structures of the public education system and unfortunately, "students of color may continue to be dependent on an educational system that teaches from an educational/pedagogical baseline that stressed White superiority" (p. 34). Classrooms at all levels, preschool through bachelor's degrees and beyond, must be culturally, linguistically, and ethnically diverse to all learners in the classroom. Being responsive to all students will help put them on the pathway to success. In the section that follows, I analyze my interviews with the 13 participants and what I found is equally eye-opening.

\section{Part 2: Analysis of Qualitative Interviews}

In Chapter IV, I introduced the 13 participants and focused on the critical event that turned each of them away from education. While it is important to share their stories and learn about what caused each individual student to drop the education sequence, this section explores all the factors that were part of their journey. Over the course of several months, I sat down with students and talked with them about why they decided to become a teacher, and then, why they ultimately did not seek a degree in education. The questions I asked them can be found in Appendix C. I included general questions about how they reached their decisions to come to Midwestern University and why they decided to become a teacher. Then I asked more specific questions in regard to their experiences as education majors, their best experiences, encounters that were unexpected or surprising, the most significant obstacles they faced, and if they would 
do anything differently. The participants were candid about their journeys. In the matrices that follow, I present my findings in two different ways in an attempt to uncover why these students dropped the education sequence and what can be done to better support students.

\section{Review of the Participants}

The purpose of my study is to examine and better understand why students who specifically came to Midwestern University to become teachers ultimately dropped the education major. I interviewed students from different secondary and K-12 programs in order to discuss the issues faced by education majors from a cross-section of programs on campus. Of the 13 participants, six identified as male and seven identified as female. In terms of race, seven of the participants self-identified as white and six self-identified as students of color. I am using the term "students of color" to protect the identity of these participants. As the demographic data shows, the number of students of color in education programs is quite small. These students were either Black, Latinx, or Asian. When I refer to a student of color, they are from one of those racial groups. I did ask the participants to share their sexual orientation, and 12 identified as straight and one identified as bi-sexual. I had hoped to compare that demographic data with that of the university, but at this time, they do not collect information regarding the sexual orientation of students. What follows is an analysis of my interviews.

\section{Time-Ordered Matrix}

After recording and transcribing the interviews, I combed through their responses to look for themes. I employed Miles et al.'s (2014) time-ordered matrix which is described as using "columns arranged chronologically by time period to determine when particular phenomena occurred" (p. 202) as a way to create the lifespan of the education major by segmenting their childhood, high school, and each year of high school. I was able to apply the questions I asked to 
the lifespan of a college student, broken down by each academic year. The full matrix can be viewed in Appendix D; however, the analysis follows the chart. Since it is quite large, I have included two students' responses as examples of the process. While asking the participants questions, I thought it was important to ask when they decided to become teachers. Of the 13 participants, only two had thought of becoming teachers when they were children. Therefore, most of the students decided to become teachers during high school (five participants) or while in college (seven participants). I included this as part of the lifecycle to give a full picture of the time order, which spans from childhood, includes high school, targets each year of college, and notes future plans.

\section{Table 13}

Teacher Education Drop Out Time Ordered Matrix

\begin{tabular}{|c|c|c|c|c|c|c|c|}
\hline Participant & Kid & HS & Freshman & Sophomore & Junior & Senior & Future \\
\hline Kelly & $\begin{array}{l}\text { Had } \\
\text { always } \\
\text { thought }\end{array}$ & $\begin{array}{l}\text { Enrolled } \\
\text { in } \\
\text { teacher } \\
\text { intern- } \\
\text { ship } \\
\text { during } \\
\text { senior } \\
\text { year }\end{array}$ & $\begin{array}{l}\text { ISU- } \\
\text { Enrolled } \\
\text { as history } \\
\text { education } \\
\text { major }\end{array}$ & $\begin{array}{l}\text { Confused } \\
\text { about } \\
\text { major- } \\
\text { took SPED } \\
\text { courses. } \\
\text { Felt } \\
\text { pressure } \\
\text { from } \\
\text { family to } \\
\text { get job } \\
\text { after } \\
\text { graduation } \\
\text { and this } \\
\text { might be } \\
\text { more } \\
\text { lucrative. }\end{array}$ & $\begin{array}{l}\text { Still } \\
\text { feeling } \\
\text { confused } \\
\text { but } \\
\text { determined } \\
\text { not to } \\
\text { follow } \\
\text { SPED. } \\
\text { Back to } \\
\text { history ed, } \\
\text { trying to } \\
\text { get grades } \\
\text { up, taking } \\
\text { content } \\
\text { exam }\end{array}$ & $\begin{array}{l}\text { Switched } \\
\text { to } \\
\text { "straight } \\
\text { history" } \\
\text { with a } \\
\text { minor in } \\
\text { sociology. } \\
\text { Will } \\
\text { graduate } \\
\text { in Dec. } \\
2018 \text {. }\end{array}$ & $\begin{array}{l}\text { Still sees } \\
\text { herself as } \\
\text { teacher, } \\
\text { thinks she } \\
\text { might } \\
\text { work, earn } \\
\text { money, and } \\
\text { then get } \\
\text { certification }\end{array}$ \\
\hline Quentin & No & $\begin{array}{l}\text { Didn't } \\
\text { even } \\
\text { want to } \\
\text { go to } \\
\text { college }\end{array}$ & $\begin{array}{l}\text { Signed } \\
\text { up the } \\
\text { day } \\
\text { before } \\
\text { classes } \\
\text { started }\end{array}$ & $\begin{array}{l}\text { Decided to } \\
\text { become a } \\
\text { teacher }\end{array}$ & $\begin{array}{l}\text { Felt like } 1^{\text {st }} \\
\text { edu class } \\
\text { was a } \\
\text { repeat of } \\
\text { CC class. } \\
\text { Slammed }\end{array}$ & $\begin{array}{l}\text { Loving } \\
\text { regular } \\
\text { content } \\
\text { classes, } \\
\text { still }\end{array}$ & $\begin{array}{l}\text { Graduating } \\
\text { w/ content } \\
\text { degree. } \\
\text { Plans to get } \\
\text { Masters }\end{array}$ \\
\hline
\end{tabular}


with working

Gateways, full time

Dropped

b/c of

ACT score

Miles et al.’s (2014) time-ordered matrix “displays time-linked data referring to phenomena that are bigger than specific 'events,' so as to understand (and perhaps later explain) what was happening" (p. 203). I have noted that this is an understudied phenomenon, and I intended to explore when and why students leave their education majors. My interviews highlighted how senior year of high school was very important to these participants; furthermore, nine of them either made their decisions to become teachers or it was during their last year of high school that their decision was solidified. In and of itself, making an initial career choice during your senior year of high school is not groundbreaking. Most American teenagers planning to attend college commit to a major during their senior year. However, what I found to be insightful about the high school time period was that the participants reported being heavily influenced by their teachers. Nine of these students were told by a high school teacher that they would make a good teacher, or they wanted to become a teacher because they were inspired by what it meant to impact students' lives. Of those nine students, only three were of color. Would that number have been higher if there were more teachers of color to make those connections with students while they are making major life decisions? Easton-Brooks (2019) would answer yes. He writes that public schools can learn from their past and "must be attuned to responding to more diverse and inclusive populations of learners" (p. 34). A diverse educator workforce would have a positive, rippling effect on society and would affirm that representation is necessary and influential. 
The four years of college were met with a variety of challenges. Nine of the participants were at Midwestern University during their freshman year working on their general education requirements. One of the participants took a freshman, content-specific, education class at Midwestern University and enjoyed the early exposure to the teaching profession. There was a common theme from the students who entered college as education majors; ultimately, they wished they started classes in the major earlier. The typical, four-year plan at Midwestern University for secondary and K-12 programs has students taking their first education course during either their second semester as a sophomore or their first semester as a junior. While taking content classes during those first few semesters, participants felt that if they had time in the classroom earlier, they could have reached their decision earlier. Or, they would have possibly stayed with the major because they would have had a larger variety of experiences over time. It was during their sophomore year when the community college students made their decisions to become teachers, largely because their time was about to expire, and they were forced to make a choice. Interestingly, five of the eight Midwestern University students reported having confusion and second thoughts during their sophomore year. The university puts a large emphasis on student retention during freshman year, and students have more personalized content with their department during their junior and senior years. I would argue that additional supports and experiences should be integrated into the sophomore year to help guide students when they are doubting their chosen major. This idea will be further addressed in Chapter VI. Based on these interviews, I found there is a direct relationship between an education major's junior year of college and whether or not the student completes their teacher education program. All 13 participants noted that they felt confused, lost, befuddled, and/or overwhelmed by the requirements of the education major. In Chapter IV, I discussed the countless additional 
tasks and monetary requirements of education majors. I turned this into a verb when analyzing the interviews because students felt the Gateway requirements, both in terms of money and time, were major roadblocks. I found myself saying, "another student got 'Gatewayed'!” While my categorization may sound catchy, the reality is that these additional requirements played a large role in deterring students from continuing with their education major. In the language itself, a "Gateway" implies that students will have to navigate an obstacle. So, it will come as no surprise that by senior year, 12 of the 13 participants were focusing on content area degrees and had, either during their junior year or prior to the beginning of their senior year, dropped the education sequence. Only one participant continued with the teacher education sequence until the last semester of college.

The time structure cannot end with college, and I made sure to ask each participant about their decision and if they still thought about becoming a teacher. Only one participant wanted nothing to do with education. Three of the participants said they could still very much see themselves teaching and plan to pursue their education degree in the future. What I found most interesting about their responses is that nine of the participants reported that they would like to do something related to teaching. Some of their thoughts about possible career choices included working in a library, doing one-on-one art therapy, developing better education policy, pursuing corporate training, working with local youth groups, and securing employment that brings joy to others. Their suggestions dispelled the prevalent notion that teaching can only take place within the walls of a classroom. While deciding on a career, these participants recognized that they wanted to help others, and they had a natural disposition to teaching, but the traditional route to licensure was full of barriers that ultimately prevented them from certifying as teachers. One participant did come full circle and was back in his education program but hoped to someday 
teach at the colligate level. This time-ordered matrix provided pertinent evidence of the lifecycle of a preservice teacher and how teacher education programs can better support students during the experience.

In summary, the time-ordered matrix revealed that students need to be exposed to education classes earlier; they require targeted support each year of college (especially sophomore and junior years); the university needs to reframe their Gateway system, and students need to be exposed to other career paths similar to education. After exploring the data in the time-ordered matrix, it became apparent that I should review the data another way. I again turned to Miles et al. (2014) to further explain my data using the variable-by-variable matrix.

\section{Variable-by-Variable Matrix}

Like the time-ordered matrix, the variable-by-variable matrix helps to "notice that a few major variables are in play, underlying many specific phenomena" (Miles et al., 2014, p. 226). Utilizing the same lifespan from the time-ordered matrix, I replaced the participant's names with the major variables participants repeatedly cited during our interviews. Similar to the timeordered matrix, the variable-by-variable matrix highlighted how the significant variables turning students away from teacher education programs are connected or interrelated. Once again, similar themes emerged. The letters in the matrix below represent each time the participants referenced a variable, placed accordingly to the same lifecycle of a perspective teacher used in the time-ordered matrix above. Comparing the close connections between the time-ordered matrix and the variable-by-variable matrix, I can affirm the conclusions made above. 


\section{Table 14}

Teacher Education Major Variable-by-Variable Matrix

\begin{tabular}{|c|c|c|c|c|c|c|c|}
\hline $\begin{array}{r}\text { Major } \\
\text { Variables }\end{array}$ & Kid & $\begin{array}{l}\text { High } \\
\text { School }\end{array}$ & Freshman & Sophomore & Junior & Senior & Future \\
\hline $\begin{array}{r}\text { Decision to } \\
\text { Become } \\
\text { Teacher }\end{array}$ & M, I & $\begin{array}{l}\mathrm{M}, \mathrm{T}, \mathrm{J}, \\
\mathrm{K}, \mathrm{D}, \mathrm{T}, \\
\mathrm{J}, \mathrm{X}, \mathrm{O}, \\
\mathrm{L}\end{array}$ & & $\mathrm{E}, \mathrm{A}, \mathrm{C}, \mathrm{D}$ & & & \\
\hline $\begin{array}{r}\text { Job/Career } \\
\text { Consideration }\end{array}$ & & & $\mathrm{M}, \mathrm{K}$ & M & $\begin{array}{l}\mathrm{M}, \mathrm{J}, \mathrm{D}, \\
\mathrm{T}, \mathrm{X}, \mathrm{C}\end{array}$ & $\mathrm{M}, \mathrm{D}, \mathrm{C}$ & M \\
\hline GPA Issues & & & & $\mathrm{M}, \mathrm{I}, \mathrm{J}$ & $\begin{array}{l}\text { M, J, L, } \\
\mathrm{I}, \mathrm{J}, \mathrm{E}\end{array}$ & $\begin{array}{l}\text { M, D, L, } \\
T, J, E\end{array}$ & $\mathrm{~J}$ \\
\hline Content exam & & & & K & $\mathrm{D}, \mathrm{C}, \mathrm{A}$ & $\mathrm{M}, \mathrm{L}, \mathrm{E}$ & \\
\hline Basic Skills & & & & & A & & \\
\hline $2^{\text {nd }}$ Thoughts & & & K & $\mathrm{K}, \mathrm{Z}, \mathrm{O}, \mathrm{L}$ & $\begin{array}{l}\mathrm{J}, \mathrm{K}, \mathrm{K}, \\
\mathrm{X}, \mathrm{L}, \mathrm{E}\end{array}$ & $\mathrm{L}, \mathrm{E}$ & \\
\hline $\begin{array}{r}\text { Family } \\
\text { Pressures }\end{array}$ & & $\mathrm{K}, \mathrm{J}$ & & $\mathrm{M}, \mathrm{J}$ & $\mathrm{C}, \mathrm{M}, \mathrm{D}$ & M & \\
\hline "Red Tape" & & & & $\mathrm{O}$ & $\begin{array}{l}\mathrm{K}, \mathrm{J}, \mathrm{J} \\
\mathrm{D}, \mathrm{C}, \mathrm{Z}, \\
\mathrm{I}, \mathrm{T}, \mathrm{O} \\
\mathrm{A}, \mathrm{E}\end{array}$ & $\mathrm{T}, \mathrm{A}$ & $\mathrm{A}, \mathrm{E}$ \\
\hline Money & & & $\mathrm{J}$ & $\mathrm{M}, \mathrm{J}$ & $\begin{array}{l}\text { M, J, D, } \\
\text { L, X, C, } \\
\text { A }\end{array}$ & $\mathrm{T}, \mathrm{A}, \mathrm{E}$ & \\
\hline Professors & & & & & $\begin{array}{l}\mathrm{M}, \mathrm{K}, \mathrm{J} \\
\mathrm{D}, \mathrm{I}\end{array}$ & I & \\
\hline
\end{tabular}

Similar to the time-ordered matrix, here too, only two students reported a desire to become a teacher dating back to childhood. High school, senior year in particular, was an important time for making decisions about their major. There was little reference to students' freshman year of college. I believe this is derived from either those students who were at community college feeling unsure or from the newness of college for those that began at 
Midwestern University. When freshmen arrive at Midwestern University, their academic advisor is not within their home academic department; rather, they work with a generalized advisor who helps to transition into college. While I noted above that sophomore year of college seems to be a time when students reported feeling lost or disconnected, I would also argue that additional education-related experiences would also be beneficial during freshman year. There could be some serious implications that so few students addressed freshman year of college. Career considerations, second thoughts, and money were the variables that students were concerned about during freshman year, so that extra reassurance and support would be beneficial. During sophomore year, four of the transfer students decided to become teachers, and eight of the participants cited a variety of concerns. Looking at the variables students cited in their interviews, this reaffirms my suggestion that education majors must have exposure to the teaching field by sophomore year of college so they can become more invested.

As indicated by the wide variety of letters in the Junior column of the lifecycle, it is a chief trouble spot for education majors. Not only can this be seen in the time-ordered matrix, but it is also apparent when reading the participants' turning point stories in Chapter IV. It is clear that junior year presents a problem, which poses the fundamental question, how can we help students at this point in the journey? Senior year brought many of these participants clarity as they have switched to a major that would allow them to graduate and pursue their next steps. The Future column only has four participants in the variable-by-variable matrix which is fewer than the time-ordered matrix. I believe that is because most of the variables listed here reference continuing in a typical teaching setting, but it was clear from my interviews that the majority of the participants wanted to pursue a career in which they could utilize their teaching skill set. The results of these two matrices suggest specific problems areas for education majors that 
institutions could easily address. To summarize the variable-by-variable matrix, students need exposure to education classes earlier in college, and the university must reframe the Gateways in a way that promotes student success. Similar to the time-ordered matrix, college students need targeted support each year, ideally embedded into their coursework.

\section{Implications of the Matrices}

A closer inspection of the matrices presented race and gender patterns as well. Of the 13 participants, six identified as either Black, Latinx, or Asian. One of those participants actually returned to the education major during senior year, and one dropped the education sequence during senior year, but the other four left the major during junior year. Nearly half of the participants were students of color which represents an emerging pattern. I did not seek out participants based on race or gender, so it was not intentional that students from the underrepresented population (teacher candidates of color) made their way to this study. It is also essential to consider the gender pattern that emerged. Seven of the participants identified as female. Since there are more female education majors than male, that pattern in and of itself is not too surprising. Given that there are more females in the programs, it would make sense that more would leave the major. The fact that four of the participants were female students of color and two were male students of color highlights a concerning pattern related to the gender and race of those students leaving the major. Referring back to the demographic charts, male teachers represent $23 \%$ of the teachers in state, but represent $49 \%$ of the students in the programs utilized for this study. Yet, two males of color and six males in total participated in this study. Along these lines, female teachers represent $76 \%$ of the teachers in the state, and $51 \%$ of the students in the programs represented in the study and were also overrepresented in both the race and gender categories. Between Fall 2015 and Fall 2018, the university added almost one 
hundred new education students, but as the demographics showed above, that increase represented more of the status quo. These patterns raise questions about teacher education that will be addressed in Chapter VI.

\section{Theoretical Frameworks and Analysis}

The purpose of this study is to address why college students who major in education do not become teachers. As I outlined in Chapter I, I applied the ideals from two contrasting frameworks that pertain to the study. The neoliberal conceptual framework highlights the disparity caused by privatization, market forces and the impact of free markets, and the accountability movement in education. Neoliberalism highlights how conservative, free-market ideals impact students entering college and the domino effect that it has on teachers. Conversely, the critical lenses, Critical Race Theory (CRT) and Critical Whiteness Theory (CWT), challenge the inequitable practices in teacher recruitment and training, highlight the effects of institutional whiteness, and address how the representation of all students, families, and communities must become a cornerstone of education. At their intersection, these contrasting conceptual frameworks highlight why a college student would fail to become teacher.

\section{Neoliberal Analysis}

This study explores the idea that neoliberal ideals have had a detrimental impact on teacher education. In the form of increased college tuition, red tape for education majors, standardized teaching tests, and the low salary of new teachers, neoliberalism has permeated the once highly regarded teaching profession. I have stated that the cornerstones of neoliberalism are privatization, market forces and impact on free markets, and the accountability movement in education (Casey, 2016; Giroux, 2005, 2014; Ravitch, 2014). These neoliberal factors have infiltrated every aspect of public education. 
Privatization. The shift toward privatization of our public schools has occurred in the form of for-profit charter schools, reduced funding, school vouchers, and a perception of education as an economic industry. Neoliberal ideals have, for example, led to a teacher evaluation system that is rooted in rewarding teachers who can prove the most student growth narrowly assessed with commercial tests, and this has led to an explosion in the educational prepackaged curriculum market. Students are seen as commodities in the form of test scores. For teacher education, this has forced programs to provide data that proves that their own graduates have continued to become "effective" teachers, despite the lack of evidence that testing and other neoliberal measures truly determine what an exemplary or strong teacher candidate looks like in a variety of teaching contexts (Giroux, 2005, 2014). The "failure narrative" guided the neoliberal charge to further privatize teacher education programs with new for-profit providers and testonly entry routes. The rationale always reverts to the important role of the teacher and "if teachers are the most important factor in students' achievement and US students' achievement is sub-standard, then US teachers are the culprits, as well as the teacher educators and institution that prepare them" (Cochran-Smit et al., 2017, p.577). Here is another example of attacking teachers, rather than addressing the larger, systemic factors that impact education. The newest outcomes and accountability measures were ushered in with the promise of curing inequality.

Teacher candidates that will serve students, families, and communities will be able to improve student achievement, although not always in standard "effective" ways in all communities. While this is not to say that student achievement and growth are not important, this neoliberal model has added on hours each day of extra work for teachers without any additional pay or recognition for the profession, ignores multiple factors known to influence student achievement, and contributes to the perception that teaching is not a desirable profession. 
Promoting equity was a common goal of nearly all modern education accountability movements, but the assumption that access to good teachers would solve underlying social, economic, and political conditions is absurd. I had a hunch that students and their families were having reservations about entering the field of public education. Initially, I had not intentionally coded for neoliberal themes when putting participants' responses into the matrices above. However, an unexpected consequence of reviewing the data allowed me to see the prevalence of these neoliberal themes. Closer examination of the time-ordered matrix highlighted that all 13 participants cited a minimum of two neoliberal reasons for dropping the education sequence. The most common being the cost of higher education, the added expense and time required of education majors, and pressures from their family and society about the deflated view of educators, which are all either directly or indirectly a result of privatization.

Market Forces and Impact of Free Markets. All of these themes help me to understand the data because they highlight how the neoliberal agenda has turned otherwise viable candidates away from teacher education. Glass (2008) believes attention should be directed toward the hyper-consumerism mentality of the middle class (p. 15). Their growing debt and lack of savings meant they turned to public intuitions, but also did not want to help fund them due to their great expense (particularly, public schools). Glass (2008) also draws a historical connection between the weakened middle class and "the assault on labor union dating from the 1970s, tax laws that began to be rewritten with the Republican victories in the general elections of 1980, free-trade agreements under neoliberals in the 1990s, and legislation continuing to today" (p. 131). Funding public schools slowly became a burden and was blamed for society's financial woes. In turn, this had a ripple effect. Underperforming and poorlyfunded schools were labeled "bad." Middle class families moved to suburbs, and their increased 
taxes meant they were draining their savings (Glass, 2008, p.135-144). When it came time for their children to attend college, the tuition cost seemed astronomical, and parents went further into debt, or college students assumed the debt. For many, the prospect of prolonged debt, and the idea of teaching with its unappealing salaries, a teaching degree might not have seemed like a smart investment. In this case, public K-12 schools and public universities felt the impact.

Accountability Movement in Education. Key themes associated with neoliberalism were repeatedly found in participants' responses. Casey (2016) sums this up best when critiquing teacher education programs and the "insistence on 'high expectations' for all students does not challenge the existing structures of domination if those high expectations stop at the attainment of a postsecondary degree and successful employment" (p. 138). This description can be compared to the empty, box-checking Gateway system that many participants cited as their reason for leaving the major. While conducting these interviews, many participants expressed that earning a teaching degree was the equivalent to jumping through hoops. Many of the participants, citing their own favorite teachers referencing this drawback to the profession, wanted to do more than check boxes during their career. Casey (2016) uses this as evidence of the ways in which "teacher education has not lived out its commitments to positioning teaching as part of a larger global project to usher forth a more just and equitable society for all people" (143). The thought process being if there is this much red tape in teacher education, what will the actual profession be like?

Neoliberal Conclusion. Both Casey (2016) and Glass (2008) highlight how the neoliberal attack on public schools at all levels still impacts teacher education today, and the participants of this study all fell victim to those ideals. The themes of increased tuition, the added time and costs of education majors, and the perception of low teacher salaries, coupled 
with the pressure to find a "good" career, ultimately turned students away from teacher education. As previously stated, the neoliberal lens in and of itself does not capture the entire picture which is why the critical lenses helped to extrapolate why systemic racial inequities contribute to the problems plaguing our public schools and teacher education.

\section{Critical Lenses Analysis}

Referring back to Yosso (2005), CRT is a "framework that can be used to theorize, examine, and challenge the ways race and racism implicitly and explicitly impact on social structures, practices, and discourses" (p. 70). Education and teacher preparation have fallen prey to racism from their inception and that is why, in addition to neoliberalism, it was imperative to also address how using the critical lenses would expose the systemic racism embedded in our public schools. The key components of the critical lenses, which I have outlined as challenging the inequitable practices in teacher recruitment and training, highlighting the effects of institutional whiteness, and addressing how the representation of all students, families, and communities, must become a cornerstone of education.

Challenge Inequitable Practices in Teacher Recruitment \& Training. The shift to this neoliberal model in education affects all students, but students of color and female students carry a heavier burden. For this study, six of the 13 participants identified as students of color. Four of those students felt job and career consideration pressure; four also confronted GPA issues; three had second thoughts; one experienced serious family pressure about the legitimacy of a career in public education; four cited increasing monetary concerns; and two were turned off by their (white) professors. All six students of color felt there was an abundance of red tape and that the institution was trying to "keep them out." I will state again that I asked all the participants the same questions and never guided the interview in a way that would allow for 
"race baiting." However, in asking students about their perceptions of the teacher education programs and why they were no longer part of the major, the students of color alluded to the cloud of racism. Their responses exposed the inequitable practices they experienced.

At the time, I did not know how important the application of CRT would be to this study, but, as I stated above, “the charts don't lie." Four of the participants identified as women of color and all cited multiple barriers when it came to their majors. Only one of those women of color was a transfer student. To review, back in Chapter IV, I explained the difficulties that transfer students faced when arriving on campus, generally under the assumption that by starting at community college, they had saved themselves time and money. After analyzing all 13 interviews, it was the transfer students of color who faced the most challenges and experienced insurmountable setbacks. After conducting such extensive research, I refused to believe that was a coincidence.

Effects of Institutional Whiteness. Matias and Mackey (2016) eloquently explained how Critical Whiteness Theory (CWT) accounts for the "hegemony of whiteness that has so naturalized itself within the field of U.S. education [and why it] goes undetected, despite the major implications it imposes on the educational equity of the students of color" (p. 34). Applying CRT and CWT in tandem matters because it allowed me to examine why students of color have been marginalized by Midwestern University's teacher preparation programs and ask why it has been systemically permissible for so long. Challenging dated practices and requirements with critical lenses means reflecting on who is hurt and who is protected by these university standards. Whether applied inadvertently or by design, the data produced from this study, both analysis of university demographics and the interviews conducted, demonstrate why changes need to be made. The barriers engrained in teacher education programs, like the 
Gateway system and the assumption that everyone can afford the additional expenses, further highlights how institutional whiteness impacted students of color in this study.

Representation of All Students, Families, and Communities. In her book White Rage: The Unspoken Truth of Our Racial Divide, Carol Anderson (2016) outlines how African Americans have been fighting for access to a quality education since the days of enslavement. She writes that "education can be transformative. It reshapes the health outcomes of a people; it breaks the cycle of poverty; it improves housing conditions; it raises the standard of living...educational attainment significantly increases voter participation. In short, education strengthens a democracy" (p.95-96). Having also completed two degrees in history, I am wellversed in the Civil Rights Movement, but Anderson (2016) is critical of the lasting impact of Brown v. Board of Education, stating that it resulted in "the economic equivalent of a permanent national recession" (p.97). Today, the Deep South, where so much of historic racism is rooted, "fall in the bottom quartile of state rankings for educational attainment, per capita income, and quality of health" (Anderson, 2016, p. 96). Yosso's (2005) definition of CRT offers a platform to challenge these inequities. While this study takes place in the Midwest, this region is certainly not free of racism. I did not explicitly ask about racism or experiencing bias as education majors of color, but those barriers were present during their time on campus.

Critical Lenses Conclusion. The combination of neoliberalism and critical lenses offers both causes and pathways to solutions for perspective teachers from all walks of life. In doing so, institutional barriers can be removed to allow for an equal playing field. Intentionally diversifying the educator work force would be an important first step and long-term commitment toward ensuring the academic and future success of all students. Easton-Brooks (2019), who is a proponent of this, questions if states are "adequately equipped in terms of having enough of an 
adult population to respond to the need to diversify the educator workforce?" (p. 35). His question comes full circle, as it demonstrates a consequence of neoliberalism, which further demonstrates why both frameworks must be applied to this study.

\section{Chapter Summary and Conclusion}

In an attempt to investigate factors which accounted for teacher education majors leaving their majors, my study utilized demographic data from the university and the presentation of interviews responses that were coded and organized using matrices. Viewed separately, the tables and the matrices each made the case that there are inherent equity issues with public education. From lack of representation of teachers and education majors of color to the institutional barriers future teachers face, the data exhibits why changes must be made. Students who arrived at Midwestern University faced neoliberal pressures in the form of higher tuition, additional education major related expenses, and tedious levels of accountability. Additionally, teacher candidates experienced the impact of institutional whiteness and lack of representation in their classes and from their professors. My key findings suggest that institutions need to incorporate more intentional recruiting of education majors, and they need to design targeted support for each year of college. I will go into more depth regarding recommendations in Chapter VI. This research has led me to a broader conceptualization of why students eagerly intend to become teachers when arriving at college but ultimately do not graduate with a degree in education. 


\section{CHAPTER VI: FINDINGS, IMPLICATIONS, CALL TO ACTION}

During my last class before comprehensive exams, I knew time was running out until I had to narrow down my topic for my dissertation. After 60 hours of coursework, I was certain my study needed to revolve around teacher preparation, but I felt stuck trying to find a topic that I was passionate about and could also make a real impact on public education. I had heard the horror stories of writing a dissertation just so it could collect dust on a shelf. When Mindy came into my office that early spring day to tell me she did not see how she could continue in the teacher preparation program, I hated the feeling that I could not help her. As an educator, I was trained to help students problem solve and offer them suggestions.

While Mindy sat there, I could not offer viable solutions. As noted in Chapter I, Mindy had failed the content exam twice and would need to repeat a few classes to get her GPA up so she could student teach. A few mediocre grades from freshman year were a nagging reminder of a simpler time, when the prospect of graduation seemed so far away. To use my own term, she was “Gatewayed." Like most educators, I left campus that day carrying the weight of Mindy's predicament, and I kept thinking about ways to help. Short of paying for another content exam, her tuition, and rent, my hands were tied. Heading to graduate class across the beautiful quad, I was angry that Mindy had gotten this far and desperately wanted to be a teacher. She picked Midwestern University for that very reason. I distinctly remember being stopped in my tracks by one of our campus's over-friendly squirrels who nearly tripped me and then looked at me like it was my fault. My mind had been racing about Mindy, while also rushing to night class, and calling home quickly to say goodnight to my kids. That is when it hit me! Mindy's story was not unique. If this happened to her, it certainly had happened to others. Here I was searching for a topic, trying to find something new to study, and with Mindy's visit to my office that day, 
everything fell into place. I saw this as an opportunity to find other students like Mindy, ask them about their journeys, study the results, and share my findings to recommend ways to improve teacher education and fix that pesky, leaky teacher pipeline.

\section{Introduction and Purpose of the Study}

To review, the focus of this study was to explore factors influencing the teacher pipeline and surmise why education majors dropped the sequence before graduating and becoming licensed teachers. I wanted to see how the teacher education sequence within the college of education was perhaps creating obstacles which prevented students from earning their teaching credentials. It has become common knowledge that there is a teacher shortage (and I started this work prior to the COVID-19 pandemic, which will be addressed below). Teachers are not remaining in the field, and enrollment in teacher education programs has been steadily declining for nearly a decade. Furthermore, there is a lack of racial and ethnic representation in public schools which only exacerbates the problem. Students of color are largely taught by white teachers, and therefore are not seeing themselves in the role of educator. The cycle continues, the pipeline continues to leak, and there are college students who want to be teachers who are not afforded the opportunity. In this final chapter, I will explore how the concept of teacher education attrition is linked to enrollment demographics and students' ability to navigate the world of academia.

\section{Research Questions}

In the section that follows, I will restate my research questions and answer each with support from the findings in my study. There is great complexity surrounding the issues I addressed as reviewing the systemic inequity within the field of education encompasses so many stakeholders. Teachers, school districts, parents, COEs, legislators, and community partners all 
need a seat at the table, and I will attempt to include them in my findings, implications, and call to action.

\section{Question 1}

What is the nature of student attrition in secondary (high school) and K-12 teacher education programs?

\section{a. What patterns in student demographics exist?}

b. What factors do teacher candidates attribute to their attrition?

As detailed in Chapter $\mathrm{V}$, teacher education majors are not immune to attrition. It goes without saying that every major on a college campus will experience some level of attrition as students change their minds about what they want to do with their degrees after college graduation. However, given the demanding nature of teaching degrees, exploring when and why education majors dropped their sequence was important to pinpoint. In order to find out, I needed to understand who majored in education. The K-12 and secondary education programs at Midwestern University used for this study (i. e., biology, chemistry, English, history-social sciences, math, music, physics, and theatre) were $82 \%$ white and $51 \%$ female. Students of color accounted for $18 \%$ across all the race and ethnicities categories provided by the university (see Table 7). These numbers aligned with Midwestern University as a whole, which is $73 \%$ white and $56 \%$ female, as well as the state's public teaching force, which is $83 \%$ white and $77 \%$ female (see Table 6). When reviewing the demographics of the students in this study, it was insightful to learn that while there were more females, overall, Midwestern University as a whole produces more male teachers (44\%) compared to the $23 \%$ that account for the state's public teachers. Since the early $20^{\text {th }}$ century, there has been steady decline in the number of male teachers in the United States, particularly in elementary education and among Black males 
(Medford et al., 2013). Despite the dominance of females in the field, six of the 13 participants identified as male, which further highlights the gender imbalance in education.

Of the eight programs in this study, only two (English and music education) could report $20 \%$ students of color. The other programs fell below that percentage, the lowest being chemistry at $14 \%$ students of color. When I dug deeper into the data, I found that more female students and more white students took summer school. GPA is often used as an indicator of student success and can prohibit students from continuing with their teacher education program. In this study, reviewing the mode GPA over a five-year trend, three of the programs, English, math, and theatre education, all had mode GPAs in the 3.75-4.0 range. Additionally, students with higher GPAs enrolled in summer school. Even though these programs added nearly one hundred students over a four-year span, the percentage of the students of color in those programs did not increase. This evidence supports the need for more racial, and for some programs, more gender, inclusion. There is too big of a disparity between who is enrolled in teacher education programs and the race of the students in public schools. This data also indicates how students with higher GPAs are taking advantage of summer school classes to get ahead, by either lightening their course load during the academic year or by adding on subsequent endorsements that would make them more marketable. If students must work full-time during the school year and the summer to put themselves through college, these numbers point to the fact that not all students have access to summer school. The demographic data from the university only provided half of the picture. To gain a comprehensive picture, I also needed to interview students who were no longer enrolled in said education programs. 


\section{Question 2}

What are key turning points for teacher candidates in deciding not to continue with teacher education?

In Chapter VI, I outlined the critical event(s) that solidified each participant's decision not to continue with teacher education. Using Wolcott's (1994) “critical or key event" approach, I was able to find common themes amongst the participants by "focusing on only one or two aspects, creating a story-within-a-story in which the essence (but not the detail) of the whole is revealed or reflected in microcosm" (Wolcott, 1994, p. 19). By sharing their entire story with me during our interviews, the participants gave me a full picture of their experiences. I coded and synthetized that data and presented my findings in the matrices in Chapter V (see Tables 13 and 14). Using Miles et al.'s (2014) time-ordered matrix, I broke down the life of a college student by academic year. The full matrix can be found in Appendix D, as Table 13 in Chapter V highlights the data sample of two students. I learned that high school is an important time for students to make their decision. I would suggest that all high school students interested in teaching as a career shadow a teacher over the course of the school year to learn the ups and downs of the profession. Ideally, students would also have interactions with practicing teachers who come from similar demographics and backgrounds to discuss the cultural implications of the career. The time-ordered matrix revealed that students need to be exposed to education classes earlier, and they require targeted support each year of college (especially sophomore and junior year). The university needs to reframe their Gateway system, and students need to be exposed to other career paths similar to education.

I also employed the variable-by-variable matrix from Miles et al. (2014) which allowed me to plot the major variables students referred to in regard to their struggles with teacher 
education and cross-reference my findings with the time-ordered matrix. Here again, I found that students need exposure to education classes earlier in college, and the university needs to reframe the Gateways in a manner that promotes student success. Both matrices highlight how college students need targeted support each year. Freshman year comes with onboarding and retention-driven support. During senior year, students are heavily entrenched in their major, so by default, their professors and advisors are very likely guiding them on a regular basis. This is why sophomore and junior years need to be given special attention.

The matrices, coupled with the students' critical events in Chapter IV, provide significant evidence of the areas in which teacher education majors struggle. Studying the participants' "stories-within-a-story" in Chapter IV provided a comprehensive view of the events mentioned in the matrices and the reason why students ultimately left teacher education. The students fell into three categories based on their critical events. Ultimately, students dropped their education majors because they were transfer students, were impeded by the numerous Gateway requirements, or had learned that teaching was not what they expected. I also think it is crucial to note how six of the 13 participants attended community college before transferring to Midwestern University. Both matrices show that support and onboarding are much needed. Ideally, it should be comparable to what freshman students receive when they arrive on campus. I have presented a preponderance of evidence by answering my first two research questions. Armed with my findings, the recommendations and call to action in the pages that follow could transform teacher education.

\section{Question 3}

Based on the study, what are the implications for teacher education and policy? 
The title of Chapter I appropriately asks, "Where Have All the Teachers Gone?" When I framed the factors impacting public education that needed to be addressed in this study, I explored the following five issues: the leaky teacher pipeline, the teacher shortage, the impact on K12 and particularly high school teachers, the effect on colleges of education, and the need for representation in classroom. By identifying these factors as contributions to why education majors do not become teachers in general, or for K-12 and high school teachers in particular, I am able to discuss the ramifications for teacher education, policy, and make recommendations in each of these five areas.

\section{Leaky Teacher Pipeline}

A nationwide statistic shows "one-third of all new teachers leave their initial placements after only three years of teaching, and $46 \%$ do so within the first five years" (Kopkowski, 2008). This statistic does not bode well when perspective teachers constantly hear that educators are unhappy and leave the field after paying for their college degree. Fixing the leaking teacher pipeline means reframing the language around schools and providing all students with access and experiences that set them up for future success. While interviewing my participants, I discovered the high school years played a pivotal role in guiding students toward their adult life. For all career possibilities, "high school plays a powerful role in shaping students' cultural competencies, serving not only as judges of academic success, but also as crafters of students' strategies for achieving it. We do poor students as a whole a disservice if we assume that their stories are all the same" (Jack, 2019, p. 21). This gets back to the idea that "one size fits all" cannot be applied to all students. Jack (2019) highlights how poor students need different supports during high school, and I would suggest that if not given the proper guidance, these students are not even encouraged to explore teaching as a career. Because more students of color 
attend schools in low income areas, there is an automatic stigma attached. Deficit language, like "hard-to-staff schools," disproportionally serve low-income students and students of color. There is also a distinction to be made between "'hard-to-staffness' which reflects poor labor conditions and gaps in 'achievement' that are a consequence of a long history of educational disenfranchisement" (Philip et al., 2019, p. 254). These are systemic and structural voids in the leaky teacher pipeline that fail to consider the contributions of teachers and students of color. Deficit language uses whiteness as the measuring stick for success and employs unfair labels to categorizes schools who are not "meeting expectations." In these schools, unappealing learning climate and low achievement often result in teachers leaving at high rates. So, the cycle continues. Teachers leave which disrupts the school culture and the relationship and trust building essential for teaching stalls.

Historically speaking, the way Black students are educated goes back to Booker T. Washington who preached that the educational purpose of Black students was to gain the basic skills needed to function with whites. He pushed for a "curriculum centered on basic reading and mathematics skills and primarily on discipline. This approach holds to the belief that students of color are less disciplined and organized and that they need to be taught skills" (Easton-Brooks, 2019, p. 90). This is illustrated today with the widely accepted deficit mindset of behavioral problems being linked to students of color. As a historian by training, I was shocked to learn that is why many high schools were created and today are still called "manual" high schools. Teachers in these settings rely heavily on scripted lessons so students of color can learn manual skills. This exposes a major leak in the teacher pipeline which is a result of decades of deliberately only teaching portions of the student population manual skills and disciplines. The narrative that Black students misbehave because they lack skills and self-discipline but 
possess character traits of the student who causes problems, has been universally accepted. However, when schools focus on students' deficiencies, they miss students' positive characteristics (Okonofua et al., 2016). This creates, as their article is appropriately titled, "A Vicious Cycle" (2016). It is assumed that racially stigmatized students do not value education. Harmful stereotypes alleged by both teachers and students negatively impact their relationships, which leads to harsh discipline. Our public school system needs to challenge and reinvent itself after their historically inequitable past. The disproportionate amount of discipline toward students of color has led to the "school-to-prison pipeline." (Okonofua et al., 2016; Oparah, 2014). Students of color are certainly challenged become teachers if they are in prison after dropping out of school due to extreme levels of discipline. In researching how to fix the leaky teacher pipeline, I also exposed why students of color are not introduced or even trained for careers that require college degrees.

In her book Linguistic Justice: Black Language, Literacy, Identity, and Pedagogy, April Baker-Bell (2020) amplifies how "anti-Black language education not only contributes to Black students despising their mother tongue, but it also causes them to see themselves through a white gaze, a way of looking and seeing the world that negates their value" (p. 21). I found this statement to be so powerful and a true testament to the helplessness students of color must feel when faced with microaggressions, prejudice, and discrimination. Students who experience this in school will obviously hold the setting in a negative regard and therefore would not want to spend their adult life (as a teacher) back in a place that so quickly dismissed them. Baker-Bell's (2020) work confirms how linguistic racism impacts Black students. She defines Anti-Black Linguistic Racism as "denying Black students the right to use their native language as a linguist resource in their language and literacy learning” (p. 21). This highlights just how detrimental it 
is when we force students to adopt a dominate culture that is not their own. Students who practice English as their Second Language experience a similar stigma. When schools marginalize students for being themselves, it sends the message that they are not embraced as students and insinuates they would not make adequate teachers. There is also a notion that white teachers are the problem or are not being purposeful with their practice: "It does imply that teachers of color are driven to see students of color succeed because they know what is at stake for these students as well as the lifelong challenges these students may face" (Easton-Brooks, 2019, p. 77). This calls attention to how deeply rooted the issues surrounding the leaky pipeline have become and why it so desperately needs to be fixed.

The implications discussed above all address issues surrounding the critical lens that were half of the conceptual framework that shaped this study. Equally detrimental to the leaky teacher pipeline is the neoliberal pressure to siphon money and resources away from public schools. As Secretary of Education during the Trump Administration, Betsy DeVos insisted the solution to fixing schools was to send private school vouchers to low-income students. This is neoliberalism at its finest. Jack (2019) insists that "instead of improving public education, [a voucher system] further disenfranchises public schools, removes funds from districts and schools that are already financially strapped, and sidesteps the problems plaguing the education system" (p. 194). This created another system of oppression and further delegitimized the work of public schools and offered an inequitable, band-aid solution. Public educators from all backgrounds feel insulted and frustrated by the voucher solution because monies follow students to private schools or creating charter schools rather than re-visualizing public schools around more relevant curriculums and training. The leaky teacher pipeline can only withstand so many holes. From 
vouchers to the issues surrounding the deficit language and thinking entrenched in public schools, addressing these problems could have positive implications for the leaky pipeline.

\section{Teacher Shortage}

The consequences of a leaky teacher pipeline have resulted in a teacher shortage. In Illinois, "between 2010 and 2016, the number of [teacher] candidates enrolling in and completing teacher preparation programs decreased by 53 percentage points" (ISBE, 2018b, p.

3). Fewer students enrolling in teacher preparation programs means there is a decrease in teachers overall and even fewer teachers of color. The first solution is to treat teachers like professionals, stop de-valuing the profession, and "make day-to-day teaching an attractive, challenging job that intelligent, creative, and ambitious people will gravitate toward" (Goldstein, 2014, p.11). The neoliberal agenda has cheapened the profession. Prior to the 1980s, Blacks often sought teaching as a respectable profession. Today, other professions are also seeking to diversify, therefore it is not surprising fewer Blacks and other communities of color are looking to become educators when potentially more lucrative professions are also recruiting them. If other professions are more actively welcoming employees of color, this becomes a more viable option for people who did not feel represented during their schooling. There has been a large shift in teacher turnover when comparing teachers of color and white teachers. In the late 1980s, "there was a 0.7 percent difference...in the following two decades there was a 3 to 4 percent difference in the turnover rate between teachers of color and white teachers" (Easton-Brooks, 2019, p. 89). If all teachers are becoming dissatisfied with their jobs, the additional cultural disconnect teachers of color experience further emphasizes why they leave the field. All educators need to have a seat at the table when it comes to how schools are run and what is taught: "Given that white professionals make up more than 80 percent of the educational 
community leading the conversation on schooling and what is to be learned, they own what knowledge is and what is taught in schools" (Easton-Brooks, 2019, p. 78). This affirms why teachers of color are leaving the field at a faster rate. Dismantling a system that has for so long excluded too many students and teachers has resulted in this teacher shortage. There are solutions, and I will address them in my "Call to Action" section, but the first step involves shifting public education systems to a framework that allows students culturally lived experiences to be part of their learning (Ladson-Billings, 1999, 2001). The leaky pipeline and the shortage have implications for those K12 and secondary teachers who have remained in the field.

\section{Impact on K-12 and High School (Secondary) Teachers}

To support teachers in the field, there are several avenues to explore in order to improve existing conditions. First, districts need to create opportunities to highlight why a teaching career is valuable. Many schools have classes for future teachers or have high school students running a preschool in their building. Those opportunities should be expanded. Another approach would be to provide scaffolded advising which is "a program that integrates students into support networks of adults with advanced degrees and allows them to engage with adults as equal partners rather than authority figures" (Jack, 2019, p. 195). Not only would all students benefit from this additional approach to advising, but those students interested in teaching could get firsthand experiences in the classroom. Scaffolded advising would bring so many benefits to all high school students and would allow for career explorations. For scaffolded advising to be properly implemented, class size needs to be small "as to allow teachers to engage in intense academic coaching" (Jack, 2019, p. 195). This would also give teachers and students the opportunity to foster a collaborative partnership. Scaffolded advising is one approach to helping 
students make decisions about life after high school but exploring achievement and discipline gaps will provide additional methods to improve teaching (and learning) conditions.

Educational reform movements have repeatedly tried to close the achievement gap. Unfortunately, despite the variety of different approaches, white and Asian/Pacific Islander students have significantly higher scores on standardized tests. Shifting the blame from schools to teachers highlights a key change between A Nation at Risk (1983) and NCLB (2001). As outlined in Chapter II, in both instances, the goal was to improve failing schools. Closing the achievement gap is crucial to the success of schools, but previous approaches have not taken into account how the discipline gap must be added to the equation. The discourse has "shifted to a focus on teachers' attitudes and beliefs about race as they relate to student achievement" (Gregory \& Mosely, 2004, p.19). In their study, Gregory \& Mosely (2004) wanted to see if discipline contributed to low achievement or vice versa. While providing a note of caution, they found teachers were not acknowledging the discipline gap, nor were they taking their students' race into account in an effort to remove race as a factor. They purposed reconceptualizing discipline by employing "culturally relevant discipline" (CRD) which considers a broad range of cultural and racial factors that contribute to a disciplinary episode" (Gregory \& Mosely, 2004, p.26). Implementing CRD would support high school teachers because it eliminates some of the predisposed assumptions associated with discipline by factoring in the students' background, culture, and race.

These changes surrounding the discourse of school discipline would ultimately address the well-documented racial disparities in discipline public schools (Okonofua et al., 2016). Considering these factors and channeling them into the classroom setting would help to expose issues before they occur. An additional layer to consider when exploring achievement and 
discipline is student exposure to same-race teachers. In their study, Lindsay and Hart (2017) found consistent evidence that "exposure to same-race teachers lowers office referral for willful defiance across all grade levels, suggesting that teacher discretion played a role in the results" (p. 485). Studies of racial disparities in discipline and its relationship to the race of the teacher are credible and must be utilized when review best practices in education. Another key factor classroom teachers need to evaluate when considering their students is the role of language. Inclusive teaching practices require valuing students' language. One-way white teachers could implement this practice would be to "value Black Language in the classroom, in order to dismantle white supremacy" (Baker-Bell, 2020, p. 6). All too often, students of color are forced to code-switch, or use the language that fits the time, place, and audience. For example, Black language is often what students would use at home and with friends. However, when they arrive in public settings, like school, they are forced to code-switch in an attempt to adopt mainstream practices. Imagine wanting to be a teacher, but as a student of color, code-switching during college and throughout one's career would not sound appealing. While efforts to recruit teachers of color are slowly gaining traction in the forms of "teacher residencies, loan forgiveness, mentoring, and induction, and principal training programs" (Carter Andrews et al, 2019, pg. 10), Black teacher turnover rate is still significantly higher. Public education and COEs cannot promote diversity in the workforce without having supports in place for the teachers of color who are hired.

Teachers need to be properly trained and equipped to educate all students and that requires ongoing professional development throughout their career. When working with students of color, teachers need to plan lessons which go beyond textbooks or their own frame of reference by including their students' backgrounds, rather than erasing them. Gloria Ladson- 
Billings addresses this issue in Crossing Over to Canaan: The Journey of New Teachers in

Diverse Classrooms. "It asks them to use language other than the one they come to school with. It asks them to dismiss their community and cultural knowledge. It erases the things that the students hold dear." The outdated notion of assimilation in the classroom must be replaced with inclusive, culturally responsive teaching. If this is not happening in districts, schools, or individual classrooms, teachers need to be given the opportunity to implement culturally responsive pedagogy within their content area or grade level. For many educators, this will mean putting in the work overtime to learn about the cultures and backgrounds of their students.

The dominant culture cannot be the only one represented in the lessons. Dr. Gholdy Muhammad, in her work entitled Cultivating Genius: An Equity Framework for Culturally and Historically Responsive Literacy (2020), created a template that can be applied to any grade level and any subject. Rooted in the principles of early Black literary societies, which are largely missing from the master narrative of history, they promoted the idea of literacy as a civil right in the early 1800s. Historically Responsive Literacy focuses on four learning goals: identity development, skills development, intellectual development, and criticality (Muhammad, 2020). She argues how when these "four learning pursuits are together, the learning becomes humanizing and more complete — giving students opportunities for personal, intellectual, and academic success" (Muhammad, 2020, p. 63). Having personally worked with Dr. Muhammad to bring her to a conference I helped plan, I have experienced how impactful her vision is for creating lessons for students with their backgrounds in mind. It should also be noted how "students of color who had a more diverse experience with teachers of color also felt more comfortable with white teachers and felt their teachers of color did a better job connecting the curriculum to their cultural backgrounds" (Easton-Brooks, 2019, p. 68). Implementing 
frameworks like Muhammad's (2020) will require a paradigm shift, but ongoing support will help to reshape outdated and exclusionary curricula.

The connection between the high school experience and the transition to college cannot be ignored. Jack (2019) urges examination of “students' experiences in their neighborhoods and high school, since there are 'gateway institutions' that fuel inequality" (p. 184). Jack (2019) digs deeper to distinguish the difference between the privileged poor, students who are poor but have the privilege of an early introduction to the world they will enter in college, compared to the doubly disadvantaged, who are poor, but are also totally unfamiliar with the new world they are introduced to in college (p. 11). This is where the high school experience comes into play and why it is so important for secondary teachers to be aware of their role in preparing students for college beyond the subject they are licensed to teach. Prior to college, if students have been exposed and have interacted with different social classes and races of privilege, upon arriving at their institution of choice, the privileged poor are more prepared to navigate their new world because they have acquired some measure of cultural capital. Access to cultural capital allows the privileged poor " ...to be at ease when engaging with their peers and professors. Yet when it comes to money, the distinction between the two groups disappears" (Jack, 2019, p. 22). Jack's (2019) study does focus on elite institutions, but he makes the case throughout the book how the privileged poor and doubly disadvantaged can be found on campuses across the country. Universities, and specifically colleges of education, need to be aware of the extra support these students will need in order to succeed in their programs.

\section{Impact on Colleges of Education}

There are some simple solutions colleges of education could implement to help the leaky teacher pipeline and the teacher shortage. Intentional recruitment would be an important first 
step. Visiting urban, suburban, and rural communities to present all the teacher education majors and then arranging for campus visits would make the college decision making process more accessible. This could also be done by establishing COE partnerships with even more districts across the state. Partnerships should focus on a pipeline from high school to the university, an agreement to accept student teachers, and then a path to employment that creates a cycle that is beneficial to all. COEs should study other programs which have successfully implemented targeted recruitment programs. One example is "Troops to Teachers" which transitions service members into a career in education (Medford et al., 2013). Under the tagline of "Proud to Serve Again," this program is intended to help all service members, but due to the number of men enlisted, the program does recruit more men. Initially created to recruit African American males to teach at the elementary level, "Call Me MISTER" (Mentors Instructing Students Through Effective Role Models) has expanded beyond South Carolina and has expanded to eight states (Medford et al., 2013). Both of these are excellent examples of intentional recruited and support. The Teach Illinois report (ISBE, 2018b) also uncovered that the highest number of unfilled vacancies exist in Chicago Public Schools (CPS) and rural school districts (p.6). While Midwestern University already has a strong pipeline with CPS, creating a rural pipeline would be the logical next step. Another obstacle students face is affordable housing during their student teaching semester. Many students move home to live because it is inexpensive. They do not have to pay rent and can focus on the semester without additional financial concerns. However, this perpetuates the problem, because by going home, white students are returning to their own communities and are more likely to look for a job where they can live for a few years while paying off their college loans. Here is another example of how "money remains a requirement for full citizenship in college, despite institutional declarations to the contrary" (Jack, 2019, 
p.22). Students from more affluent families have more options before, during, and after college. Students of color can be deterred from majoring in education upon learning of the extra financial burdens of student teaching. Viable options to compensate student teachers must be explored as a possible solution to the teacher shortage. Additionally, there are other avenues to investigate when it comes to supporting education majors.

In Chapter V, when I explored university demographics, I found many students relied on summer school. Most students enrolled in summer classes had a higher GPA, so it can be inferred these students took extra courses to lighten their course load during the school year, completed general education requirements, or as a way to earn extra endorsements. To make access to summer school more equitable, teacher education programs should offer free summer classes if students re-enroll full-time the following fall (Franke \& Bicknell, 2019). The university would benefit because students would have an incentive to return in the fall, and students would benefit because they would have access to courses. Similar to the deficit language used in K-12 schools, the Gateway system needs to be reframed to utilize supportive language rather than the current "gotcha" approach. Jack (2019) refers to structures such as the Gateway system as an example of "formal university policies [that] push poor students to the margins in a process called structural exclusion" (p. 23). Many of the Gateway requirements at Midwestern University are tied to monetary purchases like an online portfolio system, content exams, and GPA (which is linked to the classes students take and, therefore, tuition dollars). Being an education major comes with additional fees that participants in this study cited repeatedly. Within the Gateway system, COEs must also address their use of teacher dispositions and the purpose of the requirements (Ripski et al., 2011; Wilkerson, 2006; Borko et al., 2007). Diez (2007), who helped to write the Interstate New Teacher Assessment and Support 
Consortium (INTASC) standards, reflects on how the use of dispositions should be reevaluated to emphasize candidates' ability to collaborate with others as an essential analytic skill. The INTASC standards dispositions are based on were written in 1992. Diez (2007) is firm in her declaration; "It is clearly time to move beyond responding to mandates to viewing dispositions in a develop- mental way, integrated with knowledge and skill, so that teacher education programs build a community of professional practice capable of addressing the needs of all learners" ( $p$ 395). I agree with Diez (2007) whole-heartedly. Revaluating the requirements of teacher education through a culturally responsive and inclusive lens is long overdue.

There is continuous debate when it comes to determining what should be the requirements for teacher education. Finding a balance between content knowledge, skills, and professional competencies has left many institutions (Midwestern University included) requiring a laundry list of boxes to check. Reviewing GPAs and SAT scores of future teachers, Gitomer (2007) authored a report on behalf of the Educational Testing Service, an entity that administers teacher preparation tests. The conclusions drawn from this data was collected between 2002 and 2005. Two conclusions from this report stick out and require further examination. Academic quality of students taking the test has increased, but the individuals taking the test are no more diverse than a decade ago (Gitomer, 2007). The second finding was the most surprising but can also be misleading. While raising the bar for teacher certification this "has not resulted in a decrease in the proportion of minority candidates" Gitomer, 2007). Reading those two statistics makes it appear teacher education quality is improving at the expense of not addressing how to diversify the pool. Unfortunately, GPA and SAT scores are not the best indicators of a students' ability to become a teacher, but that inequitable measuring stick is still being used. Campus policies exacerbate class differences "among students, often in way that connect to historical 
legacies of race and exclusion" (Jack, 2019, p. 22). Structural exclusion can be fixed by assisting students in making these purchases and by reviewing which of the requirements are truly necessary.

There are other invisible barriers that hinder students as well. Easton-Brooks (2019) explains, "Students of color are more likely to experience problems of alienation, marginalization, and loneliness than White students" (p. 28). When speaking with the participants, I heard this from all of them in various ways during different times throughout their time on campus. I think it is important to point out, again, how critical it is to advocate for sophomores and juniors, since the system purposely already supports freshman and seniors. All too often the retention metric is more about impressive data and less about creating a balance system of advising and mentoring that would have helped the very students in this study. Another solution at Midwestern University would be to start education classes earlier so students could form a cohort and have shared experiences. Students come from all different backgrounds, so it is important to take into account "the hidden curriculum full of unwritten rules, unexplained terms, and a whole host of things that insiders take for granted...(universities) tend to reward students who enter college already familiar with these rules" (Jack, 2019, p. 190). The hidden curriculum is often different for students of color and students from low-income families to navigate.

As a teacher educator myself, I found the scholarship surrounding efforts to disrupt teacher education (Bazemore-Bertrand \& Porcher, 2020) to be a promising approach to overhaul the establishment. Like Muhammad's (2019) Historically Responsive Literacy model, disruptive practices charge faculty members with exploring their own identities and having their students investigate their identities and positionalities. In addition to instilling continuously culturally 
relevant practice into the preservice teachers' craft, Bertrand and Porcher (2020) also noted how essential it is to have "critical conversations with white faculty members about the lack of diversity of the faculty and staff' (p. 84). Another way to disrupt teacher education is to confront the program's lack of diversity because "seventy eight percent of teacher education program faculty members are white... it is possible they do not have an intimate understanding of the challenge's students of color/diverse groups face" (Easton-Brooks, 2019, p. 97). That is a fair question to ask. Furthermore, what supports will be put in place to assist professors of color? If COEs are going to put forth the effort to recruit and retain students and faculty of color, they must be able to sustain those efforts. Teacher education faculty need to be equipped with the skills, knowledge, and experiences to prepare future teachers. The curriculum must be intentional, meaningful, and deliberate, and "teacher preparation programs may contribute to this disconnect in the way in which culturally responsive teacher or multicultural education is taught" (Easton-Brooks, 2019, p. 95). To start, teacher education programs need to audit their courses, projects, assessments, and clinical experiences to ensure that future teachers are prepared to work with students of color. Programs cannot pay lip service to culturally responsive education, but it must instead be engrained in their practice. Transforming teacher education requires seeking to change values and practices "and development of asset-, equity-, and justice-oriented teachers within and across university-based teacher education programs" (Souto-Manning, 2019, p.13). For most programs, this will be a pedagogical shift, but a welcomed by students who are interested in the most up-to-date, culturally relevant teacher training. I will address culturally responsive teaching in greater detail in the "Call to Action" section of this chapter. On a final note about Colleges of Education (COEs), traditional teacher preparation programs are preparing most of the nation's white teachers. It is widely-known that "Historically Black Colleges and 
Universities (HBCUs) alone generate half of the nation's Black teachers. Alternative programs produce roughly 25 percent of the total of Black and Latinx teachers compared to 11 percent of the total white teacher workforce" (Easton-Brooks, 2019, p. 88). These numbers give further support regarding why changes need to be made in teacher preparation. COEs should be preparing more teachers of color. The fact that so many Black teachers graduate from HBCUs further illustrates why students gravitate toward hospitable programs. Education at all levels must explore ways to end the lack of representation in the classroom.

\section{The Need for Representation in the Classroom Also Known as "Lack of Diversity"}

White students account for only $48.6 \%$ of the student population in the United States, and that number is predicted to drop to $45.2 \%$ by 2026 (The National Center for Education Statistics 2016, Table 203.50). This number highlights why there is need to diversify the field of education. Black, Hispanic, Asian/Pacific Islander, American Indian/Alaskan Native, and students of two or more races accounted for $51.3 \%$ of the student body, but when combined, they only account for $19.23 \%$ of the teaching force (NCES, 2016a, Table 203.50). The numbers themselves explain why increased diversity is crucial for public schools in the years to come. Beyond the statistics, representation in the classroom really does impact students. When students of color interact with teachers of color in the classroom their academic success increases significantly compared to students of color who do not interact with teachers of color" (EastonBrooks, 2019; Ladson-Billings, 2009). Similar studies have shown similar results for Latinx students (Easton-Brooks, 2019). It is incredibly important to take these findings to heart and see how this hurts so many students. In his study, Easton-Brooks (2019) reported that "eighty-eight percent of the formers students had a positive relationship with their teachers of color and only 65 percent said they had a positive relationship with their white teachers from kindergarten 
through twelfth grade" (p. 68). When using the traditional grading scale, a 65\% is "D." Public schools must do better than this. Students need teachers who are willing to build relationships, hold them accountable, and discipline fairly in the classroom. Another way to contribute to the solution, which ties back to the teacher pipeline I referenced when discussing COEs, teachers need to be home-grown. This is true, especially for teachers of color who successfully navigated school and chose to return to their communities. This supports the underlying ethnic capital theory (Irizarry \& Antrop-Gonzalez, 2013, p. 256). Returning to one's community demonstrates willingness to invest in the community and implant roots. Returning as human capital, teachers of color can use their ethnic capital to help navigate the necessary changes within their school system. Returning to one's community to teach shows others in the community access is achievable.

\section{My Epiphany}

I started this study before the COVID-19 pandemic, but I continued researching and writing for a year while quarantining, eLearning, and working full-time with two children, a husband, and a dog at home. I watched the total disruption to our education system at all levels. No one was immune to the interruption the virus caused as schools scrambled to provide students with devices in an attempt to continue learning in their homes. I felt passionate about public education before this history-making year and was proud as my profession pivoted to online instruction over a weekend, with limited resources in many places. We all stumbled through the end of the 2019-2020 school year and hoped that fall would be business as usual. As the summer progressed and the COVID-19 numbers continued to increase, I watched in horror as teachers were painted as the villains in this ever-changing story. I could not believe that parents were willing to send students back without demanding safe working conditions for teachers, which 
doubled as learning spaces for students. Teachers attempted to educate our children while on the screen, possibly caring for their own children, all while worrying about the speed of their internet and if their students had someone at home to assist them. I watched as our country eloquently illustrated just how dependent our society and economy are on our public-school system. As a country, we expect everything out of our schools. From childcare and meals, to learning how to

read and write, to teaching socialization and maintaining everyone's social-emotional well-being, the lofty expectations of our public schools were exposed during this pandemic. A key takeaway from 2020 (and beyond) must be that teachers should be given credit for what they did over this last year. This diatribe might seem like a departure from my study, but in all honesty, finishing this during the pandemic only reinforced why we need public school teachers and how the continued efforts to support teacher preparation programs is essential. I have been teaching a secondary education (high school) methods course every semester of the pandemic (current count is at three), and I can say with pride that my course section is full, and my students are excited to enter our field. While I have not enjoyed the pandemic, I am optimistic that this will help to affirm why teachers are essential and professional workers. Schools were held responsible for everything. In places where schooling is on the margins, conditions were significantly worse. The current pandemic is further evidence of the inequities found in our public schools having a direct impact on teachers. This study can help to patch some of the holes in the leaky teacher pipeline.

\section{What Surprised Me}

When I proposed this study and went in front of my committee, I was nervous that I would not be able to find students on campus that would be willing to talk to me. In short, I was asking participants to talk about their (supposed) failures and shortcomings. I was incredibly 
nervous to ask interviewees what went wrong and what was their fault. While I crafted my questions (See Appendix C), at the end of the day I was asking college students to be vulnerable and expose their setbacks. I am incredibly grateful for the students who participated in this study and how candid they were during our interviews. They took responsibility for the setbacks they fumbled. No one is perfect in college, but I appreciated our open dialogue about lessons learned. I was also stunned that 12 of 13 candidates wanted to continue toward a career path involving something related to teaching or using the skills of a teacher. Having never tackled a study this large, I did not know what I would find, what I was looking for, or if I would fail. I was surprised how easily the study, interviews, transcription, and coding came together. Selfishly, it would have been much easier to complete the study and write this analysis without a global pandemic. I would say that was the biggest surprise of all. That being said, the pandemic exposed just how vulnerable our public schools are as a result of neoliberal pressures, so I felt that reinforced why this study was important. I was also amazed by the additional questions I found myself asking. I address those below in the future research section.

\section{What I Did Not Expect to Find}

I was a bit shocked when my methodologist suggested that I include what I did not expect to find from my study. As academics (and humans), we have long been trained to suppress our shortcomings and highlight our victories. Exposing my blind spots was humbling. My initial thought was "everything worked out great; thanks for asking." However, when I thought back to the early days of my study, I remembered how nervous I was about finding participants who were willing to talk with me on the record. While attempting to recruit, I did not expect to find so many college students of color who dropped education and were willing to participate in my study. Simply put, there are more white students, so I assumed my participants would be mostly 
white. I am grateful the students of color who participated in this study felt comfortable enough to share their stories with me, a white, doctoral candidate who had become a teacher. I was fully aware that I had to navigate the teacher education program sixteen years prior to them and became a high school teacher. However, it was the students of color who unearthed the obstacles they faced which surpassed what I already knew about the hoops teacher education students had to jump through.

I did not expect to become even more invested in my study. I was passionate about teacher education prior to this study, but I underestimated how devoted I would become to my participants and their stories. I am genuinely interested in what they are doing now. I was also not prepared to hear how hard students worked. There is an ill-formed, misconceived notion that students who "ditch class" or earn lower marks are not deserving of their positions. And while the excuse of the "party animal" may ring true from time-to-time, the students I spoke with were largely working $20-40$ hours a week, taking $12-15$ credits per semester, and still could not justify staying in the major. I did not expect the participants to offer me words of encouragement. They expressed appreciation for investigating this problem, and for involving the students in an attempt to fix the issues. I conducted the interviews before the pandemic, so I gladly accepted the unexpected hugs from a few of the students. Finally, I did not expect to evaluate my own teaching practice or to learn about ways that I can grow as an educator.

\section{Future Research}

Since teacher education attrition is largely understudied, I found myself asking a lot of questions while conducting research. I started keeping a list because I realized it would make the scope of this study too large. I suggested that K-12 and secondary majors at Midwestern University should take education classes earlier in their plan of study. I would like to know if 
there are programs at other institutions that have education classes earlier in the sequence and how they compare? Do they have less attrition? Are those students better supported during their sophomore and junior years? I also wanted to know the attrition rates of education majors compared to other majors. Similar to the life cycle of the teacher education major that I created in the time-ordered matrix, would I find similar patterns when studying a wider range of college majors?

While I was reviewing the demographic data from Midwestern University, I felt another area of exploration could be a longitudinal study from admissions, to graduation, and then within participants' first five years in the classroom. Students are not just admission statistics, and their success needs to be continuously cultivated. Diversity should not only be celebrated the day admissions statistics are published. This study highlights how the four years that follow matter just as much, if not more. I think it would be beneficial to see what factors contributed to education majors' success while in college and then in the classroom. The role of food insecurity is another issue Jack (2019) referenced greatly in his work about the college students who are poor but were introduced to the world of privilege prior to college (dubbed the privileged poor). It would be noteworthy to study the impact of food insecurity as it pertains to education majors.

My research really led me to scholarship that highlighted the disparities Black students and teachers face. If I were to conduct a future study, I would place greater emphasis on other students of color, too. The success of a group is based on how they are perceived or fit into the dominant culture. For example, the Asian student population has fallen prey to the deficit discourse. Having been labeled the "model minority," they have been perceived as academically superior. However, there are fifty ethnic sub-groups under the label Asian Americans, so 
arbitrarily grouping them together does their unique customs and cultures a disservice. In wanting to learn more about the experiences of different racial categories, it is equally important to learn about the experiences of immigrant future teachers. Since we are a nation of immigrants and the topic continues to be polarizing, I would like to learn how to encourage more immigrants to become teachers. I would also like to study LGBTQ+ college students who wish to become teachers and learn about their experiences. That might also require studying high school students and how they reach their decision to become teachers as members of the LGBTQ+ community. Overall, I feel that this study has opened my eyes to the potential to study, support, and improve teacher education.

\section{Call to Action}

As someone who trains future teachers and started my career as a public high school teacher, it might appear that my critiques of our education system seem harsh. James Baldwin said it best: "I love America more than any other country in this world, and, exactly for this reason, I insist on the right to criticize her perpetually." America's public schools must address the racial and economic disparities which would bring about impactful change. With more inclusive communities, our government (federal, state, and local) needs to address the deeply entrenched inequities. School districts must include professional development rooted in inclusion which educators can apply in their classrooms. Permit time to plan, allow for structured implementation, and provide a space to collaborate and work together to improve. This would enable teachers to have tough conversations about their own limitations in a supportive atmosphere. That would be funding and time well-spent. It is essential white teachers utilize culturally relevant training. Black teachers need support, but in a different format. The Black Teacher Project (BTP) initially offered professional development in San Francisco and New 
York City. What transpired solidified how Black teachers needs a "safe" space to have conversations, health and wellness must be addressed, and monthly book studies helped teachers better understand culture (Mosely, 2018). This example illustrates why teacher development is a key component when calling educators to action.

While finishing this study, the Culturally Responsive Teaching and Leading Standards for All Illinois Educators (ISBE, 2021) were approved. These standards apply to teacher preparation and guide programs in an effort to help future teachers engage and connect with students from all different backgrounds. It also tasks programs with preparing teachers to support student leadership and community service. Unfortunately, these standards were met with pushback from conservative politicians and groups who viewed them as stretching the boundaries of teachers' roles (Cherney at el., 2021). I would argue the opposite. There could not be a more important time to require future teachers to reflect on their own convictions and background, to examine how this will influence their teaching, and then to equip them with the skills and experiences necessary to teach students who differ from them. Preparing future teachers to understand concepts like implicit bias, historical inequities, student advocacy, and social-emotional development are important additions to teacher preparation and will be incredibly useful in field application. Ultimately, these standards will help respond to the teacher shortage. The standards do not go into effect until October 2025, which gives programs time to work hard to evaluate and rewrite their plans of study.

In the meantime, work still needs to be done to address those in the field who do not fully understand or who have not embraced culturally responsive teaching. Easton-Brooks (2019) presents how the field needs to shift teachers' effective practice toward "critical social pedagogy” (p. 69). Based on the work of Paulo Freire (2005) and Gloria Ladson-Billings (1999, 
2006), it is widely known (but not always widely practiced) that critical pedagogy teaching practice pushes back against oppression and injustice. Social pedagogy focuses on teaching as a social responsibility. By marrying the two concepts together, Easton-Brooks (2019) introduces critical social pedagogy as "the practice of understanding and using social injustices of communities for the sake of learning and enhancing the learning of others within oppressed or marginalized communities" (p. 69). The types of pedagogy employed by teachers varies, but at the heart of the skill, teachers must perfect their craft to be inclusive of all students. Like the Culturally Responsive Teaching and Leading Standards, mentioned above, that will be embedded into teacher preparation programs, the implementation of critical social pedagogy will help practicing teachers meet the needs of all their students. In addition to providing meaningful frameworks like Muhammad's (2020) Historically Responsive Literacy, districts need to help teachers identify areas of growth based on dated pedagogy and research. Muhammad's (2020) four-layered equity framework can be applied to all subject areas and grade levels. When implemented correctly, educators can provide opportunities for personal, intellectual, and academic success. The effectiveness of culturally responsive teaching requires a paradigm shift, potentially larger and more difficult for some teachers and districts. This entails a new (and improved) way of being a teacher.

One way of cultivating a culturally responsive approach to teaching necessitates the evaluation of a teacher's current level of culturally competency. When investigating how deliberate or intentional teachers are when engaging the curriculum while keeping the background of students of color in mind, Easton-Brooks (2019) developed the Culturally Responsiveness Intentionality Scale (CRIS). This scale created five criteria to "examine the intentionality of teachers through the depth in which they are aware of culturally responsive 
practice and the degree to which they are committed to intentionality in practice" (EastonBrooks, 2019, p. 70). These five levels are oblivious, irresponsible, conscious, activist, or responsive. Oblivious and irresponsible teachers will require the most work, but the three categories that give me the most hope are the conscious, activist, and responsive teachers. The conscious teachers are "aware of the cultural differences in the classroom and make efforts to include cultural elements in lesson and assignments, but they include elements based on a dominate culture" (Easton-Brooks, 2019, p. 73). Since these teachers are largely aware of the differences, they will need help bringing examples and lessons from outside the dominate culture. Activist teachers give me hope as well because they "are fully aware of multicultural education and culturally responsive practice and use the concepts effectively in the classroom and will go to bat for their students" (Easton-Brooks, 2019, p. 75). What this group would benefit from is getting to know their students on a deeper level, so they feel confident when they experience pushback. The responsive teachers are the ones who "teach from a culturally responsive framework regardless of pushback from others" (Easton-Brooks, 2019, p. 76). Imagine if school leadership focused on incorporating CRIS into their professional development; the changes to our public schools could be limitless. This would be one small step toward the inclusion of all students in the school, curriculum, and community, ultimately leading to more students of color desire to become teachers.

Retraining existing teachers to be culturally relevant will only solve a portion of the problem. Teachers already in the classroom need to be recalibrated to teach all their students. Additionally, the recruitment of education majors of color must happen concurrently. Two examples of successful teacher residency programs occurred in Boston and Seattle. Both programs intentionally recruit based on racial categories, assigned staff members to assist with 
the application process, work with community and partner organizations, and addressed structural barriers (Osler, 2016). The examples from Boston, Seattle, and San Francisco are wellstructured to address racial representation in teacher preparation, similar to Troops for Teachers and Call me MISTER (Medford et al., 2013) to attract more male educators. The title of this article called out the status quo; "Beyond brochures: Practicing 'soul care' in the recruitment of teachers of color" (2016). I am not naïve enough to think these changes will happen immediately, but it is important to replicate the success of programs successfully supporting future teachers of color, beyond simply communicating success in data infographics and brochures. They interviewed students who chose not to become teachers and their responses echoed what I learned during my interviews: "high costs of college, the profession is not viewed as honorable, not a financially sensible career, over-reliance exams, hostile racial climates, felt unwelcomed in schools, and the teacher education curriculum is irrelevant" (Osler, 2016, p. 9130.) What is most impressive about these teacher education programs is not only their high retention rate (due to embedded support), but high percentage of graduates who are still teaching. If the formulas used to by these programs could be implemented across teacher education, imagine how many teachers would remain in the field and how many more students of color would feel inclined to apply to the major.

As noted previously, Ladson-Billings (1999, 2001, 2006, 2009) has influenced and added so much surrounding the scholarship of culturally responsive teaching and teacher preparation. This "Call to Action" would not be complete without referring back to her study of The Dreamkeepers (2009). Based on the results, she proposed solutions to transform the experience of teacher candidates. Some of her recommendations are quite simple but require intentional implementation. Recruiting students who desire to teach in Black communities and creating 
sophisticated ways to help future teachers value the role of culture in the classroom would help address historically systemic problems. Ladson-Billings (2009) endorses the notion of giving teacher candidates opportunities to critique the system. How can future teachers be agents of change if they accept the inequities of public education at face value? Programs preparing predominantly white students must examine their role in the profession. "How could they (white teachers) knowingly participate in a system that put children of color (and other groups) at a disadvantage while it granted privileges to people like them?" (Ladson-Billings, 2009, p. 146). I found this found to be very thought provoking. It speaks to the enormous responsibilities teacher preparation programs carry in order to make meaningful changes. Once student teaching, Ladson-Billings (2009) encourages intentionally matching of students with the best teachers rather than random assignments handed out by administrators. I know first-hand how difficult it can be to place student teachers, so this would also require reimagining the entire system. She suggests incentives like stipends, salary increments, and fringe benefits be given to those teachers committed to working with student teachers (p. 148). These propositions seem so obvious and could truly transform teacher education. Ladson-Billings (2009) has essentially created a guidebook for culturally responsive teacher preparation supported by years of research. It is time to implement these important changes and rectify the exclusionary practices imposed on teachers of color.

In all of the research and reading completed while conducting this study, I was truly astonished by Vanessa Siddle Walker's (2019) piece entitled "What Black Educators Built." She found herself in attics and archives piecing together the rich history of Black teachers. Her years of research highlighted how Black teachers during the pre-Brown v. Board of Education (1954) era always championed their students' success and aspirations, despite living in a separate and 
unequal world. I was in awe of their almost underground professional network created to "disseminate pedagogical ideas... also used those networks to create advocacy structures to undermine segregation" (Walker, 2019, p. 16). During the slow (and in some places nonexistent) integration process, these same Black educators hoped to replicate the "aspiring climates and education advocacy networks while also obtain for their students the access they had been denied" (Walker, 2019, p. 16). At the root of my study, it all comes down to access. Students, teachers, communities, and COEs, all need access to resources and support. Walker's formula of aspiration, advocacy and success needs to be replicated and implemented across the entire field of public education and is a fitting call to action. All of the participants in this study should have been granted access to teacher preparation programs.

When studying America's teacher shortage and lack of representation in the classroom, I found it was important to explore the piece of the puzzle which is often forgotten: the teacher education major. There is no shortage of scholarship about K-12 students, classroom teacher attrition, and why diversity and representation in the classroom is so important. However, by studying why college students who major in teacher education programs are not able to successfully complete their programs, I was able to provide reasons why this happens, when it happens, and how to better support these college students. This study highlights how the leaky teacher pipeline, the teacher shortage, the impact on K-12 and secondary teachers, the impact on COEs, and the lack of diversity in education could all be improved by addressing the experiences of teacher education majors. 


\section{REFERENCES}

ACT. (2015). The condition of future educators 2014.

http://www.act.org/content/dam/act/unsecured/documents/CCCR-2014-

FutureEducators.pdf

Anderson, C. (2016). White rage: The unspoken truth of our racial divide. Bloomsbury.

Baker-Bell, A. (2020). Linguistic justice: Black language, literacy, identity, and pedagogy. Routledge.

Banks, J. A. (1998). The lives and values of researchers: Implications for educating citizens in a multicultural society. Educational Researcher, 27(7), 4-17.

Berliner, D. C., \& Biddle, B. J. (1995). The manufactured crisis: Myths, fraud, and the attack on America's public schools. Addison-Wesley Publishing Company.

Bertrand, S. K., \& Porcher, K. (2020). Teacher educators as disruptors redesigning courses in teacher preparation programs to prepare white preservice teachers. Journal of Culture and Values in Education, 3(1), 72-88. https://doi.org/10.46303/jcve.03.01.5

Borko, H., Liston, D., \& Whitcomb, J. A. (2007). Apples and fishes: The debate over dispositions in teacher education. Journal of Teacher Education, 58(5), 359-364. https://doi.org/10.1177/0022487107309977

Brown v. Board of Education, 347 U.S. 483 (1954).

Carver-Thomas, D. \& Darling-Hammond, L. (2017). Teacher turnover: Why it matters and what we can do about it. Learning Policy Institute.

Casey, Z.A. (2016). A pedagogy of anticapitalist antiracism: Whiteness, neoliberalism, and resistance in education. University of New York Press.

Cecelski, D. (1994). Along freedom road. University of North Carolina Press. 
Cherney, E, Cullotta, K, \& McCoppin, R. (2021). 'Culturally responsive teaching' or 'woke indoctrination'? New standards for Illinois teachers in training are latest flashpoint in culture wars. Chicago Tribune. Retrieved from https://www.chicagotribune.com/news/ct-illinois-teachers-cultural-competency-newstandards-20210226-xfhgzb5fs5htpmdhyiop5p4mxm-story.html

Cochran-Smith, M., Baker, M., Burton, S., Chang, W. C., Cummings Carney, M., Fernández, M. B., ... \& Sánchez, J. G. (2017). The accountability era in US teacher education: Looking back, looking forward. European Journal of Teacher Education, 40(5), 572-588.

Cross, F. (2016). Teacher shortage areas nationwide listing 1990-1991 through 2016-1027. U.S. Department of Education Office of Postsecondary Education. https://www2.ed.gov/about/offices/list/ope/pol/tsa.pdf

Darling-Hammond, L. (1996). The right to learn and the advancement of teaching: Research, policy, and practice for democratic education. Educational Researcher, (25)6, 5-17.

Darling-Hammond, L. (2003). Keeping good teachers: Why it matters, what leaders can do. Educational Leadership, 60(8), 6-13.

Darling-Hammond, L. (2006). Powerful teacher education: Lessons from exemplary programs. Jossey-Bass.

Darling-Hammond, L. (2010). Teacher education and the American future. Journal of Teacher Education, 61(1-2), 35-47.

Darling-Hammond, L., \& Bransford, J. (2005). Preparing teachers for a changing world: What teachers should learn and be able to do. Jossey-Bass. 
DeAngelis, K., Wall, A., \& Che, J. (2013). The impact of preservice preparation and early career support on novice teachers' career intentions and decisions. Journal of Teacher Education, 64(4), 338-355.

Diez, M. E. (2007). Looking back and moving forward: Three tensions in the teacher dispositions discourse. Journal of Teacher Education, 58(5), 388-396. https://doi.org/10.1177/0022487107308418

Easton-Brooks, D. (2019). Ethnic matching: Academic success of students of color. Rowman \& Littlefield Publishing Group.

Elementary and Secondary Education Act of 1965. 20 U.S.C. 6301. (2015). Retrieved from https://www2.ed.gov/documents/essa-act-of-1965.pdf

Every Student Succeeds Act, S. 1177, $114^{\text {th }}$ Cong. (2015).

Franke, R., \& Bicknell, B. (2019). Taking a break, or taking a class? Examining the effects of incentivized summer enrollment on student persistence. Research in Higher Education, 60, 606-635. https://doi.org/10.1007/s11162-018-9527-x

Freire, P. (2005). Teachers as cultural workers: Letters to those who dare to teach. Westview Press.

Gitomer, D.H. (2007). Teacher quality in a changing policy landscape: Improvements in the teacher pool. Policy Information Report.

Giroux, H. (2005). The terror of neoliberalism: Rethinking the significance of cultural politics. College Literature, 32(1), 1-19.

Giroux, H. (2014). Neoliberalism's war on higher education. Haymarket Books. 
Giroux, H. (2018). The slow and fast assault on public education. The Boston Review. https://bostonreview.net/education-opportunity/henry-giroux-slow-and-fast-assaultpublic-education

Gladwell, M. (Executive Producer). (2017, June 29). Miss Buchanan's period of adjustment (Season 2, Episode 3) [Audio Podcast episode]. In Revisionist History. Pushkin Industries. http://revisionisthistory.com/episodes/13-miss-buchanans-period-ofadjustment

Glass, G. V. (2008). Fertilizer, pills, and magnetic strips: The fate of public education in America. Information Age Publishing, Inc.

Glesne, C. (2011). Becoming qualitative researchers: An introduction $3^{\mathrm{rd}} \mathrm{ed}$.). Pearson Education, Inc.

Goldstein, D. (2014). The teacher wars: A history of America's most embattled profession. Doubleday.

Gray, L., Taie, S., \& O’Rear, I. (2015). Public school teacher attrition and mobility in the first five years: Results from the first through fifth waves of the 2007-08 beginning teacher longitudinal study (NCES 2015-337). U.S. Department of Education National Center for Education Statistics. https://nces.ed.gov/pubs2015/2015337.pdf

Gregory, A. \& Mosely, P.M. (2004). The discipline gap: Teachers' views on the overrepresentation of African American students in the discipline system. Equity \& Excellence in Education, 37:1, 18-30.

Hatch, J. A. (2002). Doing qualitative research in education settings. State University of New York Press. 
Hood, S. \& Parker, L. J. (1989). Minority bias panels and teacher testing for initial certification: A comparison of two states' efforts. Journal of Negro Education, 58(4), 511-519. www.jstor.org/stable/2295208

Hurley, E. A. (2009). The performance gap: Stereotype threat, assessment, and the education of African American children. In N.S. Anderson \& H. Kharem (Eds.), Education as freedom: African American educational thought and activism (pp. 95-119). Lexington Books.

Illinois State Board of Education. (2018a). Educator supply and demand 2018 [Data set]. Illinois State Board of Education. https://www.isbe.net/edsupplydemand

Illinois State Board of Education. (2018b). Teach Illinois strong teachers, strong classrooms: Policy solutions to alleviate teacher shortages in Illinois. Illinois State Board of Education. https://www.isbe.net/Documents/Teach-Illinois-Memo.pdf Illinois State Board of Education. (2019a). Educator licensure: Unfilled positions 2019 [Data set]. Illinois State Board of Education. https://www.isbe.net/unfilledpositions

Illinois State Board of Education. (2019b). Illinois State Report Card 2019. https://www.isbe.net/Documents/2019-Illinois-State-Report-Card.pdf

Illinois State Board of Education. (2021). Culturally responsive teaching and leading standards for all Illinois educators. https://www.isbe.net/Documents/23-24RG-P.pdf

Irizarry, J. G., \& Antrop-Gonzalez, R. (2013). RicanStructing the discourse and promoting school success: Extending a theory of culturally responsive pedagogy for diasporicans. In A. D. Darder \& R. D. Torres (Eds.), Latinos and education: A critical reader ( $2^{\text {nd }}$ ed.) (pp. 243-260). Routledge. 
Jack, A. A. (2019). The privileged poor: How elite colleges are failing disadvantaged students. Harvard University Press.

Klein, A. (2016). The Every Student Succeeds Act: An ESSA overview. Education Week. http://www.edweek.org/ew/issues/every-student-succeeds-act/

Kopkowski, C. (2008). Teacher retention: Why they leave. NEA Today 26(7), 21-25. Retrieved July 8, 2014, from http://www.nea.org/home/12630.htm

Ladson-Billings, G. (2001). Crossing over to Canaan: The journey of new teachers in diverse classrooms. Jossey-Bass.

Ladson-Billings, G. (1999). Just what is Critical Race Theory and what's it doing in a nice field like education? International Journal of Qualitative Studies in Education, 11(1), 7-24.

Ladson-Billings, G. (2006). It's not the culture of poverty, It's the poverty of culture: The problem with teacher education. Anthropology \& Education Quarterly. 37(2), 104-109.

Lindsay, C.A. \& Hart, C.M. (2017). Exposure to same-race teachers and student disciplinary outcomes for Black students in North Carolina. Educational Evaluation and Policy Analysis, 39, 485-510.

Lupinski, K., Jenkins, P., Beard, A., \& Jones, L. (2012). Reflective practice in teacher education programs at a HBCU. Educational Foundations, 26(1), 81-92.

Marsh, H. W., Martin, A. J., \& Cheng, J. H. S. (2008). A multilevel perspective on gender in classroom motivation and climate: Potential benefits of male teachers for boys? Journal of Educational Psychology, 100(1), 78-95. https://doi.org/10.1037/0022-0663.100.1.78

Matias, C., \& Mackey, J. (2016). Breakin' down whiteness in antiracist teaching: Introducing critical whiteness pedagogy. Urban Rev, 1(48), 32-50. 
McIntosh, P. (2001). Unpacking the invisible knapsack. In M. Andersen \& P. Collins (Eds.), Race, class, and gender (pp. 95-105). Wadsworth.

Medford, L., Knorr, R., \& Cook, M., (2013). Men missing from the PK-12 classroom: A discussion of research-based explanations. SRATE Journal 22(2), 14-28.

Mehta, J. (2013). The allure of order: High hopes, dashed expectations, and the troubled quest to remake American schooling. Oxford University Press.

Mendez, et al. v. Westminister School District of Orange County, et al., 64 F.Supp. 544 (S.D. Cal. 1946).

Miles, M. B., Huberman, A. M., \& Saldana, J. (2014). Qualitative data analysis: A methods sourcebook ( $3^{\text {rd }}$ ed.). Sage Publications.

Mills, M., Martino, W. and Lingard, B. (2004). Attracting, recruiting, and retaining male teachers: Policy issues in the male teacher debate. British Journal of Sociology of Education, 25(3), 355-369.

Mosely, M. (2018). The black teacher project: How racial affinity professional development sustains black teachers. Urban Review (50)267-283.

Muhammad, G. (2020). Cultivating genius: An equity framework for culturally and historically responsive literacy. Scholastic, Inc.

National Center for Education Statistics. (2016a).

Enrollment and percentage distribution of enrollment in public elementary and secondary schools, by race/ethnicity and region: Selected years, fall 1995 through fall 2026 (Table 203.50) [Data Set]. Digest of Education Statistics. https://nces.ed.gov/programs/digest/d16/tables/dt16_203.50.asp?current=yes 
National Center for Education Statistics. (2016b). Number and percentage distribution of teachers in public and private elementary and secondary schools, by selected teacher characteristics: Selected years, 1987-88 through 2015-16 (Table 209.10). [Data Set]. Digest of Education Statistics. https://nces.ed.gov/programs/digest/d17/tables/dt17_209.10.asp?current=yes

National Commission on Excellence in Education. (1983). A nation at risk: The imperative for educational reform.

Nieto, S. (2015) Still teaching in spite of it all. Educational Leadership. 72(6), 54-59. Retrieved May 21, 2018, from http://www.ascd.org/publications/educationalleadership/mar15/vol72/num06/Still-Teaching-in-Spite-of-It-All.aspx

No Child Left Behind Act of 2001, 20 U.S.C. § 6319 (2001).

Office of Postsecondary Education. (2015). Enrollment in teacher preparation programs. Title II Higher Education Act: News You Can Use. U.S. Department of Education. https://title2.ed.gov/Public/44077_Title_II_Issue_Brief_Enrollment_V4a.pdf

Okonofua, J.A., Walton, G.M., \& Eberhardt, J.A., (2016). A vicious cycle: A socialpsychological account of extreme racial disparities in school discipline Perspectives on Psychological Science, 11, 381-398.

Oparah, J. (2014). Challenging complicity: The neoliberal university and the prison-industrial complex. In P. Chatterjee \& S. Maira (Eds.), The imperial university: Academic repression and scholarly dissent (pp. 99-121). University of Minnesota Press.

Osler, J. (2016). Beyond brochures: Practicing "soul care" in the recruitment of teachers of color. Retrieved from http://www.wcstonefnd.org/wp-content/uploads/2016/12/SFTRSoulCare-Final1.pdf. 
Philip, T. M., Souto-Manning, M., Anderson, L., Horn, I., J. Carter Andrews, D., Stillman, J., \& Varghese, M. (2019). Making justice peripheral by constructing practice as "core": How the increasing prominence of core practices challenges teacher education. Journal of Teacher Education, 70(3), 251-264.

Plessy v. Ferguson, 163 U.S. 537 (1896).

Policy and Program Studies Service. (2016). State and local expenditures on corrections and education [Brief]. U.S. Department of Education. https://www2.ed.gov/rschstat/eval/other/expenditures-corrections-education/brief.pdf

Powell, S. D. (2012). Your introduction to education: Explorations in teaching. Pearson Education.

Ravitch, D. (2010). The death and life of the great American school system: How testing and choice are undermining education. Basic Books.

Ravitch, D. (2014). Reign of error: The hoax of the privatization movement and the danger to America's public schools. Vintage Books.

Redding, C. (2019). A teacher like me: a review of the effect of student-teacher racial/ethnic matching on teacher perceptions of students and student academic and behavioral outcomes. American Educational Research Association, 89(4), 499-535. doi:10.3102/0034654319853545

Ripski, M. B., LoCasale-Crouch, J., \& Decker, L. (2011). Pre-service teachers: Dispositional traits, emotional states, and quality teacher-student interactions. Teacher Education Quarterly, 38(2). 77-96.

Sleeter, C. (2008). Equity, democracy, and neoliberal assaults on teacher education. Teaching and Teacher Education, 24(8), 1947-1957. 
Souto-Manning, M. (2019). Transforming university-based teacher education: Preparing asset-, equity-, and justice-oriented teachers within the contemporary political context. Teachers College Record, 121(6), 1-26.

Tyson, K. (2011). Integration interrupted: Tracking, black students, \& acting white after Brown. Oxford University Press.

Valencia, R. R. (Ed.). (1997). The evolution of deficit thinking: Educational thought and practice. Routledge.

Walker, V. S. (2019). What Black Educators Built. Educational Leadership, 76(7), 12-18.

Wilkerson, J. R. (2006). Measuring teacher dispositions: Standards-based or morality-based? Teachers College Record. Retrieved from http://www.tcrecord.org/Content.asp?ContentID=12493

White, T., Woodward, B., Graham, D., Milner Iv, H. R., \& Howard, T. C. (2020). Education Policy and Black Teachers: Perspectives on Race, Policy, and Teacher Diversity. Journal of Teacher Education, 71(4), 449-463.

Wolcott, H. F. (1994). Transforming qualitative data: Description analysis and interpretation. Sage.

Yosso, T. J. (2005). Whose culture has capital? A critical race theory discussion of community wealth. Race, Ethnicity, and Education, 8(1), 69-91. 


\begin{abstract}
APPENDIX A: ONLINE SURVEY
Survey to Identify Participants for Dropping Education Major Study*

Name

Email

Age

Current Major

Were you previously an education major?

How do you identify your Race/Ethnicity?

How do you identify your Gender?

How do you identify your Sexual Orientation?

Would you please share with how you came to the decision to switch out of teacher education?

How would you explain your experiences within teacher education?

Some people will be selected to be interviewed on this topic. Would you like to be selected?

If so, please provide your preferred contact information?
\end{abstract}

*Questions were distributed via a Qualtrics Survey. 
APPENDIX B: CONSENT FORM FOR THE INTERVIEWS

\begin{abstract}
"A TEACHER SHORTAGE AND LACK OF REPRESENTATION IN THE CLASSROOM: A NEOLIBERAL AND CRITICAL RACE STUDY OF THE BROKEN TEACHER PIPELINE AND THE IMPACT ON EDUCATION MAJORS"
\end{abstract}

Dear

I am a graduate student under the direction of Dr. Dianne Renn in the Department of Educational Administration and Foundations (EAF) at Illinois State University. I am conducting a research study to why you are no longer a teacher education major. Your participation will involve a onehour interview, which will be audio recorded.

Your participation in this study is voluntary. If you choose not to participate or to withdraw from the study at any time, there will be no penalty and it will not influence your future involvement with the program. Your responses are confidential and any information that might allow someone to identify you will not be disclosed. After your data has been deidentified, your data may be used in other research projects.

There are minimal risks involved with participation beyond those of everyday life. A potential risk could be loss of confidentiality, but all data will be kept in a locked, secure location to ensure this does not happen. Although there may be no direct benefit to you, a possible benefit of your participation is a better understanding of how to support teacher education major. You may have a copy of this form for your records.

If you have any questions concerning the research study, please call me at 815.370 .3777 or Dr. Dianne Renn at 309.438.2040.

Sincerely,

Sara Piotrowski

I consent to participating in the above study.

Signature

Date

If you have any questions about your rights as a participant, or if you feel you have been placed at risk, contact the Illinois State University Research Ethics \& Compliance Office at (309) 4385527 or IRB@ilistu.edu. 


\section{APPENDIX C: INTERVIEW QUESTIONS}

1.) Tell me a little about yourself?
a. Name:
b. Race:
c. Gender:
d. Sexual Orientation:

2.) How did you decide to come to ISU?

3.) How did you decide to become a teacher?

a. Do you have any family members who are teachers?

b. When did you decide you wanted to be a teacher education major?

c. How did you reach the decision?

4.) Please walk me through your experience as a teacher education major up to this point?

a. What classes have you taken?

b. Clinical experiences?

5.) How would you describe your best experiences in the program?

6.) In your journey to become a teacher at ISU, what has been unexpected or surprised you?

a. Surprises around coursework?

7.) Can you describe a specific moment or turning point that shifted you away from teacher education?

8.) What were some of the most significant obstacles you faced?

9.) If you were to go back, would you do anything differently?

10.) How do you feel now about your decision to change your major away from teacher education?

a. Do you ever still think about wanting to be a teacher?

11.) What else do you think would be important for me to know that I didn't ask you about today?

12.) Do you have any questions for me? 
APPENDIX D: FULL TEACHER EDUCATION DROP OUT TIME ORDERED MATRIX

\begin{tabular}{|c|c|c|c|c|c|c|c|}
\hline & Kid & HS & Freshman & Sophomore & Junior & Senior & Future \\
\hline Mindy & $\begin{array}{l}\text { Had } \\
\text { always } \\
\text { thought }\end{array}$ & $\begin{array}{l}\text { Enrolled in } \\
\text { teacher } \\
\text { internship } \\
\text { during } \\
\text { senior year }\end{array}$ & $\begin{array}{l}\text { ISU- } \\
\text { Enrolled as } \\
\text { history } \\
\text { education } \\
\text { major }\end{array}$ & $\begin{array}{l}\text { Confused } \\
\text { about major- } \\
\text { took SPED } \\
\text { courses. Felt } \\
\text { pressure } \\
\text { from family } \\
\text { to get job } \\
\text { after } \\
\text { graduation } \\
\text { and this } \\
\text { might be } \\
\text { more } \\
\text { lucrative. }\end{array}$ & $\begin{array}{l}\text { Still feeling } \\
\text { confused but } \\
\text { determined } \\
\text { not to follow } \\
\text { SPED. Back } \\
\text { to history ed, } \\
\text { trying to get } \\
\text { grades up, } \\
\text { taking content } \\
\text { exam }\end{array}$ & $\begin{array}{l}\text { Switched to } \\
\text { "straight } \\
\text { history" with } \\
\text { a minor in } \\
\text { sociology. } \\
\text { Will } \\
\text { graduate in } \\
\text { Dec. } 2018 \text {. }\end{array}$ & $\begin{array}{l}\text { Still sees } \\
\text { herself as } \\
\text { teacher, thinks } \\
\text { she might } \\
\text { work, earn } \\
\text { money, and } \\
\text { then get } \\
\text { certification }\end{array}$ \\
\hline Trevon & No & No thought & $\begin{array}{l}\text { Junior } \\
\text { College with } \\
\text { interest in } \\
\text { Computer } \\
\text { Science }\end{array}$ & & $\begin{array}{l}\text { Couldn't get } \\
\text { into intro to } \\
\text { education class } \\
\text { for } 2 \text { semesters }\end{array}$ & $\begin{array}{l}\text { Frustrated } \\
\text { because he } \\
\text { thought he } \\
\text { saved money } \\
\text { by going to } \\
\text { community } \\
\text { college }\end{array}$ & $\begin{array}{l}\text { Returned to } \\
\text { the program, } \\
\text { wants to get } \\
\text { Masters, } \\
\text { eventually a } \\
\text { professor }\end{array}$ \\
\hline Andre & No & $\begin{array}{l}\text { Didn't even } \\
\text { want to go } \\
\text { to college }\end{array}$ & $\begin{array}{l}\text { Signed up } \\
\text { the day } \\
\text { before } \\
\text { classes } \\
\text { started }\end{array}$ & $\begin{array}{l}\text { Decided to } \\
\text { become a } \\
\text { teacher }\end{array}$ & $\begin{array}{l}\text { Felt like } 1^{\text {st }} \\
\text { edu class was } \\
\text { a repeat of CC } \\
\text { class. } \\
\text { Slammed with } \\
\text { Gateways, } \\
\text { Dropped bc of } \\
\text { ACT score }\end{array}$ & $\begin{array}{l}\text { Loving } \\
\text { regular } \\
\text { content } \\
\text { classes, still } \\
\text { working full } \\
\text { time }\end{array}$ & $\begin{array}{l}\text { Graduating w/ } \\
\text { content degree. } \\
\text { Plans to get } \\
\text { Masters }\end{array}$ \\
\hline Cora & No & None & $\begin{array}{l}\mathrm{CC} \text { to save } \\
\text { money }\end{array}$ & $\begin{array}{l}\text { Decided to } \\
\text { major in edu }\end{array}$ & $\begin{array}{l}\text { Needed } \\
\text { language class, } \\
\text { overwhelmed } \\
\text { as transfer, no } \\
\text { transportation } \\
\text { for clinicals, } \\
\text { hidden fees }\end{array}$ & $\begin{array}{l}\text { Had to fix } \\
\text { the GPA she } \\
\text { messed up } \\
\text { during } 1^{\text {st }} \\
\text { semester }\end{array}$ & $\begin{array}{l}\text { Plans to work } \\
\text { in libraries. } \\
\text { Wants to help } \\
\text { HS students } \\
\text { learn to } \\
\text { research. }\end{array}$ \\
\hline Enzo & No & None & $\mathrm{CC}$ & $\begin{array}{l}\text { End of the } \\
\text { road at CC, } \\
\text { wanted to } \\
\text { help people } \\
\text { improve }\end{array}$ & $\begin{array}{l}\text { Hard transition } \\
\text { as transfer, } \\
\text { took } 2 \\
\text { semesters off } \\
\text { b/c of debt }\end{array}$ & $\begin{array}{l}\text { Took } \\
\text { content } \\
\text { exam } 5 \\
\text { times, lack } \\
\text { of diversity } \\
\text { at clinicals, }\end{array}$ & $\begin{array}{l}\text { Graduated, } \\
\text { thinking about } \\
\text { teaching in 5- } \\
10 \text { years }\end{array}$ \\
\hline Joshua. & No & $\begin{array}{l}\text { Wanted to } \\
\text { be culture, } \\
\text { share love of } \\
\text { content }\end{array}$ & $\begin{array}{l}\text { Didn't take } \\
\text { classes } \\
\text { seriously }\end{array}$ & $\begin{array}{l}\text { GPA issues, } \\
\text { not going to } \\
\text { class }\end{array}$ & $\begin{array}{l}\text { Like observing } \\
\text { a lot, GPA still } \\
\text { low }\end{array}$ & $\begin{array}{l}\text { Couldn't } \\
\text { afford to } \\
\text { retake } \\
\text { classes }\end{array}$ & $\begin{array}{l}\text { Graduating on } \\
\text { time, didn't } \\
\text { realize other } \\
\text { opportunities } \\
\text { with ed degree }\end{array}$ \\
\hline Lauren & $\begin{array}{l}\text { Loved } \\
\text { pretending }\end{array}$ & $\begin{array}{l}\text { Told by HS } \\
\text { teachers she }\end{array}$ & $\begin{array}{l}\text { Got } \\
\text { involved }\end{array}$ & $\begin{array}{l}\text { Thought } \\
\text { about other }\end{array}$ & $\begin{array}{l}1^{\text {st }} \text { edu class } \\
\text { overwhelming, }\end{array}$ & $\begin{array}{l}\text { Didn't love } \\
\text { the teaching }\end{array}$ & $\begin{array}{l}\text { Accepted into } \\
\text { student affairs }\end{array}$ \\
\hline
\end{tabular}




\begin{tabular}{|c|c|c|c|c|c|c|c|}
\hline & $\begin{array}{l}\text { to be a } \\
\text { teacher }\end{array}$ & $\begin{array}{l}\text { would be a } \\
\text { good teacher }\end{array}$ & $\begin{array}{l}\text { with student } \\
\text { affairs }\end{array}$ & $\begin{array}{l}\text { content } \\
\text { areas }\end{array}$ & $\begin{array}{l}\text { observations } \\
\text { different than } \\
\text { private HS she } \\
\text { went to }\end{array}$ & $\begin{array}{l}\text { clinical but } \\
\text { pressed on. } \\
\text { Failed } \\
\text { content } \\
\text { exam } 3 \\
\text { times }\end{array}$ & $\begin{array}{l}\text { Master's, } \\
\text { wants to work } \\
\text { at college level }\end{array}$ \\
\hline Daniel & No & $\begin{array}{l}\text { Taught by } \\
\text { inspiring } \\
\text { people in his } \\
\text { content area }\end{array}$ & $\begin{array}{l}\text { Focused on } \\
\text { GenEds }\end{array}$ & $\begin{array}{l}\text { GenEds, } \\
\text { grades } \\
\text { started } \\
\text { slipping }\end{array}$ & $\begin{array}{l}\text { Learned a lot } \\
\& \text { liked edu } \\
\text { classes, GPA } \\
\& \\
\text { procrastination } \\
\text { issues }\end{array}$ & $\begin{array}{l}\text { Learned how } \\
\text { to read \& } \\
\text { write, mental } \\
\text { health issues }\end{array}$ & $\begin{array}{l}\text { Has a job lined } \\
\text { up after } \\
\text { graduation }\end{array}$ \\
\hline Olivia & No & $\begin{array}{l}\text { Inspired by } \\
\text { HS teacher }\end{array}$ & Gen Eds & $\begin{array}{l}1^{\text {st }} \text { intro to } \\
\text { ed course. } \\
\text { Nothing } \\
\text { stood out }\end{array}$ & $\begin{array}{l}\text { Thrown into } \\
\text { everything all } \\
\text { at once }\end{array}$ & $\begin{array}{l}\text { Anxiety, } \\
\text { didn't like } \\
\text { being in } \\
\text { front of the } \\
\text { class }\end{array}$ & $\begin{array}{l}\text { Looking into } \\
\text { helping } \\
\text { students } \\
\text { through } \\
\text { therapy, 1-on- } \\
1\end{array}$ \\
\hline Kayla & No & $\begin{array}{l}\text { Sr. Year } \\
\text { teachers told } \\
\text { her she had } \\
\text { good } \\
\text { temperament }\end{array}$ & $\begin{array}{l}\text { Gen Ed \& } \\
\text { political } \\
\text { organization }\end{array}$ & $\begin{array}{l}\text { Gen Ed \& } \\
\text { political } \\
\text { organization }\end{array}$ & $\begin{array}{l}\text { Like } \\
\text { discussions in } \\
\text { edu classes. } \\
\text { Learned about } \\
\text { all the "red } \\
\text { tape" }\end{array}$ & $\begin{array}{l}\text { Misses the } \\
\text { collaboration } \\
\text { of edu }\end{array}$ & $\begin{array}{l}\text { Respects } \\
\text { teaching, } \\
\text { wants to } \\
\text { impact policy }\end{array}$ \\
\hline Imani & No & $\begin{array}{l}\text { Didn't like } \\
\text { HS teachers } \\
\text { who counted } \\
\text { students out }\end{array}$ & Gen Eds & Gen Ed & $\begin{array}{l}\text { Hated first edu } \\
\text { course. Work } \\
\text { load of teacher } \\
\text { didn't seem } \\
\text { worth it, like } \\
\text { content better, } \\
\text { fears parents }\end{array}$ & $\begin{array}{l}\text { Loved } \\
\text { focusing on } \\
\text { content } \\
\text { classes }\end{array}$ & $\begin{array}{l}\text { Wants to go to } \\
\text { grad school. } \\
\text { Wish she } \\
\text { would have } \\
\text { figured out } \\
\text { earlier, taken } \\
\text { different } \\
\text { classes, } \\
\text { respects } \\
\text { teachers }\end{array}$ \\
\hline Xavier & No & $\begin{array}{l}\text { Inspired by } \\
\text { HS teacher }\end{array}$ & $\begin{array}{l}\text { Amazing } \\
\text { experience, } \\
\text { welcomed, } \\
\text { partnered } \\
\text { with older } \\
\text { student }\end{array}$ & $\begin{array}{l}\text { Worked } \\
\text { with local } \\
\text { HS students, } \\
\text { experience } \\
\text { role of } \\
\text { teacher }\end{array}$ & $\begin{array}{l}\text { Overwhelmed } \\
\text { after } 1^{\text {st }} \text { edu } \\
\text { class, too } \\
\text { many } \\
\text { Gateways, } \\
\text { edTPA, } \\
\text { wanted to } \\
\text { focus on } \\
\text { content }\end{array}$ & $\begin{array}{l}\text { Wish he } \\
\text { made } \\
\text { decision } \\
\text { sooner }\end{array}$ & $\begin{array}{l}\text { Wants to do } \\
\text { something } \\
\text { with ed } \\
\text { componence, } \\
\text { not in } \\
\text { classroom } \\
\text { (youth } \\
\text { program) }\end{array}$ \\
\hline Jessica & No & $\begin{array}{l}\text { Was told } \\
\text { she'd make } \\
\text { a good HS } \\
\text { teacher }\end{array}$ & Gen Eds & Gen Eds & $\begin{array}{l}1^{\text {st }} \text { edu classes, } \\
\text { observations } \\
\text { felt thrown in, } \\
\text { asked if she } \\
\text { actually } \\
\text { wanted to } \\
\text { teach }\end{array}$ & $\begin{array}{l}\text { Enjoyed } \\
\text { content, } \\
\text { picked up } \\
\text { minor }\end{array}$ & $\begin{array}{l}\text { Doesn't want } \\
\text { career that } \\
\text { causes stress } \\
\text { and lacks } \\
\text { enjoyment }\end{array}$ \\
\hline
\end{tabular}

